\section{andigh}

DEC 281987

\title{
Physics Modeling Support Contract FINAL REPORT
}

\author{
TRW, Inc. \\ One Space Park \\ Redondo Beach, Ca. \\ 90278
}

September 30, 1987

\begin{abstract}
DISCLAIMER
This report was prepared as an wocount of work sponsored by un agency of the United Sates Goweratient. Neilber the Unitad States Covemment nor any agepcy theresf, oor any of their employes, makes any warranty, expres or implied, or exeumes any legel linbility or responsi-

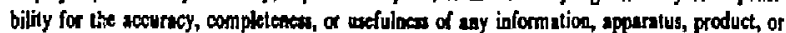
proces diachoed, or represents that its use would not infringe privtely owned rights. Reference herein to any qucilic commercial produst, process, or service by trade anme, trattemerk, monufacturer, or oberwive does not neceutarily constitute or imply its endorsement, recommeadation, or favoriag by the United States Government of any agency thereof. The views and opinions of authors expresud herein do aot aecessarily state of teflest those of the Uited Sintes Government of iny ageary therect.
\end{abstract}


This document is the final report for the Physics Modeling Support contract between TRW, Inc. and the Lawrence Livermore National Laboratory for fiscal year 198i. It is organized into five independent parts. Persons contributing to the tasks are noted on a separate cover page for each part. Each part has its own numbering system for pages, figures, and tables. Part 1 pertains to the TIBER Physics Modeling and Systems Code Derelopment task and the Part 2 to the Advanced Blanket Modeling task. These two parts comprise the original Physics Modeling Support contract. Parts 3,4 , and $4 a$ describe results from the tasks performed in support of the add-on to the original contract. Work on these latter tasks began in March 1987. The tasks are Time Dependent Studies (Part 3) and the Free Electron Maser (FEM) for TIBER II (Parts 4 and 4a). Part 4 is the main FEM section, and $4 a$ is an addendurn. This addendum describes the energy recovery system for the electron beam. An overview of each part will be presented in this summary.

\section{TIBER Physics Modeling and Systems Code Development - M.E. Fenstermacher}

For the 1987 fiscal year, tasks in the general category TIBER Physics Modeling and Systems Code Development were organized in twelve areas. Results from work in nine of these areas (numbers 2- $8,11,12$ in our proposal) are summarized in Part 1. Time dependent physics modeling calculations (tasks $1,9,10$ ) have been done by $D$. T. Blackfield, and are seported under the heading Time Dependent Modeling below in Part 3. In Part 1, the time independent modeling work has been re-organized into five main categories: 1) TIBER physics modeling, 2) TETRA systems code module development, 3) MUVAK code development, 4) cognizance with the CIT community and ETOC recommendations, and 5) comparisons with the European ETR design, NET, the Japanese design, FER, and the Soviet design, OTR.

\subsection{TIBER Physics Modeling}

The following physics models have been developed in 1987 for the TIBER study:

- The loop voltage during pulsed inductive operation has been modeled including a detailed neo-classical resistivity calculation. Finite aspect ratio effects and radial profiles of plasma density and temperature are taken into account. 
- A scaling formula for the bootstrap fraction of the total toroidal current has been developed through a collabcration with R. S. Devoto (LLNL) and A. A. Mirin (MFECC). The functional dependences of bootstrap current on the thermal component of the poloidal beta, the inverse aspect ratio, and the plasma effective charge are included in the model.

- A model has been developed for the pressure of the fast alphas and hot beam ions based on work done at the University of Wisconsin. Radial profiles of plasma density and temperature are included.

- A neutral beam attenuation and power deposition model has been developed for a monoenergetic pencil beam. Cross sections for electron and ion impact ionization and charge exchange are included.

All of these models have been used in determining the baseline steady state operating point described in Part 1.

\subsection{TETRA Systems Code Module Development}

Several modules bave been developed and incorporated in the TETRA systems code during FY8T. Some of these include adaptations of models which were developed for the MUMAK code during FY86. The modules which have been delivered to the FEDC systems code group are the following:

- A current drive efficiency module which calculates Amps/Watt conversion efficiencies for electron cyclotron resonance harmonic, lower hybrid slow wave, icn cyclotron harmonic fast wave, and neutral beam current drive has been delivered. Simplified versions of the MUMAK models have been developed for this systems code module.

- The fusion power from neutral beam-bulk plasma reactions is calculated as part of the plasma physics module based on models from the MUMAK code. Subroutines from MUMAK were adapted for the systems code for this case.

- A model for the partitioning of the non-inductive current in the core and edge plasma regions has been developed for the systems code. This calculation, when integrated, will be done as part of the physics module.

Final integration and testing of these modules will continue in FY83. 


\subsection{MUMAK Code Development}

Several upgrades of the MLMAK' code have been made this year. Subroutines corresponding to the physics models described above have been added to the code. In addition, several new types of MUMAK calculations have been developed including:

- Plasma OPerating CONtour (POPCON) analysis for pulsed ignited operation has been developed. Comparisons of ignition capability for various devices can now be done with MLMAK.

- Steady state current drive calculations with the neutron wall loading constrajned to a user specified value are now possible.

- Average surface heat load estimates on the first wall have been added.

MUMAF has also been made available to other users in the TIBER community this year. Global access files containing the source, sample input and output files, files needed for compiling and loading the source, and instructions have been created on the MFECC computer system. The instructions give enough detail that first time usets of MUMAK can begin doing parametric analysis without additional references.

\subsection{Cognizance with CIT and ETOC}

POPCON analysis with MLMAK was developed to maintain cognizance with the CIT community in which pulsed ignited operation is the first priority. The MUMAK calculations have been benchmarked against independent POPCON results for CIT. The ignition capabilities of TIBER with the physics assumptions used for CIT are presented in Section IIl of Part 1. The recommendations of the ETOC have been incorporated in the calculation of the steady state baseline operating point. Specifications of beta limit scaling formulas, wall loading and plasma $Q(=$ fusion power/input power) goals, and plasma profiles have been used for the baseline.

\subsection{Comparisons with NET, FER and OTR}

Finally, comparisons of TIBER pulsed ignited performance with that of NET, FER and OTR have been made using POPCON analysis. The major difference between the physics assumptions of TIBER and FER or OTR is the energy confinement scaling law used. Results for TIBER using the scaling laws from the FER and OTR 
designs are given in Section III of Part 1. Comparison with NET involves differences in the assumed beta limits, placma profiles and energy confinement scaling law. TIBER results using the NET assumptions are also presented in Section III.

\subsection{Conclusions}

In conclusion, all tasks relating to time independent power balance modeling for TIBER have been completed as described above. Tasks involving time dependent analysis were addressed by D. T. Blackfield with the Tokamak Time-Dependent Systems Code (TTSC) and are reported below. Results from this work have been reported at several plasma physics conferences including the American Physical Society Plasma Physics meeting, November 1986 in Baltimore $\mathrm{MD}$ and the Sherwood Plasma Theory meeting, April 1987 in San Diego CA. Results are also documented in the ULMAK report, LLVL UCID-21038, April 198T, Sections 2.4, 2.5 and Appendix A of the TIBER-II Final Design Report, LLNL CCID-21150 Octoher 1987, and the TETRA systems code report ORNL/FEDC-8T/i (198i).

\section{Advanced Blanket Modeling - R.B. Campbell}

\subsection{Description of Concept}

The microwave superheater is a concept which can use the synchrotron radiation from a thermonuclear plasma to heat gas seeded with an alkali metal to temperatures far above the temperature of material walls. The idea is used in the innovative Compact Fusion Advanced Rankine (CFAR) cycle, atthough other blanket configurations could be substituted. Because of the need for copious amounts of synchrotron radiation, the microwave superheater is best suited for use with plasmas burning an advanced fuel such as $\mathrm{D}-3 \mathrm{He}$.

An advanced blanket such as CFAR is important to future tokamak reactor designs because it has the potential to eliminate the costly balance-of-plant. It is able to do this because the CFAR concept converts the fusion power directly into electricity within the confines of the reactor vault, eliminating the need for large turbines and associated bujldings and equipment, and long runs of nuclear-grade piping.

Figure 1 in Part 2 shows a schematic diagram of the CFAR cycle using a microwave superheater. In its simplest form, the microwave superheater is a cylin- 
drical tube made of high temperature ceramic. The ceramic is transparent to the microwaves and serves as a window. The wall is maintained at a temperat ure which keeps microwave losies low. and may require transpiration cooling. Transpiration cooling involves the passage of a slip- stream of unseeded working fluid through tiny pores in the wall.

\subsection{Scope of the Superheater Study}

The present study is concerned with the description and modeling cf the microwave superheater. We perform a detailed examination of heaters in the laminar fow regime, appropriate for a small scale denionstration experiment, although scaling to larger superheaters appears possible. Through parametric analysis, we determine the sensitivity of heater performance to changes in key parameters, such as gas pressure, seed fraction, and microwave intensity. Figures 6 through 9 in Part 2 show these results.

We have developed two steady-state codes which couple fluid dynamics, radiation transport, and plasma physics to predict the performance of the microwave superheater. A relatively simple 1-D code calculates the axial profiles of the bulk gas properties. Contour plots in parameter space obtained from this code are shown on Figure 4 of this part.

A more detailed 2-D code calculates botb the radial and axial profiles of gas properties. Since issues of radial uniformity of the microwave heating are import ant, Part 2 will primarily concentrate on results of the 2-D model. The complete set of equations used in the model are described in detail in Section 3 of Part 2.

\subsection{Important Results}

We have considered experimental-sized superheaters operating in the laminar fow regime using helium seeded with lithium. The gas is heated by a monochromatic spectrum at $56 \mathrm{GHz}$ produced by a gyrotron. At reasonable pressures $(0.1$ to 1 atmospheres) and seed fractions $\left(\leq 10^{-4}\right)$ we have found that the radial uniformity of the heating is sufficient to allow the bulk outlet temperatures to reach nearly $30000 \mathrm{~K}$, when the inlet temperature is about $12000 \mathrm{~K}$ and the wall temperature is $1000^{\circ} \mathrm{K}$. The seed concentration and intensity of the microwave radiation must be carefully controlled to avoid either overheating or underheating. Table 1 shows some parameters of the baseline superheater. The column "Without" is the same 
case, but ignoring the radial energy loss channel for electrons. Without realistic radial losses, the amount of undesirable edge absorption increases dramatically, and the efficiency of the superheater is decreased.

\subsection{Conclusions}

Our conclusions from this study are that high bulk outlet temperatures can be achieved with microwave superheating in small proof-of-principle experiments. Quick scans of parameter space are accomplished with a radially averaged set of moment equations. The issue of radial non-uniformity of the heating is addressed with a radially resolved 2-D code.

In the range of operation we have studied, the microwave heating is sufficiently uniform that bulk gas temperatures above $3000^{\circ} \mathrm{K}$ are possible when the wall temperature is at $1000^{\circ} \mathrm{K}$. Parametric studies indicate that the heating becomes more non-uniform when either the pressure, seed fraction, or radiation intensity is increased. It is particularly important to be able to control the radiation intensity to avoid owctheating or underheating the gas. For superheaters with modest operating parameters, transpiration cooling will not be necessary. More work is needed to find out if reactor-sized superheaters will need it.

Simple scaling arguments indicate that superheaters for reactors can be built with microwave absorption properties similar to the smailer sizes. This scaling must be verified by detailed calculations using the 2-D code before anything definite can be claimed.

\section{Time Dependent Modeling - D.T. Blackfield}

\subsection{Code Description and Capabilities}

To perform this task, the Time-dependent Tokamaik Systems Code (TTSC) was developed. TTSC solves radially-averaged time-dependent particle and energy balance equations together with various engineering constraints. The physics and engineering modules are time-dependent versions of the MUMAK and TETRA codes as they existed in early 1987. Models from these two codes were incorporated, made time. dependent, and combined with an MHD equilibrium scaling routine. The MHD scaling routine determines the required poloidal field and transformer coil currents to provide equilibrium and the necessary volt-seconds. 
TTSC uses the steady-state plasma data from a TETRA output file and finds a reasonable st artup scenario. TTSC determines auxiliary heating and fueling requirements, volt-second capability and startup time. These are features which MLMAK and TETRA. by their time-independent nature, cannot readily address. In addition, TTSC provides an initial assessment of the required $\mathrm{OH}$ and PF coil waveforms and checks to see if $J B_{\max }, B_{\text {max }}$, and stress limits are exceeded.

TTSC has thre basic modes of operation. In the fully time-dependent mode, time-varying particle sources for each ion species and heating sources for all species (including electrons) are known and the density and energy equations are solved. On the other hand, the desired density and temperature behavior may be prescribed and the required particle source is calculated. Finally: a realistic power source and density may be specified and the time-varying species temperatures determined.

\subsection{Results}

Part 3 in this document describes the model in more detail, specifically Sections 2.12.2 through 2.12.4. Figures 1-23 show various plasma engineering parameters as a function of time for a possibie start up scenario for TIBER.

\subsection{Conclusions}

We have developed a O-D time-dependent physies-engineering code which can quickly examine various startup scenarios and when coupled to the steady state non-linear optimization code TETRA, ascertain if the "optimal" steady-state operating conditions are achievable. TTSC can estimate volt-second requirements and capabilities and auxiliary heating and fueling requirements. In addition, TTSC can address potential magnet stress problems by examining $B_{\text {max }}$ and $J B_{m n z}$ at various coil locations.

TTSC has shown the effectiveness of auxiliary power in reducing the volt-seconds requirement during startup and has found a reasonable startup scenarjo for the pulsed-operation mode of TIBER. In addition, TTSC can estimate the burn time and volt-second capability of the magnet set.

The next version of the TTSC will include the most up-to-date physics and engiveering routines from MUMAK and TETRA. We also hope to address the effect of If current drive (in particular lower-hybrid) on the volt-second requirement and on the equilibrium scaling. We also intend calculating stresses in the $\mathrm{OH}$ and 
PF coils to determine the burn time and volt-seconds capability. We will also use TTSC to examine expanding radius startup scenarios, since presumably at very low densities the plasma will be smaller and more circular. Finally, we will examine the effect of changing $Z_{\text {eff }}$ from approximately 5 to the steady state value of 1.32 on the volt-seconds consumed during startup.

\section{Free Electron Maser (FEM) for TIBER II - $\mathrm{H}$. Böhmer, et. al.}

\subsection{Scope of Study}

As part of the TIBER-Il development program, a conceptual design of a C.W. Free Electron Vaser (FEM) was performed. The FEM is intended as a source of microwaves for suppresision of distuption in the Tokamak reactor via ECRH. Units with 2 megawatt power output at 450 and $225 \mathrm{GHz}$ were considered. The requirements for the FEM systems are shown on Table I of Part 4 . The operating parameters for a suitable FEM we have designed are listed in Table Il.

Although all system requirements are met by the FEM parameters of Table I, it would be desireable to increase the gain bandwidth. For example, this could be done by increasing the interaction strength by increasing the beam current which also increase efficiency and output power. A previous conceptual design of a FEM for TIBER-I demonstrates this. Figure 4 of part 4 shows efficiency and gain bandwidth using a $2.36 \mathrm{MV}, 40 \mathrm{~A}$ beam together with $\lambda_{w}=5 \mathrm{~cm}, B_{\omega}=2 k G$ wiggler resulting in 5.7 MW output power at $240 \mathrm{GHz}$. The gain curve for this case is $10 \%$ wide at $75 \%$ of peak gain.

\subsection{Conclusions}

The FEM design detailed in Parts 4 and $4 a$ shows that a C.W. microwave source based on the FEM principle with electrostatic acceleration and a depressed voltage beam collector is a feasible choice for ECH in TIBER-II. Both second harmonic and fundamental heating are considered. Only standard technology is used in the design. With a total efficiency of $55 \%$ at $450 \mathrm{GHz}$ and $2.9 \mathrm{MW}$ of output power, the FEM should be a cost effective component of the TIBER-II reactor.

Apart from the modeling of the FEM interactions which will determine the 
baseline paraneters of the system, the most critical and time consuning part is the proper design of the electron beam line. Because of the late start of the FEM part of the TIBER.II program not all bean line calculations, particularly the design of the high power depressed voltage electron beam collector, could be done in time for the preparation of the final report. This necessitated the addendum to the FEM report, which we call Part $4 \mathrm{a}$ in this ieport. 
PART 1

TIBER PHYSICS MODELING AND SYSTEMS CODE DEVELOPMENT

CONTRIBUTOR(S): M.E, FENSTERMACHEK 
TIBER PHYSICS MODELING AND SYSTEYS CODE DEVELOPMENT

FINAI REPORT

\author{
K. E. FENSTERHACHER
}

OCTOBER 15,1987 


\section{TIBER PHYSICS HODELING AND SYSTEMS CODE DEVELOPMENT}

FIMLL REPORT

\section{E. Fenstermecher}

Oetober 15, 1987

\section{TIBER PHYSICS NODELIKG}

The following sections describe some of the results from the TIBER Physics Hodeling and Systems Code Development tasks performed during FY87. The majority of the effort wes spent in improving the models in the MUMAK tokamak power balance code and using the code for parametric anslysis of TIBER-II. Several of these models were also adapted for and incorporated in the Tokamak Engineering Test Reactor Analysis (TETRA) systems code developed during FY87 at the Fusion Engineering Design Center (FEDC).

The remainder of this documentation is organized as follows. A description of the baseline operating point for TIBER-II which was generated with MUMAK is given in Section II. References are also given to more detailed descriptions of the models in MUMAK and the physics basis for the baseline operating point. Section III describes parimeters of alternate operating points for TIBER-IT generated by MUMAK. The capabilities of the code for Plasma OPerating CONtour (POPCON) analysis of pulsed operating polnts and parametric analysis of stady state burn operation are described. Section IV gives a brief description of the MUMAK code architecture with references to more detailed documentation of the code models. Section $V$ describes the steady stace current drive models which were developed for the TETRA code as part of this averal physics support efifort. A sumary of the work is given in Section VI.

\section{TIBER-II BASELLNE OPERATING POINIT}

\section{I Introduction}

Plasma parameters for the baseline operating point of TIBER-II are described in this section. The baselfne operating mode is steady state with non-inductive current drive by neutral bears injection (NBI), and lower hybrid (LH) curre:it drive. Borststrap current is ixciuded. The baseline parameters are sumarized in Table II.1. The physics assumptions which are used in calculating these parameters are described in Ref. 1.

Conservative physics assumptions have been used in the baseline 
calculations in order to achleve high machine avallability for nuclear testing under beseline conditions. Alternate operating polnts with wore optinlstic physies assumptions are presented in Section III.

\section{2 Busuline Pover Balance}

The detalled power belance parameters for the baseline operating point are given in Table II-2. All tens in the power balence take into account the radial profiles of the density and temperature by integrating numerically the expressfons for the powers using the assumed profiles (see Ref. 1).

Kaye-Goldston ${ }^{2}$ energy confinement scaling is used with the power degradation term taken to be the sum of the alpha power and the currene drive power ainus the total zadiation power (see Ref. i). The radiation power fncludes bremstrahlung and synchrocron radiation. The impurity is assumed to be oxygen with concentration $n_{\text {oxymen }} /\left(n_{0}+n_{T}\right)=C_{\text {oxygen }}-.024$. The concentration of thermal alpha ash is taken to be $C_{a} m .05$. This results in an effective plasma charge $Z_{\text {eff }}-2.1$. The wall reflectivity for the synchrotron power calculation is assumed to be $90 \%$.

The themal diffurivity for lons is raken to be equal to

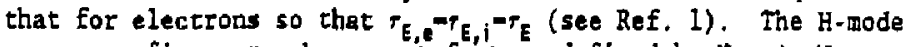
energy confinewent enhancement factor, defined by $\mathrm{H}=\mathrm{f}_{\mathrm{E}} / \tau_{\mathrm{E}}$ ( $\mathrm{L}$ mode), has been selected to be $\mathrm{H}=1.14$. For the baseline beta constraint ( 0.75 times the bellooning beta limit) and the $y$-mode enhancement factor constraint, $1 \leq H \leq 2$, (see Rof. 1), th. is value optimizes both the wall loading and plaswa $Q$ value (zusion power/total input power) for the oparating point. The average neutron wall loading is $\langle\Gamma\rangle-1.3 \mathrm{mH} / \mathrm{I}^{2}$, which pretuces nuclear heating in the faner leg of the toroidal field (TF) coils equal to the maximum set by the baseline assumptions for the vagnet desigr including safety factors (see Ref, 1). The plasma $Q$ value is 5.0 in this cate. Higher values of $H$ produce higher plasma $Q$ value at lewor wall loading for fixed beta; lower values of $H$ give higher wall loading and lower $Q$.

The plasna shape is evaluated using the parameters ior the 958 flux surface (see Ref. 1). The average neutron wall loading is est: ated using an average scrapeoff thickness $\Delta r_{3}=0.117 \mathrm{~m}$. The model for the first vall assumes that this scrapeofi layer is uniform around the plase periphery, although it is actually thinner on the inside than on the outside (see Ref. 1).

The partitioning of fast beam lon and fast alpha power to bulk electrons and lons durfing slowing down is calculated using a tese particle formalisa, 3 . Following gef. 2, the equation for the test particle energy, $\varepsilon$, assuming $v_{i}<v_{\text {test }}$ " $v_{e}$ where $v_{i}$

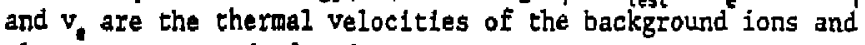
electrons respectively, is

$$
d E / d t=-2 E\left[1+\left(E_{c} / E\right)^{1.5}\right] / \tau_{t}
$$

where the critical energy is (see also Ref. 5) 


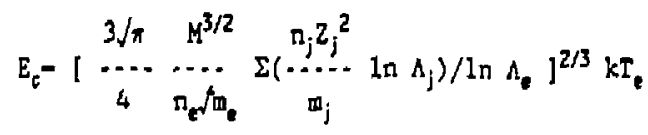

and the slowing down time is

$\left.T_{s}=\frac{3\left(\mathrm{kT}_{e}\right)^{3 / 2}}{-\cdots\left(2 \pi \mathrm{m}_{e}\right)^{1 / 2 \mathrm{Z}^{2}}} \mathrm{e}^{4 \pi \epsilon_{\mathrm{o}}} \mathrm{e}^{2}\right)^{2} \mathrm{M} /\left(\mathrm{n}_{\mathrm{e}} \ln \mathrm{A}_{\mathrm{e}}\right)$

The fraction of the test particle energy given to bulk jons then follows from

$$
f_{i}=2 v_{c}^{2} N_{0}^{2} \int_{0}^{x_{c}} \quad x
$$

where

$$
V_{-} \& k 2 S c^{2}-2 E_{c} / M, \quad V_{0}^{2}-2 E_{0} / M, X_{c}=V_{o} N_{t}
$$

$E_{0}$ is the birth energy, and $M$ is the test partcle mass. For the baseline operating point, all of the alpha power and neutral beam power is assumed to couple to the buik plasma electrons and ions. Alpha and hot ion ripple losses have been computed and are found to be negligible $e^{6}$. All of the LH power is assumed to couple to the bulk plasma electrons since the fast tail electron slowing down time is much shorter than the electron energy confinement time.

Finally, the beam hot ion - bulk plasma fusion power is determined using reaction rate parameters calculated by the SIGV code? The fast fon densily is obtained from

$$
\pi_{\text {hot }}-I_{b} \tau_{1, \text { aff }} / V_{p}
$$

where the effective slowing down time is

$$
\tau_{\text {s,eff }}=\left(\tau_{\mathrm{s}} / 3\right) \text { In }\left[1+\left(E_{b} / E_{c}\right)^{1.5}\right]
$$

$T_{1}$ is the classical slowing down tite, and $V_{p}$ is the plasma volume. The fast ion pressure, $P_{\text {hot }}$, is calculated from the formalism in Ref. 2 (see Section II.3) and the average fast ion energy is

$$
E_{\text {hat }}-1.5 \text { phat } ; \pi_{\text {hot }}
$$

This energy is used in the SIGV calculation to obtain the fusion reaction rate for hot Ion-bulk Maxwellian reactions. The fusion power is calculated using average densities; no radial distribution 
of fast ions has been calculated.

\section{3 Fast Ion Beta}

The finite pressure of fast alphas and fast beam ions is calculated fron a slowing down distribution, ${ }^{3,4}$. Following Ref. 4, the distribution function for fast 1ons, neglecting upscattaring, satisfies the equation

$$
\partial / \partial E[g(E) d E / d t)]=S(E)
$$

where $d \Sigma / d t$ is given by Eq. II-1. For a monoenergetic and isotropic source,

$$
s(E)=S_{0} \delta\left(E-E_{0}\right)
$$

the solution to Eq. II. 6 is

$$
\left.B(E)=S_{0} s_{s} / 2 E\left[1+\left(E_{c} / E\right)^{1.5}\right]\right) \text { for } E<E_{0}
$$

and $g\left(D>E_{0}\right)=0$. The pressure of the hot ion distribution is obtained from

$$
p=M S_{0} r_{3} V_{c}^{2} / 3 \int_{0}^{x_{c}} d x \begin{gathered}
x^{4} \\
\hdashline \ldots . . . \\
\left(1+x^{3}\right)
\end{gathered}
$$

where the definftion of $V_{c}$ is given in Eq. II-5. The fast ion pressure is included in the IHD beta limit for the baseline operacing point.

\section{4 Gurrent Drive Parameters}

Detailed parameters for the NBI and $U H$ current drive systems are given in Table II-2. The total non-inductive current requirement is given by $I_{c d}-I_{p}-I_{b e}$ where $I_{b e}$ is the bootstrap current. The scaling relation for the bootstrap current is given in Ref. 1. Neutral beams of sufficient energy to penetrate to the plasma axis are used for core current drive; lower hybrid glow waves are used on the outer flux surfaces. The radius within which the $L H$ waves do no penetrate, $r_{\max }$, is determined by combining tis conditions for wave accessibility and avoidance of strong quasi-line:- electron Lands:1 damping (see Ref. 1).

The partitioning of the total non-inductive current between the NBI and LH systens is done usine wadel current density profiles. The current density profile for the total plasma current, $f_{p}(r)$, is consistent with the equilibrium solution (see Ref. 1). A model current density profile for the bootstrap current, $J_{b}(r)$, is obtained from Fokker-Planck analysis ${ }^{8}$ (see Appendix $C)$. The remaining current density profile, $J_{c d}(r)=$ $j_{p}(r)$ - $j_{o s}(r)$ is integrated out to the radius of maximum penetration for the $L H$ waves, $r_{\operatorname{mx}}$, to give the core current fraction $f_{f}$. The neutral beam and lower hybrid currents are then 
$I_{r b}-f_{c} I_{c d}$ and $I_{l h}=I_{c d}-I_{n b}$ respectively. The current drive efficiency calculations are described in Ref. 1.

\section{5 Fueling Requirements and Alpha Ash Removal}

The fueling requirements for steady state operation of TIBER are given in Table II.4. The total deuterium (tricium, assuming a 50:50 mixture) current which nust be replenished in steady state is $121.8 \mathrm{~A}$. This includes $17.8 \mathrm{~A}$ of fuel ion burnup and $104 \mathrm{~A}$ of direct particle loss. To estimate particle lifetimes for steady state operation, the alpha particle balance equation is solved for the themal alpha confinement time, $r_{p, a}$, assuming a thermal alpha concentration, $\mathrm{C}_{\alpha}-0.05$, The thermal fuel ton confinement time, ${ }^{p}, 1$, is then assumed to be equal to the thermal alpha confinment time. The neutral beans supply 87.3 A of deuterium in steady state, assuming the fast ion confinement time is long compared with its slowing down time. The remainder of the required current must be supplied by the fueling system (see Ref. 1).

Note that for the baseline parameters, ${ }^{\tau_{p} \alpha} \approx 10 \mathrm{~T}_{\mathrm{E}}$ to be consistent with the assumption that $C_{a}-0.05$. Experimental results typically indicate that $r_{p_{1} i}=3.5 r_{E}$. If this were the case for TIBER in steady state, the thermal alpha concentration would be reduced but the fueline requirements would increase.

\section{IIT. ALTERNATE OPERATING POINTS}

III.1. Introduction

Parameters for operating points of TIBER-II, different from the baseline operation described in Section II, are described here. This section also serves as an introduction to the description of pulsed operating scenerios given in Ref. 1. All of the calculations described below were made with the MUMAK time-independent, zero-diwensional power balance codes (see Appendix A). Results of time dependent calculations, which produce scenerios for evolving the plaswa from initiation through current rampup, densiflcation ind heating, and ultimately to the baseline and alternate operating points ealculated with MLMAK, are given in Ref. 1.

III.1.1 Motivation. The baseline operating mode for TIBER-II is steady state operation uf th neutral bean injection (NBI), lower hybrid (LAH) current drive, and bootstrap current. Other operating modes are of interest, however, especially in the context of comparing the capabilities of the TIBER design with other national designs such as the Next European Torus (NET), the Fusion Engineering Reactor (FER) and the Soviet design (OTR). There are three reasons for exploring alternate operation points for IIBER.II. First, the potential of the design for reaching an ignited operating point must be assessed so that comparisons 
with athor tokank reactor studles, in which ignielon is the driving factor in the design decisions, can be made. Second, the ranges of advanced steady state physics experiments and advanced engineering tests which are possible without making wajor modifications to the devica, nust be assessed. These results have an impact on plans for the operation of the machine toward the end of its operating lifecime. Flnally, results from studies of both pulsed ignited and advanced steady state operating poincs provide targats for tine dependent analysis of TIBER.II, in which the tine history of the plasas bufld-up to the steady state or ignition conditions musc be determined.

The general franesork for the studies presented in this section is sumarized in Table III-1. The scope of paraneters for sach study is described below followed by the result.s.

IIT.1.2 Scope of the Pulsed Operating Points. Pulsed operacion, with the goal of schieving ignition, has been studied for the IIBER.II design using a range of toroidal currencs and with a varlety of energy confinement scsiling laws. Cases will be presented using a set of assumptions which are consistent with those used in the CIT ${ }^{10}$ studies (see Ref. 1. for discussion of the physics basis for TIBER). The currents used range from $2 M A$ to 12.5MA. In addition, cases at toroidal current of 8MA have been run with the four energy confinement scaling laws used by the EIR design teams in the U.S. ${ }^{1,11}$, Europe ${ }^{12}, J_{a p a n}{ }^{3}$, and the Soviet Unton'.

The results are presented in all cases in the form of Plasme OPerating CONtour (POPCON) ${ }^{15}$ plots. These are contour plots of the auxilliary power required to sustain the power balance at points in a density versus temperature space. Density limits, from elther the Murakam $1^{16}$ or Greenwald ${ }^{17}$ formulas, and beta limits, fron elther the Iroyon ${ }^{10}$ or the Yanazaki ${ }^{19}$ formulas, tend to produce boundaries for an "operating window" in density vs. temperature space in which the required auxilliary power is less than or equal to zero, Zero auxiliary power requitement means that the plasna pover losses are balanced by the alpha heating and the Joule dissipation (ohwic heating) alone. Negative awriliary power requirement indicates that some additional degradation of confinement or enhanced radiation power loss, which has not been accounted for in the modeling, can be tolerated during operation. This is often referred to as an "ignition margin".

The final step is to estimate the loop voltage for conditions in the operating window. Combining this with the available flux swing (Volt-seconds) from the magnet set allows an estinate of the ignited burn time to be made. Combining this with the neutron wall loading during the bum allows estimates of the fluence fron ignited operation to be determined. These calculations w11 be presented in Ref. I

III. 1.3 Scoes of the Steady State Hidh Performance Operating Polnts High perforance steady state operation has been investigated with the assumption that NBI and IH would be used 
for current drive in the co:e and edge plasma reglons, respectively, as in the baseline operating point. Cases opersting at the limits set by physics constraints, without the margin incorporated in the baseline operating point, have been generated. High plasna $Q$ value ( $Q$ fusion power/total power input to the plasma $\approx 20$ ) and high peak neutron wall loading $\Gamma \approx$ $3.5 \mathrm{HW} / \mathrm{m}^{2}$ have been calculated.

High performance operation of TIBER-II with NBI and IH current drive has been achieved at lower toroldal current than in the baseline scenerio. Scoping studies have shown that the plasma $Q$ value for NBI + IH scenerios tends to naximize for intermediate values of toroldal current with large bootstrap current fraction. The bootstrap current fraction $I_{b a} / I_{p}$, where $I_{p}$ is the toroidal current, scales linearly with the thermal component of the poloidal beta (see Ref. 1) This implies that the toroidal current must be as low as possible (for fixed toroidal beta given by a beta limit) to give low poloidal magnetic field and hence high poloidal beta. However, the energy confinement time and the toroida! beta lifit decrease with decreasing current (see Ref. 1) so an intermediate current of BMA for TIBER-II seems to produce the best performance.

Other characteristics of the high performance cases include: 1) operation at the full ballooning beta limit given by the Yamazaki formula, 2) full H-mode energy confinement enhancement (factor of two increase in confinement tiae over Kaye-Goldston L-mode) for the high $Q$ cases, 3) pure deuterium neutral beans with $1 \mathrm{KeV}$ energy, and 4) lower hybrid waves with 908 of the power launched in the diraction of the toroidal current. The corresponding baseline assumptions were (see Section II): 1) operation at a more conservative kink beta limit, 2) partial H-mode enhancement (factor of 1.14 increase in confinement time) 3) $500 \mathrm{keV}$ neutral beams and 4) LH waves with only $80 z$ of the power launched in the direction of the toroidal current.

The bootstrap current fraction scaling used in these cases includes the dependence on the thernal component of the poloidal beta, the inverse aspect tatio, and the plasma effective charge (see Ref. 1). Finally, the assumption has been made that only 608 of the beam hot ion beta is ineluded in the toroidal beta limit. This value has been used to reflect preliminary theoretical estiastes of the bulk plasma stabilization due to hot beam Ion flnite larnor radius effects ${ }^{20}$.

In the sections below, high performance physics operating points and advanced engineering operating points will be contrasted and the device nodifications, if any, required to achieve each scenerio will be described.

\section{III.2 Pulses operating Points}

Scoping studies have been made to determine the capability of the TIBER-II design for achieving ignition under varlous physics assumptions. The calculations are grouped into two study areas: 1) effects of various energy confinement scaling 
laws and, 2) consequences of operation at varfous toroldal currents, I . The results are presented in the form of POPCON plots. A typical POPCON plot is shown in Fig. III-1. The capability for achioving ignition is evaluated from these plocs by the existence and size of an operating window in which the plasma power losses are sustained by the alpha heating and the ohmic heating alone. The operating window boundarles (outlined in Fig. III-1) are the contour of zero auxilliary power, the density linit and the MHD bete linit.

IIr.2.1. Effect of Toroldal Gurrent Parincions. Cases which have been run in the study of toroidal current effects Include plasuas with 8,10 , and 12.5KA toroidal current. The assumptions wade in all of these cases are sumurized in Table III-2. The energy confinement scaling law used will be denoted the Kaye-Goldston plus Neo-Alcator (KG+NA) scaling. For this scaling, the gross energy confinement time $\tau_{E}$ is the quadracurc sun (as proposed by Goldston ${ }^{21}$ ) of the Kaye-Goidston time ${ }^{2}, \tau_{K G}$, and the Neo-Alcator time $22, \tau_{\text {Hh }}$ (see Ref. 1) as

$$
\tau_{E}=\left[\left(\mathrm{H} \tau_{\mathrm{KG}}\right)^{-2}+\tau_{\mathrm{M}}^{-2}\right]^{\cdot 1 / 2}
$$

where $H$ is the H-mode enhancement factor caken to be in the range $1 \leq H \leq 2$. Cases with full H-node $(\mathrm{H}-2)$ are shown in Figs. III-I - III-3 for TIBER operated with 8,10 , and $12.5 \mathrm{MA}$ respectively, A case at $I_{p}=12.5 \mathrm{MA}$ using L-mode (H-1.0) confinement is shown in Fig. III-4. The density limits shown in these figuies correspond to the lurakami formula ${ }^{16}$ with leading coefficient 1.5 (hereafter referred to as the kurakam 1 imit) and 0.75 times the Greenwald formula ${ }^{17}$ (hereafter referred to as the Greenwald limit). The beta limit which is highlighted in the figures corresponds to the Troyon kink formula 1 it th leading coefficlent 2.81. As expected, the increase in energy confinement and Troyon beta limit as the current increases tends to open the ignition operating window. The following conclusions can be drawn from these results:

$I_{D}-8 \mathrm{MA}, \mathrm{H}-2$ : No 1gnition window exists for densities below the Murakant limit. A narrow window exists for densities below the Greenwald limit for texperatures in the range $7<\mathrm{T}<12 \mathrm{keV}$. The power required to get through the saddie point is $9 \mathrm{MTH}$.

$I_{p}-10 \mathrm{MA}, \mathrm{H}-2$ : Ignition is marginal below the Murakaml limit and a window exists only for high temperatures $\mathrm{T}>12 \mathrm{keV}$. A substantial ignition window exists for densities belaw the Greenwald limit for temperatures in the range $6<T<15 \mathrm{keV}$. The power required to get through the saddle point is $9 \mathrm{kt}$.

$I_{p}-12.5 \mathrm{KA}$, H-2 : An Ignition window exists below the Murakami 
limit for temperatures in the range $8<T<$ $15 \mathrm{keV}$. The beta limit is not important in this case. The power required to get through the saddle point is $9 \mathrm{MW}$.

H-1 : A nariow ignition window exists below the Greenwald limit for temperatures in the range $8<T<10 \mathrm{kel}$. The power required to get through the saddle point is $18 \mathrm{MW}$.

These results are sumarized in Table III-3.

III.2.2 Effect of Energy Confinement Scaling tow. Cases which have been run in the study of energy confinement scaling include calculations with KG + NA (Eq. III-1), Mirnov ${ }^{23}$ scaling

$$
\tau_{\text {Mir }}=0.15 I_{p}\left(A_{p} / \pi\right)^{0.5}
$$

and Mereshkin scaling ${ }^{24}$

$$
\tau_{\text {Her }}=4.43 \times 10^{-3} n_{\text {e2O }}\left(a / R_{0}\right)^{.25} R_{0}^{3.0} q_{M E T} A_{i}{ }^{0.5} T_{e 10} \cdot 0.5
$$

using the assumptions listed in Table III-2. in Eqs. III-2 and III-3, $A_{p}$ is the plasma cross sectional area $\left(m^{2}\right)$, and the equivalent atomic mass is taken to be $A_{f}=A_{2} A_{T} / 2-3$. Additional calculations have been done with the assumptions given in Table III- 2 modified as shown in Table III-4 and using the Asdex H-mode energy confinement scaling ${ }^{25}$,

$$
\tau_{A s}=0.065 I_{P} R_{0}\left(A_{D}+A_{T}\right)^{0.5}
$$

This last set of calculations shows the performance of TIBER-II under the physics assumptions used to evaluate the ignition capability of NET ${ }^{12}$. In all cases, the coroidal current is $I_{p}=8$ KA. Results are shown in Figs. III-5 - III-7. The beta limit outlined in these figures corresponds to the Troyon value with leading coefficient $g-2.8$. Note that the assumption used for NET is $\mathrm{g}-3.5 \%$, corresponding to the dashed curve labelled 0.059 in Fig. III-T. The operating window for Ignition is substantially larger with this assumption. Conclusions which can be drawa from these figures are the following:

KG + NA scaling : No Ignition window exists below the Nurakami $\mathrm{H}$-mode density linit. A narrow ignftion window exists for densities below the Greenwald limit for temperatures in the range $7<\mathrm{T}<12 \mathrm{kev}$. The pourer required to get through the saddle point is $9 \mathrm{kw}$. 
Mereshkin scaling : No Ignition window exists below the Murakami H-mode 1init. A narrow ignition window exists for donsities below the Greenwald limit for tenperatures in the range $T<T<10 \mathrm{keV}$. Tho power required to get through the saddle point is $14 \mathrm{NW}$.

Mirnov scaling : No Ignition window exists below the Murakami linit. A narrow ignition window exists for densities below the Greenwald limit for temperatures in the range $8<\mathrm{T}<13 \mathrm{keV}$. The power requiled to get through the saddle point is $11 \mathrm{~kW}$. High temperature, T $>10 \mathrm{keV}$, is required at the saddle point.

NET assunptions : Ignition is mbrginal for densities below the (with $\mathrm{g-2.88)}$ Murakani limit at high temperatures, $\mathrm{T}>15 \mathrm{keV}$. A narrow Ignition window exists for densities below the Greemald linit for temperatures in the range $9<\mathrm{T}<17 \mathrm{keV}$. The power required to get through the saddle polnt is $8 \mathrm{~kW}$. High teuperature, $T>15 \mathrm{keV}$, is required at the saddle point.

These conclusions are sumarized in Table III-5.

\section{III.3 Steady State HIgh Performance Operating Polnts}

The baseline steady state operating point for IIBER-II incorporates conservative physics and engineering assumptions in a number of areas. In this section, alternate steady state operating points are presented, using NBI and Lh current drive systems as in the baseline device, in which several of the conservative physics and engineering limits are removed.

The most important of the physies 1imits is the MHD beta 1imit. In the baseline scenerio the operating beta is taken to be the conservative kink IIait given by the Troyon formula with coefficient $\mathrm{g}-2.8$. For the cases below, the full ballooning beta IIrit given by the Yamazakf fotmula is used. For TIBER +II parameters $B_{0}-5.55 T, \kappa-2.4, \delta=0.4$, using a toroldal current of $8 \mathrm{MA}$, and the full minor radius to the seperatrix a-.855m, this means that the operating beta increases from $\beta_{p p}$ (Troyon) $-4.7 \%$ to $\beta_{o p}($ Yamazak1) -6.64 .

other physics parameters have been changed for the high performance calculations. The plasms effective charge $Z_{\text {eff }}$ has been reduced from 2.1 to 1.5 because the scaling of the bootstrap curi'unt fraction with $Z_{\text {uf }}$ produces ingher values as $Z_{\text {eff }}$ decreases (see Ref. 1). The bean energy has been Increased to $E_{b}$-IMeV for higher current drive efficlency. This would require an upgrade of the accelerator technology in the neutral beam system (see Ref. 1). Finally, it has been assumed that 
improvements to launching grill designs for the LH waves could increase the fraction of the $H$ power launched in the direction of the toroidal current from the 80 assurned in the baseline to 904. These characteristics are summarized in Table III-6. Another physics constraint which becomes Important when maximun wall loading cases are calculated is the density limit. High wall loading cases with densities up to the full Greenwald value have been explored. In the baseline calculation it is assumed that the density limit is 75 of of the Greenwald value. The baseline operating point is actually well below this limit even with the 25 margin because the maximum achlevable wall loading (and therefore the required density to achieve this wail loading) is limited by conservative limits on neutron heating in the inser leg of the toroidal field (IF) coils (see Ref. 1) The IF coil syster has been designed to operate with nearly a factor of two higher heat load than is produced by the haseline operating point. high performance operating poines have been Investigated which produce up to a factor of two higher wall loading $\left(\left\langle D \approx 2.6 \mathrm{mH} / \mathrm{m}^{2}\right)\right.$ compared with the baseline $\left(<T>-1.3 \mathrm{MW} / \mathrm{m}^{2}\right)$. In principle these operating points could be achieved without modifications to the coils or shield. With Improvements in the forced flow cooling capabilities in the TF coils, even higher wall loading might be possible in TIBER.II.

To 1dentify optimu operating points for both high $Q$ and high neutron wall loading, scans of pover balance solutions have been made using values of the $H$-mode enhancement factor in the range $1.0<\mathrm{H}<2.0$ and using an operating beta fraction normalized to the full Yanazaki ballooning beta limit, $f_{b}=$ $\beta_{o p} / \beta$ (Yamazaki), in the range $0.7<E_{b}<1.1$. The results are given in Fig. III-8. Contours of the plasma $Q$ value (solid lines) and the average neutron wall loading ( $1 \mathrm{WW} / \mathrm{m}^{2}$. dashed lines) are shown. For fixed beta equal to the ballooning limit $\left(f_{b}=1.0\right)$, the $Q$ value maximizes at $Q-21$ for $H-2.0$. The wall loading is maximum for $f_{b}=1.0$ at $H=1.45$ where $\left\langle>-2.4 \mathrm{mw} / \mathrm{m}^{2}\right.$. The peak-to-average wall loading ratio for TIBER-II geometry is approxinately 1.5 so this corresponds to peak wall loading of $\Gamma$ $3.6 \mathrm{~mm} / \mathrm{m}^{2}$.

Parameters from the individual cases corresponding to the maximum $Q$ and $\Gamma$ values in Fig. III-8 are given in Table III.7. These cases have been reflned sonewhat compared with the corresponding points in Fig. III-8 particularly in the calculation of the radius of maximum penetration for the $\mathrm{LH}$ waves. This refinement also affects the partitioning of the neutral beam and lower hybrid driven currents.

\section{III.4 Summary}

Two classes of alternative oferating points have been examined for TIBER-II. Pulsed ignited operating points have been studied with POPCON analysis. High performance steady state operating points have been found which give high plasma $Q$ value and alternately high neutron wall loading. 
The consequences of operacion at various toroidal curstuts have been determined for pulsed scenerlos. As expected, the ignition window becomes larger as the current increases because both the density liait and the bete linit increase with current. In addition, the obale power contribution to the power balance increases with current (at each point in density vs. temperature space) wh1ch further widens the operating window for ignition. These results are summarized in Table III-3. Also, the effects of varloue energy confinemant scaling laws have been studied including KG + NA, Mezeshkin, and Kimov scalings. Studies using the NET assureptions (including Asdex 4 -mode scaling) have also been done. Ignition is marinal for all four of these scalings for densities below the Greenwald limit and beta less than the Troyon kink limit with a leading coefficient of $2.8 \mathrm{t}$. The temperatures in the ignieion windows and at the saddle points of the POPCON plots are higher for the cases with Mirnov scaling and with the NET assumptions than for the $K G+N A$ and MereshkIn scalings. For fixed Inductive volt-seconds available during the burn, higher temperature means longer burn time because the loop valtage decreases with terperacure. These realts are sumarized in Table III-5.

It has been found that with NBI + Ih current drive, optimum steady stato performance occurs in IIBER.II at an intermediate value of toroidal current, $I_{p}=8 \mathrm{MA}$. This results from a balance between the performance advantages of high bootstrap current fraction (ie. low toroldal current) and high beta and confinement time (1e. high tozoidal current). Calculations using this current and physics assumptions which are less conservative than those incorporated in the baseline operating point have found operating points with high Q - 20 and high neutron wall loading $\Gamma=3.7$ $\mathrm{MW} / \mathrm{m}^{2}$. The most important assumptions used in these scenerios are : 1) operation at the ballooning beta linit and 2) use of $1 \mathrm{MeV}$ neutral begas for good peretration to the axis at higher densities than in the baseline operating point. These high performance points can be sustained in steady state with no more current drive power than is specified in the baseline scenerio. 


\section{I Introduction}

MUAA ${ }^{9}$ is a zero-dimensional (volume averaged), time independent power balance code for mcjeling plasma particle and energy flow in tokamaks The equations describing the steadystace power balance inalude terms for alpha power from $D-T$ burning plasmas, inductive (ohmic) as well as non-inductive currenc drive power, conduction power losses described by empirical energy confinement scaling laws, and radiation power losses. Radial profiles of plasma density and temperature are controlled by imput parameters and are assumed fixed for the power balance calculations.

MOMAK also performs calculations of $\$ \mathrm{mi}$-inductive current drive efficiencies for alecron cyclotion harmonic (ECH), neutral beal injection (NBI), lower hybrid (LH) slow wave, and fast wave (FW) current drive. The ECH modris luclude relativist: $r$ effects and degradation of the efficiency due to electron trapping effects. The NBI models also include the effects of electron trapping as well as the beam energy dependence. The IH models take into account both the accessibility lirite and the condition for avoiding strong electron Landau damping of the wave to decermine the radius of maximum penetration for the waves.

Anctllary calculations performed by MMAK include the determination of volumetr: $c$ neutron source strength from $D-T$ burning plasms, thermal stability analysis of tie sisady-state burn operacing point, and numerous graphical diagnosties. Radiai plots of cyclotron and plasna frequencies, optical depth for ECH waves of various polarizations and the volumetric neutron source strength san be generated. Results frim one and two Jimensional scans of parameter space can also be plotted.

MUMAK also contains several modeis which address issues that are unique to steady-state tokamak operation. The f1rst one is the particle balance of fusion alpha particles. This particle balance is computed at the solution (operating) poirt and the required alpha particle confinement time necessary to maintain the steady-state themal alpha concentration (user specified) is determined. Tokamak designs with burn pulses much longer than this time must specify some mechanism by which the alphas are removed or the accumulation of alpha ast will eventually choke off the burn.

Another unique feature of steady state tokamak burn modeled by MUMAK is that the current drive power $P_{D D}$ is comparable to the alpha power. For fixed coroidal currenc, $P_{C D}$ is also sinsitive to the plasna density and temperature at the operating point. The overall power balance is therefore quite sensitive to the currenc drive efficiency scaling and to the partitioning of the current drive power between bulk electrons 
and lons,

\section{IV.2 Mothod of Solution}

The power balance equations in MUMAK are formulated as a set of $N$ non-linear equations in $N$ unicnown ( $N-3$ or 4). The non-11near oquacion solvor COSNCE from the NAG anthematics library ${ }^{26}$ is used to obtain a solution (a zero) to these equetion to a sectified accuracy. Routines are also available to search for anliple solutions to the equations. This is done by renoralizing the power balance equations after the first solution is found so thet a now set of equations is generated for which the flrst solution is no longor acceptable. This renosmalization is dono in such a way that if a solution to the new set of renormelized equations is found it will satisfy the orfginal power balance.

Power balance solutions are found by varying plasma temperatures, densities, energy confinement time, and operating beta. A two-fluld rodel is used witks suparate power balance equations for electrons and lons including electron-ion drag. The electron power balance equation eakes the form

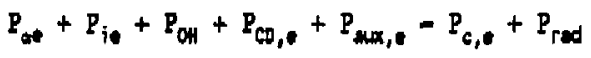

where

$$
\begin{aligned}
& P_{\text {an }} \quad \text { - alpha power deposited in bulk electrons } \\
& P_{\text {is }} \quad \text { - Lon-electron drag power } \\
& P_{\text {oul }} \quad \text { ohmic heating power }
\end{aligned}
$$

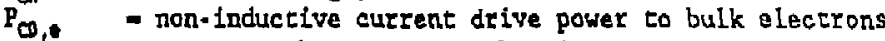

$$
\begin{aligned}
& P_{\text {aux }} \quad \text { - duxiliary bulk electron heating power } \\
& P_{c, 0} \quad-\text { bulk electron transport power } \\
& P_{r e d}^{c,} \text { - bulk election radiacion power }
\end{aligned}
$$

The electron radiation term includes bremsstrahlung and synchrotron power losses. The fon power balance equation is

$$
P_{a i}-P_{i \bullet}+P_{\Phi, i}+P_{m x_{0} 1}=P_{c_{i} 1}
$$

where

$$
\begin{aligned}
& \mathrm{P}_{a, i} \quad \text { - alpha power deposited in bulk ions } \\
& \mathrm{P}_{c 0, i} \quad \text { - non-inductive current drive power to bulk ions } \\
& \mathrm{P}_{a u, i} \text { - auxillary bulk lon heating power } \\
& \mathrm{P}_{c, i} \text { - bulk ion transport power }
\end{aligned}
$$

Detafled exprossions for the terms in Eqs. (IV-1) and (IV-2) are given in Raf. 9.

The independent varlable corresponding to the electron power balance equation is the density welghted volume averaged electron temperature, $T_{0}=\left\langle n_{0} T_{0}\right\rangle /\left\langle n_{p}\right\rangle$ (angle brackets denote volume avaraging). Temperature and density profiles are taken to be of the form

$$
X(r)=X(0)\left[1-\left(r^{2} / a^{2}\right)\right]^{a} x
$$


where $X-n, T$. Volune averaging over these profiles is done using a circular flux surface model. For the ion power balance the fon temperature $T_{i}=\left\langle\pi_{i} T_{i}\right\rangle\left\langle\left\langle n_{j}\right\rangle\right.$ or the gross energy confinement the, ${ }_{E}{ }_{E}$, parunetrlzed by an $h$-node enhancement Eactor, $H={ }_{E} / \tau_{E}$ (L-aode), can be varied. The third equation is a gross pressure balance constraint which requires that the total plasma pressure normelized to magetic fteld squarad be equal to a user specified operating beta. Typically this equation is used to deteralne the volune averaged electron density $n_{e}=\left\langle n_{e}(r)\right\rangle$. For solutions with user specified $n_{e}$, this equation can also be used to speclfy the operating beta. Finally a fourth aquation is aveilable which constratns the solution to a user spectfled value of average neutron wall loading $\Delta\rangle$. In this case, either the operating beta or the energy confinement enhancepent factor, $\mathrm{H}$, can be varied providing it is not being used as the independent variable for one of the other equations.

Typlcally, the user specifies the cotal coroldal current, the empirical scaling law for energy confinement, and the type of current drive to be used. From the current and the plasma shape MUMAK derives the beta linit either from the Troyon ${ }^{\text {to }}$ expression or the Yamazaki 19 formulas and the density limit from the Murakami ${ }^{16}$ or Greenwald ${ }^{17}$ expressions. The user also specifies either the H-mode energy confinement enhancement factor, $H$, or the Eraction $f_{\text {berir }}=\beta_{\text {(oporating }} / \beta_{\text {(teritical) }}$ (or both if $\langle\Gamma\rangle$ is allowed to vary). Scenarlos without current drive power, in which the plaswa current is assumed frozen (long $I / R$ decay tine) can also be modeled. For soue special cases, the current drive power may be input and the models will calculate the resulting toroidal current.

HUMAK can iso perforn Plasma OPerating CONtour (2OPCON) analysis. The user specifies $\mathrm{NEQ}-2$ and sets the density and temperature to the desfred values. The auxilliary fowet required to satisfy power balance for the electrons and for the ions is calculated separately. The sum of the electron and ion powers can easily be plotted for each density and temperature in a density versus temperature space to generate a PORCON plot.

\section{IV.3 Future Opgrades}

Though MUMAK contains all of the basic components for a complete zezo-dinensional description of steady-state tokamak power balance, several improvements can still be made. The model which determines the core current fraction, in cases using multiple current drive schenes sinultaneously, will be upgraded sa that the currane density profile data can be read in from external files. This will allow results from 2-D MHD calculations to be read by MOMAK without changing the source and recoupling. Results fron Fokker-Planck and transport caleulations which predict the bootstrap current density profile 
will be accessible by MUMAK in the sane way. This should Increase the accuracy of the parcleloning of coroldel current into bootetrap and oultiple current drive componenes calculated by MUNAK.

The NB current drive models wlli be improved to include lon trapping offects and the degradation of the officiency due to toroldal plasu rotation. Prolininary eselmates indicate these two effects any decrease the $A / W$ conversion efficlency for NBI current drive by 10-304. For NBI calculations, improvements are also required in the hot fon nodel. Particular attention will be given to improving the calculation of the average hot ion energy. This nay have an appreciable effect on the hot ion fraction of the oporating beta. This is an inportant caiculation since the performance of many ETR class tokantaks may be linited by achievable beta nore than other factors.

The delecorious offects of bean fon Instabilicies on the NBI current drive efficiency mut be nodeled in MUMAK. For beams with particle velocities above the Alfven speed in the plasna, Instabilitilus may increase the bean lon slowing down ${ }^{27}$ thereby significantly reducing the current drive efficiency. The beneficlal offects of bulk plasm stabilization by beam ions must also be modeled. . Prelininary theoretical estimates ${ }^{20}$ Indicate that the toroidal beta linit may bo Increased with bean injection.

Finally, the MUMAR power balance nodels may be expanded to treat the core and edge power balances separately. This upgrade would require models for energy transfer between regions, separate energy transport scaling for each region and accurate partitioning of the current drive and auxiliary power to the regions in which the power is absorbed. This kind of calculation may be required to more accurately treac scenarios in which $\mathrm{LH}$ power is absorbed in the edge and heats electrons there while another form of current drive power is absorbed in the core.

\section{4 Documentation}

A report ${ }^{9}$ exists which is intended to serve both as a reference to the physics models incorporated in MUMAK and as a user's gulde to running MUMAK. Since MUMAR is presently conflgured as a BASIS package $20-30$, users will need to become somewhat familiar with BASIS to appreclate the full capability of the MUMAK package for parametric analysis. The user's guide in this document wlll give enough information on running MUMAK under BASIS to generate Individual cases and simple parametrics. Readers interested only in using MUNAK as a "black-box" can skip Secs. 3-6 in the report without loss of continuity.

The report is organized as follows. Section 2 presents an overview to the mathematical approach for solving the power balance equations, including a description of some of the unique features of steady-state tokamak operation w..Ich are modeled. The detalled power balance equations are described in Sec. 3. 
The stesdy state current drive efficiency models are presented in Sec. 4. Several additional calculations performed by MOMAK such as the volumetric neutron source calculation and the thermal stability analysis are described in Sec. 5. Sample results for the IIBER-II configuration are given in Sec. 6 . A self conceined user's guide is given in Sec, 7. A sumary, including the present status of the MOMAK modeling effort and future plans, is presented in Sec. 8.

\section{NON-THDUCTIUE CORRENT DRIVE YODELS IN THE TETRA CODE}

The models used in the TETRA code to calculate amps-perwatt conversion efficiencies for various non-inductive current drive schemes are described below. These models are found in subroutine CURDRIV of the TEIRA code. This subroutine is aodular so that modiflcations can be nade to any of these models without affecting the others. Models of current drive schemes which are not presently included can be added easily.

As in all modules of the TETRA code, a balance has been struck here between the need for accuracy in the computations and the requirement that the nodels be simple enough for use in a systems code environment. References will be made below to areas where more work is required to develop systems code coupatible adaptations of more detailed calculations which can be installed in the TETRA code next year.

\section{V.2 Neutral Besm Injection Current Drfve}

The conversion efficiency for current drive by neutral beam injection, $\eta_{n b}$ is calculated in a subroutine ETANB which is called by CURDRIV. The modeling equatiors in ETANB are described in detail In Refs. 31-35. The equation for the efficiency is

$\eta_{i b}(A / N)=f_{d} T_{e} J(x, y) F_{\omega b}\left[1 \cdot e^{-T} T_{b}\right] /\left(R_{0} n_{020} \ln \Lambda\right)$

where $f_{d}$ is a coefficient which callbrates this scaling formula to Fokker-Planck results $\left(f_{d}-2.65\right.$ is used at present), $T$, is the electron tempreature $(\mathrm{keV}), \mathrm{J}(\mathrm{x}, \mathrm{y})$ is a function ${ }^{5}$ of the bean energy $\left(x^{2}-E_{b a w} / E_{\text {eritical }}\right)$ and the plasma effective charge $[y-f(2, f)], F_{n b}$ is a degradation factor ${ }^{32,33}$ to take account for electron spin-up effects ( $F_{n b}=0.76$ is used at present), $T_{n b}$ is the effective optical depth for the beam lons ${ }^{5}$ [1e. the shinethrough fraction is $\left.f_{a}-\exp \left(-\tau_{t}\right)\right], R_{0}$ Is the plasna major radius (II), $n_{\mathrm{e} 20}$ is the electron density $\left(10^{20} \mathrm{~m}^{-3}\right)$ and $\mathrm{ln} \Lambda$ is the Coulomb logarithm. For typical TIBER. II parameters, $I_{\approx} \approx 18-20$ keV, $\pi_{220} \times 1.0, R_{0}=3.0 \mathrm{n}$ the efficiency is $\eta_{\mathrm{nb}} \approx .08 \cdot .10(\mathrm{~A} / \mathrm{W})$.

The required neutral bean pover for current drive, $P_{n,}$ is calculaced as $P_{n b}-I_{n b} / n_{n b}$ where $I_{n b}$ is the current to be driven by the beams. At this writing, the nodels in the code assume that 11 of the neutral bean power is eventually transferred to the background plasna lons as the beam lons slow down. Models 
for calculating the partitioning of the bean power between beckground olectrons and lons, which are described in Refs. 31 . 35, w111 be adepted for use in the IETRA code noxt year. This partitioning is laportant for the power balance calculation when solutions are couputed for the electron and fon power balances separately.

\section{V.2 Lowar Hybeld Gurent Drive}

The scaling forwula used in the TETR code for calculating lower hybrid current drive efficiencies is a fit by Logan ${ }^{35}$ to efflciencies calculated by krmey and Flsch ${ }^{36}$. For parallel Indicas of refraction, $N_{11}$, of the lower hybrfd waves in the range $1.5 \leq N_{\|} \leq 2.0$ the efficiency is approximated well by

$$
\eta_{\text {Ih }}(A / W)=0.36\left(1+\left(T_{N} / 25\right)^{1.16}\right] /\left(R_{0} n_{e 20}\right)
$$

where $T_{0}, \pi_{020}$ and $R_{0}$ have been defined previously. An option also exists in the code to use a scaling recomended for the INTOR studies ${ }^{37}$

$$
\eta_{\text {Ih }}{ }^{1 \text { iron }}(\mathrm{A} / \mathrm{W})=0.3 /\left(\mathrm{R}_{0} \mathrm{n}_{020}\right)
$$

Equation (2) tends to over estinate the efficiency at hlgh $\mathrm{T}_{\mathrm{e}}$ ( $>25 \mathrm{keV}$ ) because it does not Include th effect of relativistic mass increase of the current carcying electrons in the tall of the distribution as $T_{\text {. increases. Equation (3) tepresents }}$ present experimental rasults but tends to give lower efficiencies than dotailed theoretical calculations for IIBER-like parareters. Neither formula takes into account trapped electron effects which reduce the efficlency, nor do they take into account any lower hybrid weve power which nay be launched in a direction opposite to the current. Detailed wodels for sone of these effects (given in Ref. 1) will be adapted for use in the TETRA code soon. Finally, the required lowar hybrid power is calculated from $P_{1 h}=I_{l h} / \eta_{l h}$ where $I_{l h}$ is the lower hybrid driven current. The code dodels assune thet all of this power eventually couples from the fast eurrent carrying electrons to the bulk plasma electrons.

\section{V.3 Electron Cyelotron Rasonence Current Drive}

The efficiency of current drive by electron cyclotron resonance (ECR) waves is calculated in the TETRA code from the forwule

$$
\eta_{\text {ser }}(A / W)=0.21 I_{\sigma} /\left(R_{0} n_{e 20} l n A\right)
$$

This scaling reproduces the result by Karney and $\mathrm{FLsh}^{36}$ for a nirrow spectrum of cyclotron waves, fundamental frequency, in the non-relativistic IImit, for a background plasma with $Z_{\text {aff }}-1$. when the rasonance parallel velocity of the current carrying electrons 1s approxiantely 2.5 itmes the thermal velocity of the bulk 
electrons. Linear theory (see Refs. 9,38,39) indicates that for TIBER-11ke parameters $\left(T_{0}=20 \mathrm{keV}, \mathrm{R}_{0}-3 . \mathrm{m}, \mathrm{w}_{\mathrm{pe}}^{2} / \mathrm{w}^{2} \mathrm{ce} \approx .5\right)$ the optical depth for ECR waves at the fundamental is in the range $100 \leq \tau \leq 500$ so that the resonance parallel velocity is in the range $2 \leq v_{\|} \leq 3$. For the systews code we have chosen an internediate value. Equation(4) does not 1nclude degradacion of the effictency due to electron trapping effects, relativistic detuning of the resonance, or the phenomenon of higher harmonic overlap when ECR waves with high $\mathrm{N}$ (for efflclent cutrent drive) are injected into a plasma with high $T_{a}$ (>10kev). Modelo for some of these effects (see Ref. 9) will be adapted for use in the TETRA code in the next year. Simple models for the harmonic overlap effect have yet to be developed. It should be stressed at this point that Eq. (4) should be used with caution in systens studies of configurations for which the electron temperature exceeds $10 \mathrm{keV}$ (harmonic overlap effect) and/ox the aspect ratio of the tokamak is less than 4.0 (electron trapping effect). Finally, the $E C R$ power is calculated fros $P_{\text {ter }}-I_{\text {ecr }} / \eta_{\text {ecr }}$ where $I_{\text {ter }}$ is the current to be driven by ECR waves. The model assumes that all of this power eventually couples to the bulk electrons.

\section{V.4 Lover Hybrid Fast Bave Currene Drtre}

The models for lower hybrid fast wave current drive in the TETRA code have been formlatated by Ehst ${ }^{49}$. The conversion efficiency formula is

$$
\eta_{f H}(A / R)=Z_{c}\left(0.034+0.196 \beta_{t}\right) T_{t}^{0 . \pi} /\left(R_{0} n_{e 20}\right)
$$

where

$$
\begin{aligned}
& z_{e}=0.08\left[32 /\left(5+z_{\text {eff }}\right)+2+z_{f}\right] \\
& z_{f}=12\left(6+z_{\text {eff }}\right) /\left[\left(5+z_{\text {eff }}\right)\left(3+z_{\text {eff }}\right)\right]+3.76 / z_{\text {eff }}
\end{aligned}
$$

where $z_{\text {aff }}$ is the bulk plaswa effective charge, and $\beta_{t}$ is the total beta. This paranetrization was derived from a series of if current drive and MHD equilibria calculations. Linear Landau damping was assuaed and the effects of transit time ragnetic pumpling were not included. In addition, the parasitic damping of the fast waves by high energy fusion alphas was not considered in obtalining Eq. (V-5).

\section{IV.5 Bootstrap Current}

Neo-classical bootstrap current effects are modeled in the IETRA code with a scaling foraula which includes the dependence on poloidal beta, aspect ratio and plasma effective charge. The bootstrap current is calculated as

$$
I_{b e}=I_{p} \beta_{p, t h} / c\left(1+0.94 / Z_{e f f}+0.43 / Z_{e f f}{ }^{2}\right)
$$


where $I_{p}$ is the total torotdal current, $\theta_{p, t h}$ is the thermal component of the polotdal beta, $c \mathrm{ma} / \mathrm{K}_{0}$ is the inverse aspect ratio and $Z_{\text {uff }}$ is the plasme effective charge. The total current which must be driven by the current drive system(s) is $I_{c d} I_{p}$. $I_{\text {bx }}$. Equation (V.8) was developed fron a series of Fokker-Planck and power balance calculations for TIBER-1ike conditions.

\section{IV.6 Gombinetions of Current Drive Systoms}

For sone configurations it nay be advantageous to use two or more current drive systens to drfve the total current. For systems andysis thls requires that the partitioning of the required current for each systen be calculated. At present the only option implemented in the TETRA code is a combination of NBI and $L H$ current drive with $I_{n}=f I_{h h}$. The value $f-1.13$ corresponds roughly to the resules of more detailed calculations for IIBER-Iike conditions (see Ref. 1). Simplified calculations of this partitioning have been adaptod fron the detalled calculations in Ref. 1 and are in the process of being added to the TETRA code.

\section{IV.7 Sumary}

At present, simplified models of current drive by neutral beam injection, lower hybrid slow and fast waves, and electron cyclotron waves are available in the TETRA code. Lower hybrid slow waves and neutral bean eurrent drive way be combined in a rudimentary way, Simplified nodels of more detailed calculations for each current drive wethod are under development and will be included in the systems code as soon as they are available.

Limitations on the parameter ranges over which the models are valid vary from one current drive method to another. The neutral beam model is valid except in cases with very high plasma density ( $\pi_{0} \geq 4 \times 10^{20} \mathrm{n}^{-3}$ ) or low bean energy ( $\mathrm{E}_{\text {bem }} \leq 200 \mathrm{keV}$ ) for which a wore detailed penetration calculation is required to assure that the beams reach the core of the plasma. The lower hybrid model is valid providing the bulk electran temperature in the region of lower hybrid wave propagation sat1sfies $T_{e}=15 \mathrm{keV}$. At higher temperatures the model over-estimates the current drive efficiency. The ECR model is valid only for low cemperature $T_{\mathrm{g}}<10 \mathrm{keV}$ plasmas in devices with large aspect ratio, $\mathrm{B}_{0} / \mathrm{a}>4$. Electron trapping effects and the phenomenon of higher harmonfc overlap must be included in the model to remove these limitations. Finally, the lower hybrid fast wave model is valid only for the outer radial regions of the plasma where alpha particle oamping of the waves will not be important. Work continues to develop algorithms whlch extend the ranges of validity for each of these models, 


\section{SDPRARY OF TIBER PHYSICS SUPPORT}

Physics support for the TIBER study has been provided during FY87 in a number of areas. Baseline operating points have been generated with the MUAK tokamak power balance code?. The models used in this code for steady state operation have been developed with full cognizance of the recommendations on physics from the CIT community, Including the Ignition Physics Study Group (IPSG), and the ETR Technical Oversight Comittee (ETOC). Though not reported here, several of the models now in MUMAK reflect results of more detailed calculations using Fokker-Planck and ray tracing codes for neutral beas injection (NBI) and lower hybrid (LH) current drive and bootstrap current effects ${ }^{8}$. MUMAK models of steady state current drive have also been adapted for inclusion in the TETRA systems code.

These models have also been extended to include pulsed ignited operation and POPCON ${ }^{15}$ analysis. Alternate pulsed ignited operating points for IIBER-II have been generated including cases with the physics assumptions recommended by the CIT community 10 . and those of the NET $T^{12}, F^{13}$, and OTR ${ }^{14}$ designs. Comparisons of the ignition capability of TIBER under these different assumptions have been made. 
1. TIBER Tean, "IIBER-II/ETR Final Design Report," Lawrence Livermore Nationel Laboratory roport UCID-21150, October 1987.

2. S. M. Kaye and R, J. Goldston, Nuclear Fugion, 25, 65 (1985).

3. B. Q. Deng and G. A. Emante, "Fast Ion Pressure in Fusion Plasnas, "Untversity of Wisconsin report UTFDM-718 (1987)

4. J. G. Cordey and M. J. Houghton, Nuclear Fusion, 13, 215 (1973).

5. D. R. M1kkelsen and C. E. Singer, Nuclear Technology/Fusion, 4. 237 (1983).

6. R. B. White, Princeton Plasma Physics Laboratory, Princeton, NJ, private communication (1987).

7. R. S. Devoto and J. D. Hanson, "SIGV - A Code to Evaluate Plasua Reaction Rates to a Specifled Accuracy," Lawrence Ifvermore National Laboratory report UCRL-52559 (1978).

8. R. S. Devoto, M. E. Fenstermacher, and A. A. Mirin, to be published; Bulletin of the American Physical Society 31 . 1519 (1986); see also J, Killeen, A. A. Mirin, and M. G. MeCoy, Modern Plaswa Physics (IAEA, Vienna, 1981) p. 395.

9. M. E. Fensterwacher, "MOMAX - A Computer Code for Modeling Plasma Power Balance and Current Drive in Tokamaks," Lawrence Livermore National Laboratory report UCID-21038 (1987).

10. J. Sheffie1d, et al., "Physics Guidelines for the Compact Ignttion Tokanak," Proceedings of the Seventh Topical on the Technology of Fusion Energy, Reno, in Fuston Technology, 10, 481 (1986).

11. C. D. Henning and B. G. Logan eds., "TIBER-II Tokamak Ignition/Burn Experimental Reactor - 1986 Status Report," Lawrence Livermore National Laboratory report UCID-20863, (1986).

12. NET Team, "Next European Torus (NET) 1985 Status Report," report EUR-FU/XII-80/86-51, December 1985.

13. T. Tone, et al., "Fusion Experfmental Reactor (FER) Design Concept," IAEA Technical Conmitcee Heeting and Horkshop on 
Fusion Reactor Design and Technology, Yalta, U.S.S.R., 26 May - 6 June, 1986, IAEA-TC-392.3 (1986).

14. B. Kadomtsev, et al., "OTR .. Experimental Fusion-Fission Tokamak Reactor Concept, "IAEA Technical Committee Meeting and Workshop on Fusion Reactor Design and Technology, Yalta, U.S.S.R., 26 May - 6 June, 1986, IAEA-TC-392.3 (1986).

15. W.A. Houlberg et al., Nuclear Fusion 22, 935 (1982).

16. M. Murakami et al., Nucleat Fusion 16, 347 (1976).

17. M. Greenwa1d, "A New Look at Density Limits in Tokamaks," MIT report PFC-JA-86-22 (1986).

18. F. Troyon et al, , Plasma Physics and Controlled Fusion 26, 209 (1984).

19. K. Yamazaki et al., Nuclear Fusion 25, 1543 (1985).

20. J. W. Connor and R. J. Hastie, Physies of Flulds, 12, 1727 (1976).

21. R. J. Goldston, Plasma Physics and Controlled Fusion 26, 98 (1984).

22. R. Parker, Nuclear Fusion 25, 1127 (1985),

23. E. P. Gorbunov, S. V. Mirnov, and V. S. Strelkov, Nuclear Fusion 10, 43 (1970).

24. V. G. Mereshkin and V. S. Mukhovatov, Soviet JETP Letters 3 , 446 (1981).

25. F. Wagner et al., Physical Review Letters 49, 1408 (1982).

26. NAG FORTRAN Library Manual - Mark 11, Numericsl Algorithms Group, $110131^{\text {st }}$ Street, Downers Grove IL (1986).

27. H. L. Berk, W. Horton Jr., M. N. Rosenbluth, and P. H. Rutherford, Nuclear Fusion, 15, 819 (1975).

28. P. F. DuBols, "Basis Users Manual, " Lawrence Livermore National Laboratory, IIvermore, CA, Repori K-189, June 1987.

29. P. F. DuBois, "WrIting Basis Packages," Lawrence Livermore National Laboratory, Livermors, CA, Report M.194, February 1987.

30. P. F. DuBois, "MPPL User's Hanual," Lawrence Livermore National Laboratory, Livermore, CA, Report $M-187$, Oecober 2986. 
31. R.S, Devoto, "Neutral-Beun Current Drive in Tokamaks," Lwrence Liverwore National Laboratory report UCRL.95799. October 1986.

32. D.F.H. Start, J.G. Cordoy, and E.M. Jones, Plasma Phys. 22, $303(1980)$.

33. D.F.H. Start and J.G. Cordey, Phys. Fludds 23, 1477 (1980),

34. J.D. Gaffey, J. Plasma Phys. 16, 149 (1979).

35. C.D. Henning, B.G. Logan et al., "TIBER-Tokamak Ignition/ Burn Experimental Research, Findl Design Report, "Lawrence Livermore National Laboratory report UCID-20589, November 1985.

36. C.F.F, Kazney and N.J. Fisch, Phys. Fluids 28, 116 (1985).

37. "International Tokanak Reactor - Phase Two A, Part 1," International Atomic Energy Agency report ISBN 92-0-131283. 0, (1983).

38. K.I. Thonassen ed., "Free-Electron Laser Experiments in Alcator C," Lawrence Livermore National Laboratory report LLL-PROP-00202, July 1986.

39. M. Bornaticl el al., Nuc. Fus. 23, 1153 (1983),

40. G.R. Smith, R.H. Cohen, and T.X. Mau, "Harmonic Overlap In Electron-Cyclotron Current Drive at High $T_{1}$ " Lawrence Livermore National Laboratory report UCRL-96364 preprint, March 1987 (to be published in Physics of Fluids).

41. D. Ehst, "TIBER-II, Tokamak Ignition/Burn Experimental Reactor, 1986 Status Report - Apendix C," C.D. Henning and B.G. Logan Eds., Laxrence Livermore National Laboratory report UCID-20863, OCtober 1986. 
Table II-1 Baseline Parameters

\begin{tabular}{|c|c|c|}
\hline $\begin{array}{l}\text { Parameter } \\
\mathrm{R}_{0}(\mathrm{~m}) \\
a(\mathrm{~m}) \\
\kappa \\
6 \\
V_{p}\left(\mathrm{~m}^{3}\right) \\
S_{p}\left(\mathbb{m}^{2}\right) \\
\mathrm{B}_{0}(\mathrm{~T})\end{array}$ & $\begin{array}{l}\text { Description } \\
\text { plasma major radius, } \\
\text { plasma minor radius" } \\
\text { elongation" } \\
\text { triangularity" } \\
\text { plasma volume" } \\
\text { plasma surface area" } \\
\text { toroldal fleld at } \mathrm{B}_{0}\end{array}$ & $\begin{array}{c}\text { Value } \\
3.0 \\
0.834 \\
2.4 \\
0.4 \\
96 \\
170 \\
5.55\end{array}$ \\
\hline $\begin{array}{l}\mathrm{P}_{\text {fus }}(\mathrm{MH}) \\
\mathrm{Q} \\
\left\langle\mathrm{D} ; \Gamma\left(\mathrm{MW} / \mathrm{m}^{2}\right)\right. \\
\mathrm{P}_{\text {NB }}(\mathrm{MWN}) \\
\mathrm{P}_{\text {LH }}(\mathrm{MW})\end{array}$ & $\begin{array}{l}\text { fusion power } \\
\text { fusion power/input power } \\
\text { average (peak) wall loading } \\
\text { neutral beam power } \\
\text { lower hybrid power }\end{array}$ & $\begin{array}{l}314 \\
5.0 \\
1.3 ; 2.0 \\
44 \\
19\end{array}$ \\
\hline
\end{tabular}

Ip (MA) total plasma current $\quad 10.0$

$I_{b s}$ (MA) bootstrap current $\quad 2.7$

$I_{L H}$ (MA) lower hybrid driven current $\quad 3.9$

$I_{\mathrm{HB}}$ (MA) neutral beam driven current 3.4

$\gamma_{L H}\left(10^{20} \mathrm{~m}^{-2} \mathrm{~A} / \mathrm{W}\right)$ lower hybrid efficiency 0.47

$\gamma_{\mathrm{AB}}\left(10^{20} \mathrm{~m}^{-2} \mathrm{~A} / \mathrm{W}\right)$ neutral beam efficiency 0.25

$\gamma_{C D}\left(10^{20}-2_{A}-W\right)$ overall current difve efficiency 0.52

(NBI + $\mathrm{LH}+$ bootstrap currents)

$\left\langle T_{e}\right\rangle ; T_{e}$ (keV) average (peak) electron temperature $19: 25$

$\left\langle\mathrm{I}_{i}\right\rangle ; \mathrm{T}_{i}$ (keV) average (peak) Ion temperature $20: 26$

$<\pi_{e}>\pi_{0}\left(10^{20} \mathrm{~m}^{-3}\right)$ average (peak) electron density $1.1 ; 2.1$

$n_{\text {Greemuld }}\left(10^{20} \mathrm{~m}^{-3}\right)$ Greenwald density liolt 2.57

$n_{\text {murakeaj }}\left(10^{20} \mathrm{~m}^{-3}\right)$ Murakadi density limit

$\begin{array}{lll}C_{\alpha} & \text { theral alpha concentration } 0.05\end{array}$

$C_{\text {oxygen }} \quad$ thermal impurity concentration 0.024

$\begin{array}{lll}Z_{\text {eft }} & \text { plasma effective charge } & 2.1\end{array}$

$r_{E}(s) \quad$ gross energy confinement time $\quad 0.68$

- Values on the $95 \%$ flux surface (see Ref. 1) 
Table II-2 Baseline Power Balance Parameters

Paramater Description value

\begin{tabular}{|c|c|c|}
\hline 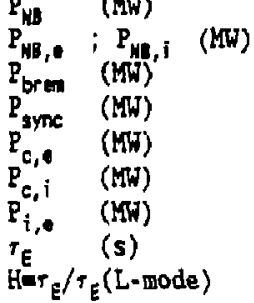 & $\begin{array}{l}\text { total fusion power } \\
\text { beam-bulk fusion power } \\
\text { alpha power } \\
\text { alpha power to electrons (ions) } \\
\text { lower hybrld power } \\
\text { neutral boan power } \\
\text { neutral bean power to electrons (ions) } \\
\text { bremsstrahlung power } \\
\text { synchrotron power lost" } \\
\text { electron conduction power lost } \\
\text { Ion conduction power lost } \\
\text { Ion- lectron drag power } \\
\text { gross energy c-afinement time } \\
\text { H-mode energy confinement enhancement }\end{array}$ & $\begin{array}{c}314.0 \\
44.5 \\
62.8 \\
42 ; 21 \\
18.7 \\
43.7 \\
12 ; 32 \\
7.3 \\
2.0 \\
63.5 \\
52.3 \\
0.91 \\
0.68 \\
1.14\end{array}$ \\
\hline
\end{tabular}

Table II-3 Baseline Current Drive Parameters

Parameter Description Value

\begin{tabular}{|c|c|c|}
\hline (MW) & neutral bean power & 43.7 \\
\hline (MW) & lower hybrid power & 18.7 \\
\hline (HA) & neutral beam driven current & 3.43 \\
\hline (MA) & lower hybrid driven current & 3.87 \\
\hline ( & bootstrap current & 2.70 \\
\hline & lower hybcid parallel refractive index & 1.60 \\
\hline & $\begin{array}{c}\text { accesslble parallel refractive index } \\
\text { (high field side) }\end{array}$ & 1.55 \\
\hline & normalized till parallel energy & 8.0 \\
\hline (m) & radius of maximum penetration (IH) & 0.45 \\
\hline$(\mathrm{keV})$ & average electron temperature (IH) & 5.5 \\
\hline$\left(10^{20} m^{-3}\right)$ & average electron density (LH) & 0.75 \\
\hline & dielectric constant at $I_{\max }$ & 0.33 \\
\hline$\left(10^{20}+3\right)$ & hot ion density & 0.031 \\
\hline$\langle k e V\rangle$ & hot lon average energy & 2.54 \\
\hline
\end{tabular}


Table II-4 Baselfine Fueling Parameters

\begin{tabular}{|c|c|c|}
\hline Parameter & Description & Value \\
\hline & deuteriun (tritfut) loss current & 104 \\
\hline (A) & deuterium (tritium) burn-up c'urrent & \\
\hline (A) & deuterfum current from $\mathrm{NBI}$ & 32 \\
\hline (A) & deuterium fueling current required & 35 \\
\hline fuel (A) & tritium fueling cirrent required & 122 \\
\hline$=(s)$ & $\begin{array}{l}\text { thermal alpha (ion) confinement time } \\
\text { thermal energy confinement time }\end{array}$ & $\begin{array}{r}5.9 \\
0.68\end{array}$ \\
\hline
\end{tabular}

Table III-1 Framework for Studies of Alternating Operating Points for TIBER-II.
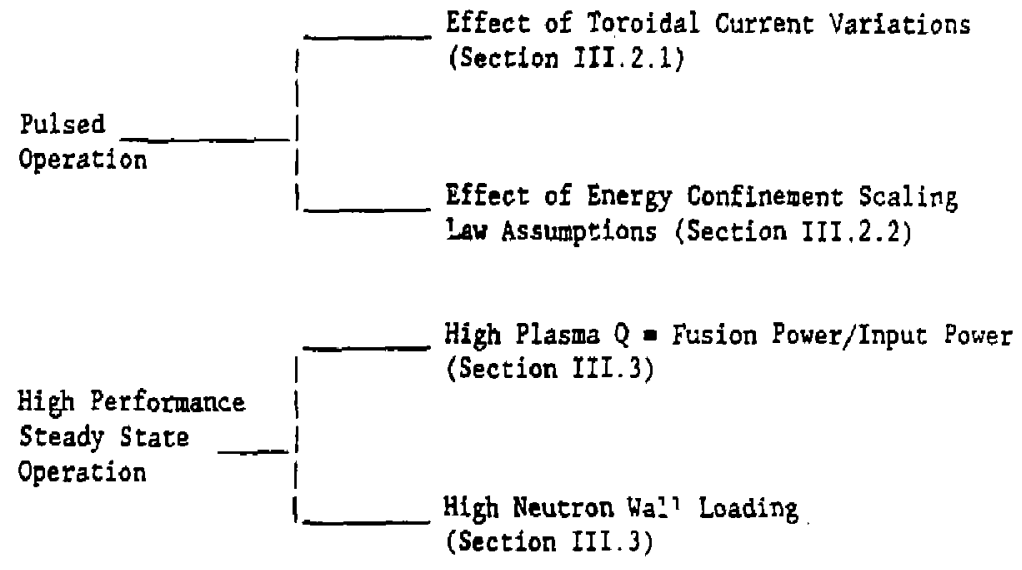
TABLE III-2 Assunptions Used for Ignttion POPCONS with Various Toroldal Currents.

\begin{tabular}{|c|c|}
\hline Geometry & $: R_{0}=3 m, a-.83 m, a_{m i l}=.95 n, n=2.4,8=0.4, B_{0}=5.551$ \\
\hline Impurftles & $: n_{\alpha} /\left(n_{D}+n_{T}\right)=.05, z_{a f f}-1.5$, oxygen impurity, $n_{0}-n_{T}$ \\
\hline Profiles & $: X(r)-X(0)\left(1-r^{2} / 2^{2}\right)^{a} x, X-n, T ; \quad \alpha_{n}=0.5, \alpha_{T}=1.0$ \\
\hline Safety Factor & $: q_{M E T}-5 a^{2} B_{0} K^{2} / R_{0} I_{P}$ \\
\hline Power Degradation & $\begin{array}{l}\text { : Power } P \text { used In the Kaye-Goldston energy } \\
\text { confinement scaling } P=P_{4}+P_{w x}-P_{b r m}+P_{\text {syme }}\end{array}$ \\
\hline $\begin{array}{l}\text { Neo-Alcator } \\
\text { Scaling }\end{array}$ & $: \tau_{m A}=0.071<\pi_{a 20}>R_{Q}^{2}\left(A_{p} / \pi\right)^{H} q_{H}$ \\
\hline
\end{tabular}

Table III-3 Sumary of Results from Ignicion Studies at Various Toroidal Currents.

$\begin{array}{rcccc}\text { Current, H } & \begin{array}{c}\text { Ignition } \\ \text { Murakani }\end{array} & \begin{array}{l}\text { Ignition } \\ \text { Greenwald }\end{array} & \begin{array}{l}\text { Beta } \\ \text { Limited }\end{array} & \begin{array}{c}\text { Power } \\ \text { Required }\end{array} \\ 8 \mathrm{MA}, 2.0 & \text { no } & \text { marginal } & \text { yes } & 9 \mathrm{MW} \\ 10 \mathrm{MA}, 2.0 & \text { no } & \text { yes } & \text { yes } & 9 \mathrm{MW} \\ 12.5 \mathrm{MA}, 2.0 & \text { yes } & \text { yes } & \text { marginal } & 9 \mathrm{MW} \\ 12.5 \mathrm{MA}, 1.0 & \text { no } & \text { marginal } & \text { yes } & 18 \mathrm{KW}\end{array}$


'ABLE III-4 Assumptions Used to SImulate NET Design Constraints

Geometry $: R_{0}=3 m, a=.855 m, a_{w 014}=.95 m, k-2.74,6=0.77, B_{0}=5.55 \mathrm{~T}$

Impurities

$: n_{\alpha} /\left(n_{p}+n_{T}\right)-.08, z_{e f f}-1.5$, Dxygen impurity, $n_{D}-n_{\uparrow}$

Profiles

$$
: X(r)-X(0)\left(1-r^{2} / a^{2}\right)^{a} x, \quad X-n, T ; \quad a_{n}=0.3, \quad a_{T}=0.3
$$

Table III-5 Summary of Results from Ignition Studies with

Various Energy Confinement Scaling Laws

\begin{tabular}{|c|c|c|c|c|c|}
\hline Scaling & $\begin{array}{l}\text { Ignition } \\
\text { Murakami }\end{array}$ & $\begin{array}{l}\text { Ignition } \\
\text { Greenwald }\end{array}$ & $\begin{array}{l}\text { Window } \\
\text { Temperature }\end{array}$ & $\begin{array}{l}\text { Saddle Point } \\
\text { Temperature }\end{array}$ & $\begin{array}{l}\text { Power } \\
\text { Require }\end{array}$ \\
\hline$K G+N A, H$ & no & marginal & $7 \cdot 12 \mathrm{keV}$ & $5 \mathrm{keV}$ & $9 \mathrm{MW}$ \\
\hline Mereshkin, H & no & marginal & $7-10 \mathrm{keV}$ & $5 \mathrm{keV}$ & $14 \mathrm{MN}$ \\
\hline Mirnov & กต & merginal & B. $13 \mathrm{keV}$ & $10 \mathrm{keV}$ & $12 \mathrm{~m}$ \\
\hline $\begin{array}{l}\text { NET Assumptions } \\
\text { (Asdex H-mode) }\end{array}$ & $\begin{array}{l}\text { marginal } \\
\text { ( } \mathrm{D}>15 \mathrm{ke}\end{array}$ & v) marginal & $9-17 \mathrm{keV}$ & $13 \mathrm{keV}$ & $8 \mathrm{NW}$ \\
\hline
\end{tabular}

Table III-6 Parameters and Physics Assumptions Used for the High Performance Cases.

Geometry

Impurities

Profiles

Energy Confinement : Kaye-Goldston, H-mode $(I<\mathrm{H}<2)$

Power Degradation : Power $P$ used in the Kaye-Goldston energy confinement scaling $P-P_{a}+P_{\text {aux }}-P_{\text {brem }}-P_{\text {syne }}$

LH Forward Launch : 908

Beam Energy $\quad: 1.0 \mathrm{MeV}$ 
Table III-7 Plasma Parameters for the HIgh $Q$ and High Wall Loading Cases.

\section{Parameter Description}

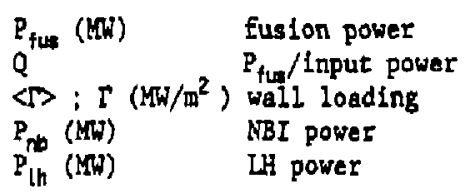

$\mathrm{T}_{\mathbf{6}} ; \mathrm{T}_{\mathbf{i}}(\mathrm{keV})$

$n_{e} ; n_{b t}\left(10^{20} x^{-3}\right)$

$\Omega_{\text {gretrmald }}$

$Z_{\text {eff }}$

$\beta_{\text {op }} ; \beta_{\text {ymazoki }}$

$\beta_{\text {fat alphe }}(8)$

H

$\tau_{E}\langle s\rangle$

$I_{p}(M A)$

$I_{\text {(b) }}^{p}$ (MA)

$I_{\text {lh }}$ (MA)

$I_{b}$ (MA)

Een ( $\mathrm{MeV}$ )

$N_{11, \ln } ; N_{11, \infty}$

$\gamma_{1 \mathrm{~h}}(1020 \mathrm{~m} / \mathrm{W})$
e-Ion temperature

e-DT density

density limit

effective charge

$h=r_{E} / r_{E}$ (l,-mode)

confinement time

plasma current

NBI current

LL current

bootstrap current

NBI energy

refractive index

LH efficiency

NBI effleiency
High Q

High $\Gamma$

$\begin{array}{cc}340 & 590 \\ 21.6 & 13.1 \\ 1.4: 2.1 & 2.4 ; 3.7 \\ 11.5 & 31.3 \\ 4.1 & 13.9\end{array}$

$22.2 ; 20.8$

$11.4 ; 10.5$

$0.96 ; 0.80$

2.51

1.50

$6.6 ; 6.6$

1,32

2.0

1.1

$2.2 ; 1.88$

2.51

1.50

$6.6 ; 6.6$

0.48

1.45

0.70

8.0
2.0
1.4
4.6
1.0
$.53 ; 2.52$
0.61
0.50

8.0

1.5

1.0

5.5

1.0

$2.1 ; 2.0$

0.35

0.31 
Fig. III-1 POPCON for TIBER using $K G+N A$ scallng, I $=8 \mathrm{KA}$, $\mathrm{H}-2.0$. The Murakami density limit is nuepo-1.1; the Greenwald limit is $n_{\mathrm{Gr} 20^{-2}}$.3. The beta limit is $\theta_{\text {linim }}-4,88$.

Fig. III.2 POPCON for TIBER using $K G+N A$ scaling, I $=10 \mathrm{MA}$, H-2.0. The Nurakami density limit is $\pi_{4 u 20}-1.35$; the Greenwald linit is $n_{\text {grzo }}-2.9$. The beta limit is $\hat{\beta}_{1 \text { in }}-6.08$.

Fig. IIT-3 POPCON for TIBER using KG + NA scaling, I $-12.5 \mathrm{MA}$, $H=2.0$. The Murakami density limit id $n_{M \cup 20}=1.7$; the Greenwald limit is $\pi_{\text {trat }}-3.6$. The beca limit is $\beta_{\text {i in }}=7,69$.

Fig. III-4 POPCON for TIBER using $\mathrm{KG}+\mathrm{NA}$ scaling, $I_{P}-12.5 \mathrm{MA}$, $\mathrm{H}-1.0$. The Murakami density limit is $\mathrm{n}_{\mathrm{p}}-1.7$; the Greenwald linit is $n_{6 r 20}-3.6$. The beta limit is $\beta_{\text {If }}=7.68$.

Fig. III-5 POPCON for TIBER using Mereshkin scaling, $I_{\mathrm{P}}-8 \mathrm{MA}$, $\mathrm{H}-2.0$. The Murakani density limit is $n_{\text {Mut }}-1.1$; the Greenwald limit is $\mathrm{n}_{\mathrm{or} 2 \mathrm{O}^{-2}} \mathrm{2}, 3$. The beta limit is $\theta_{\text {lim }}=4.88$.

Fig. III-6 POPCON for TIBER using Mirnov scaling, $I_{p}=B \mathrm{MA}$, $\mathrm{H}-1.0$. The kurakami density limit is $\mathrm{n}_{\mathrm{puza}}-1 . \mathrm{I}$; the Greenwald limit is $n_{\text {Grzo }}=2.3$. The beta limit is $\beta_{\text {lim }}-4.84$.

FIg. III.7 POPCON for TIBER using NET assurptions including Asdex H-mode scaling, $I_{0}=8$ MA. The Hurakami density

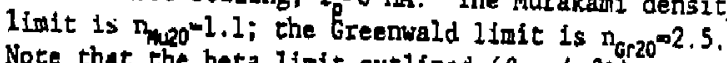
Note that the beta limit outlined $\left(\beta_{1 \text { in }}-4.8 t\right)$ corresponds to the Troyon value with $g=2.88$. The NET assumption, g-3.58 corresponds to the dashed curve
labelled 0.059 .

Fig. III-8 Cantours of $Q$ (solld lines) and \langle\rangle$\left(M W / m^{2}\right.$. dashed lines) for TIBER using the high performance assumptions (see Table III-6). 


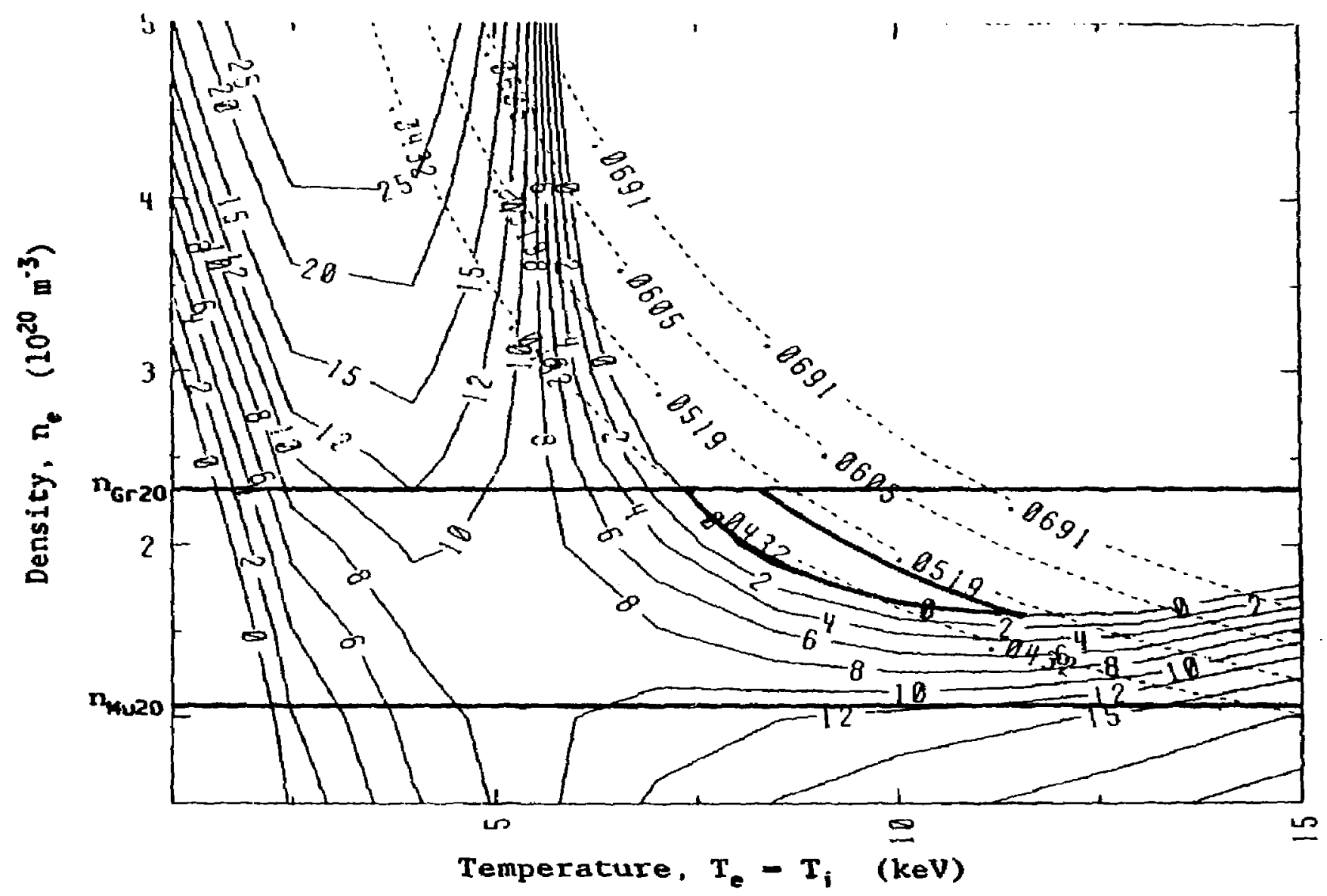

Fig. 1 


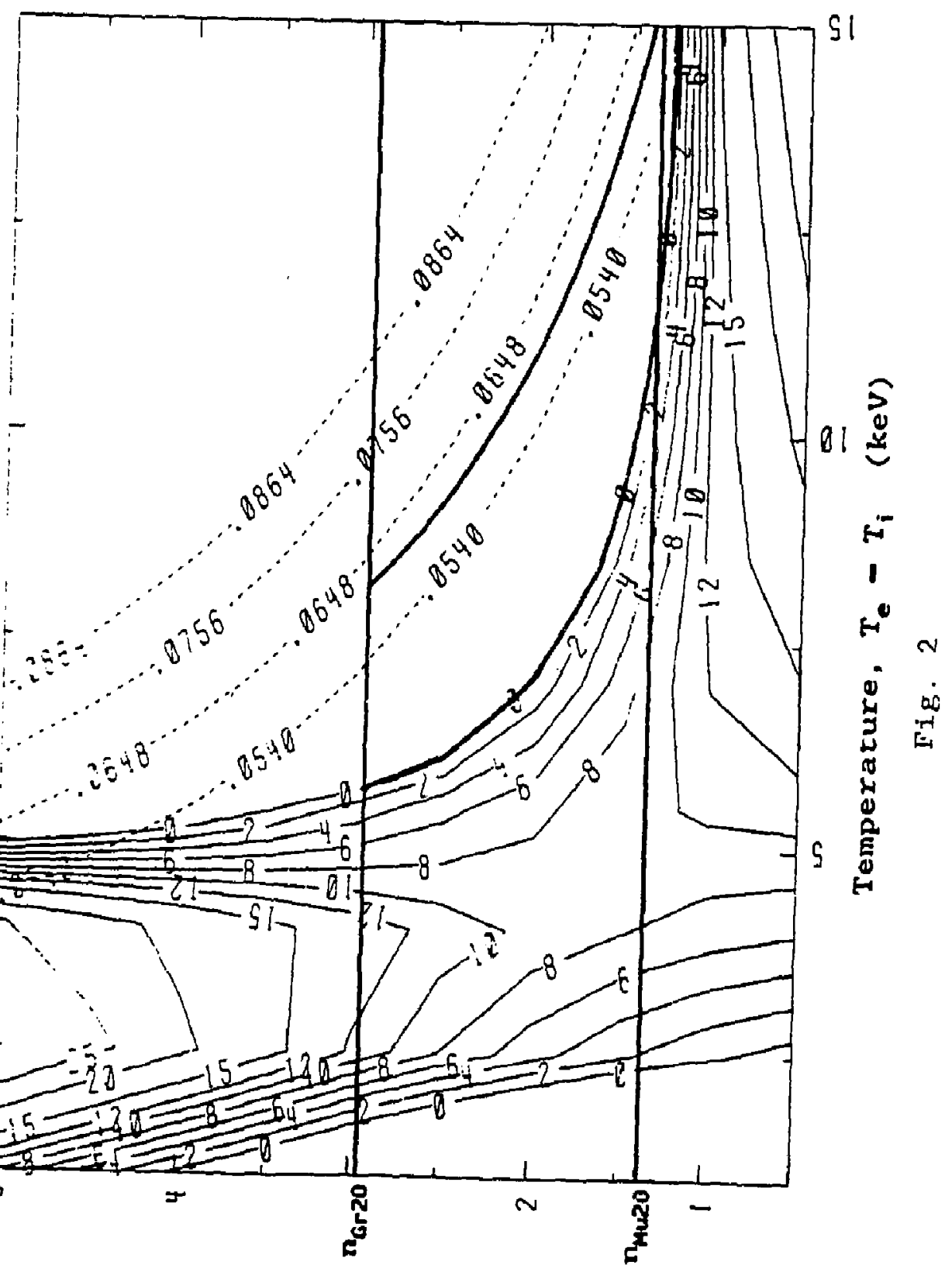

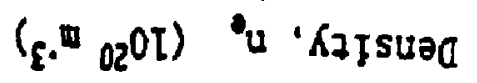




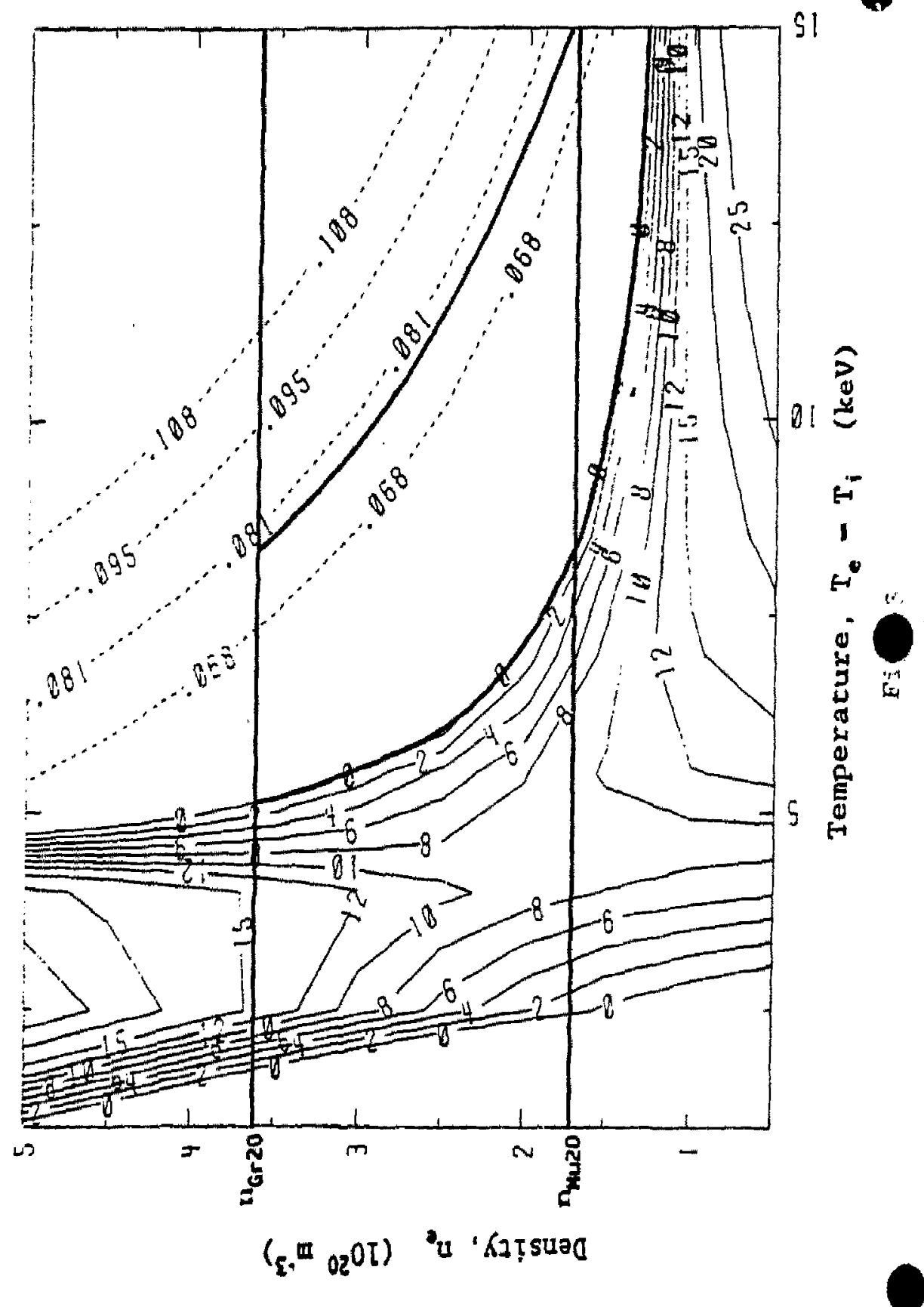




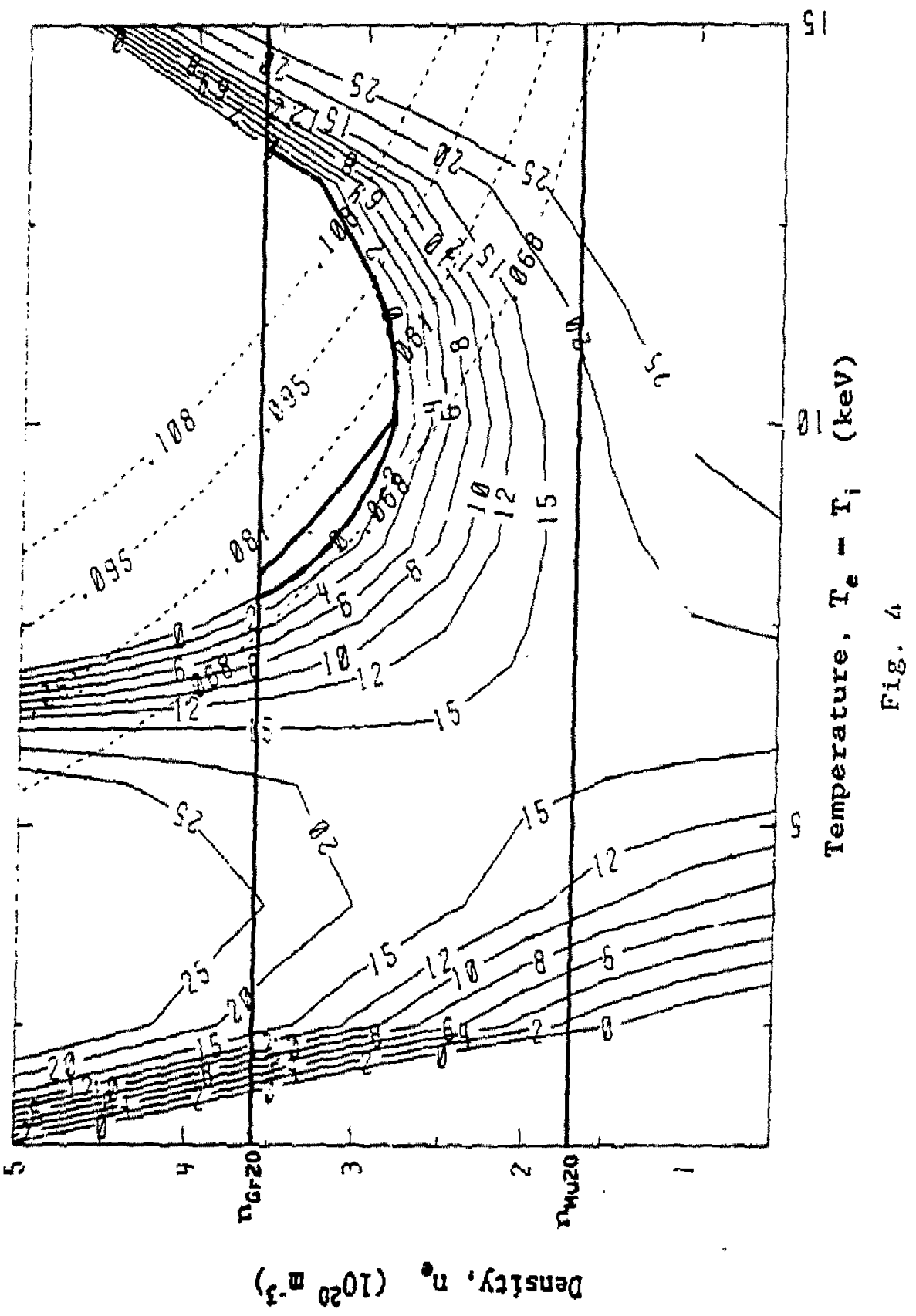




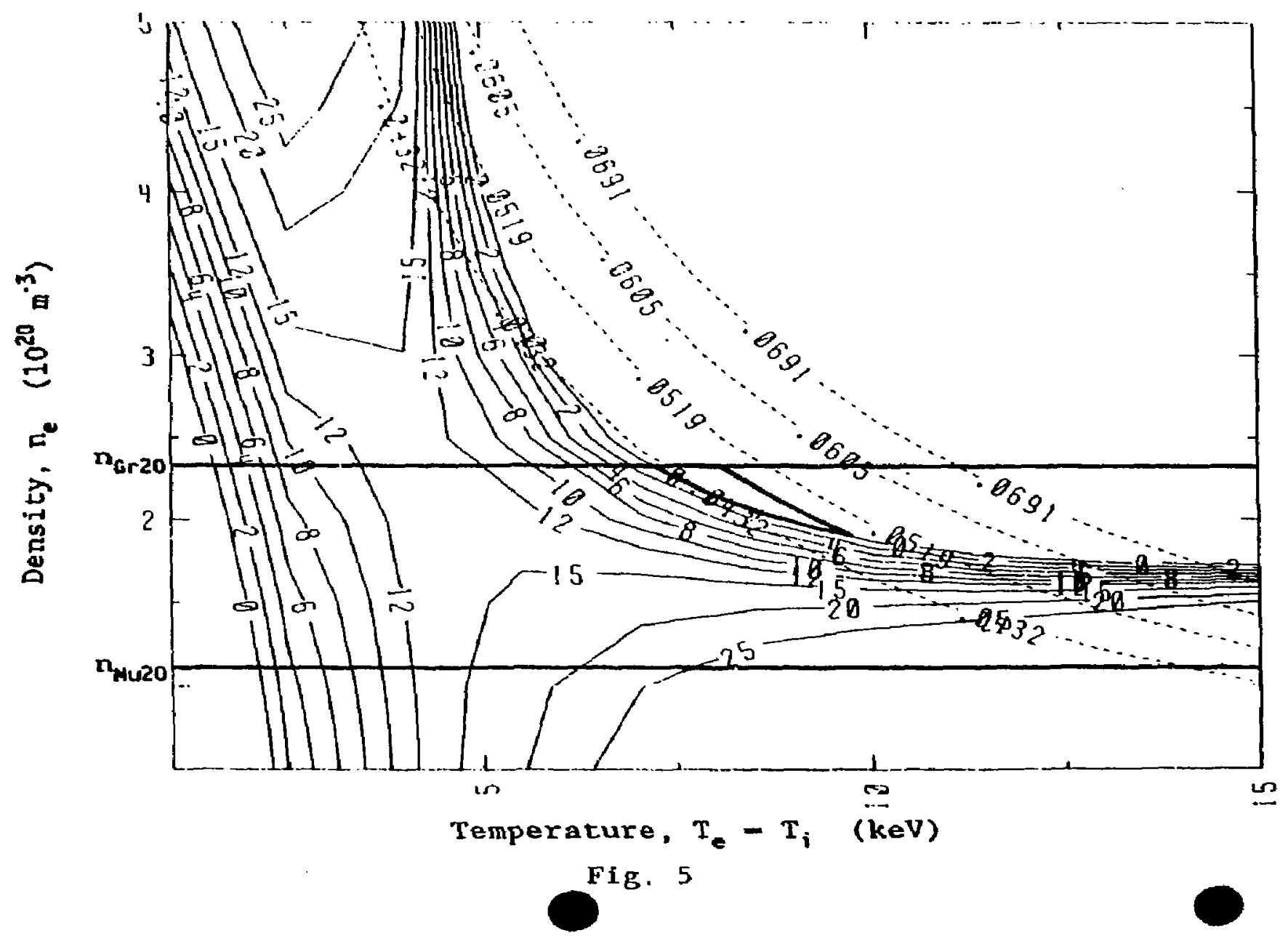




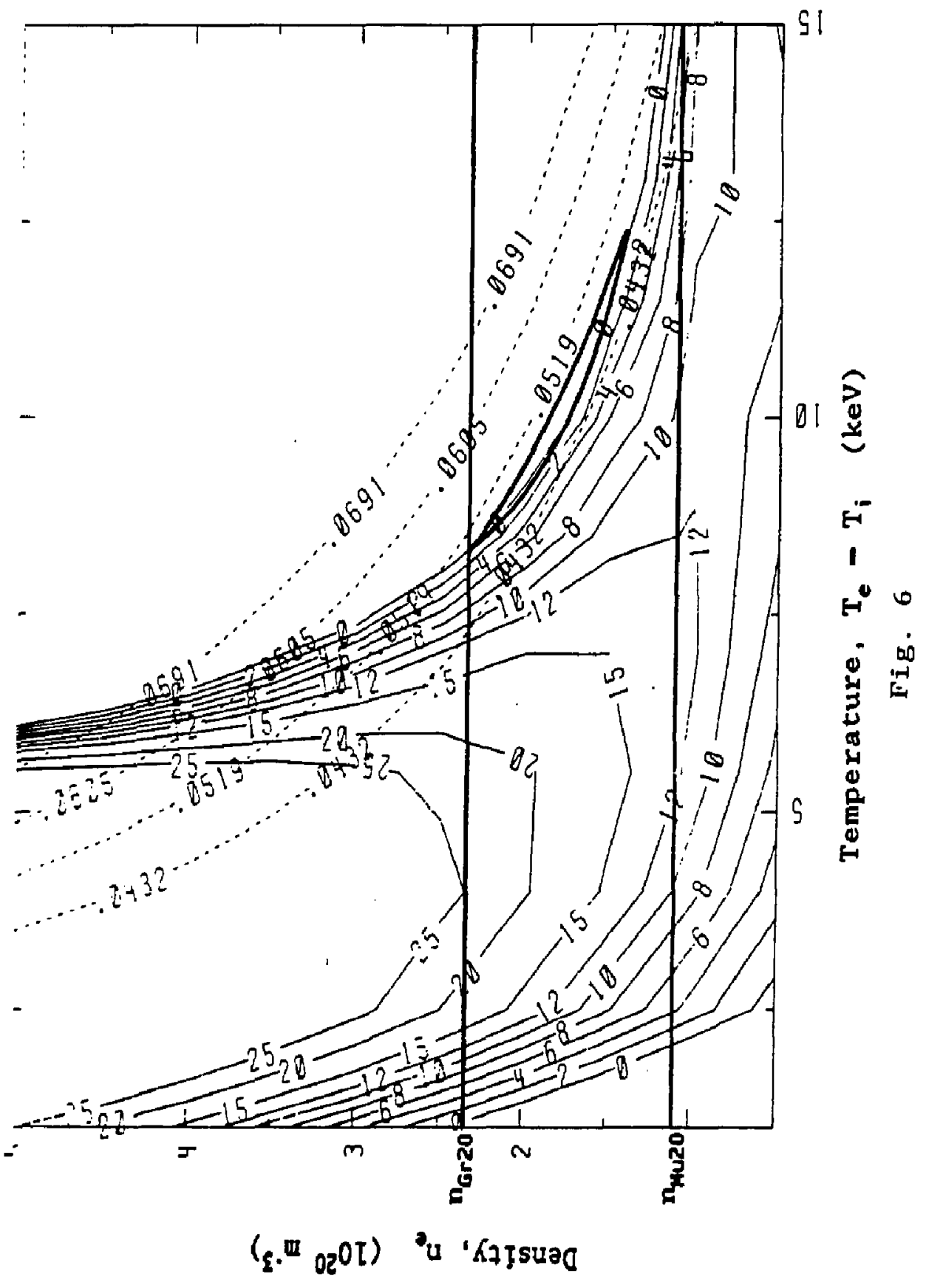




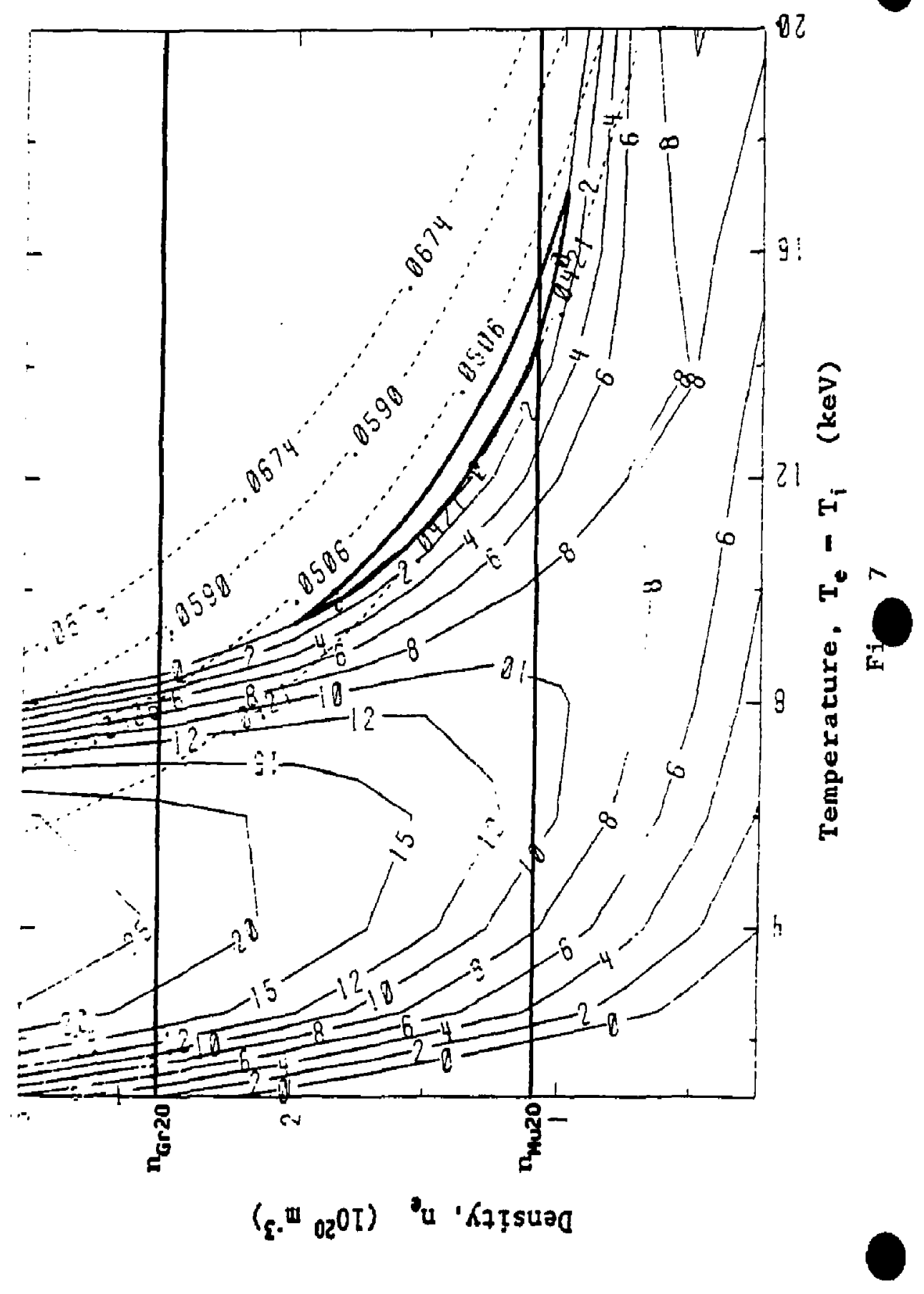




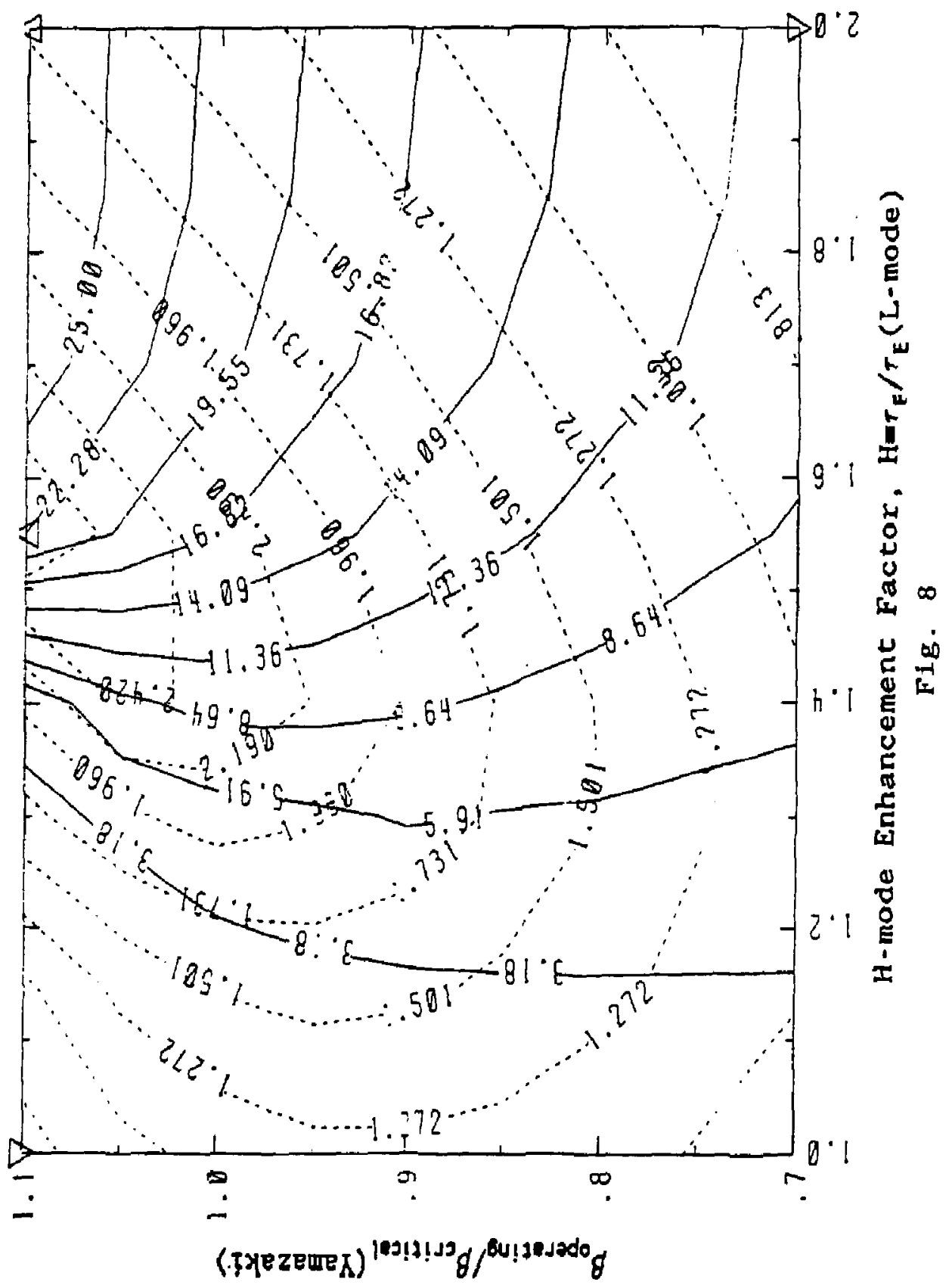


PART 2

ADVANCED BLANKET MODELING

(THE MICROWAVE SUPERHEATER)

CONIRIBUTOR (S): R.B. CAMPBELL 


\section{Advanced Blanket Modeling- The Microwave Superheater}

Robert B. Campbell

October 6, 1987 


\section{Contents}

1 Introduction 2

2 Superheater Description and Design Issues 3

3 Physical Model 4

3.1 Overvjew of Mode $\ldots \ldots \ldots \ldots \ldots \ldots$

3.2 Gas Moment Equations $\ldots \ldots \ldots \ldots$

3.3 Electron Moment Equations . . . . . . . . . . . . . . . . . . 8

3.4 Heal Source from Microwave Absorption . . . . . . . . . . . . . 11

4 Results of Calculations 15

4.1 One-Dimensional Mode] . . . . . . . . . . . . . . . . . 15

4.2 Two-Dimensional Model . . . . . . . . . . . . . . . . . 15

4.3 Scaling to Reactor Grade Systems $\ldots \ldots \ldots \ldots \ldots$

5 Conclusions 18

\section{List of Figures}

1 An Energy Conversion System Utilizing a Microwave Superheater . . 3

2 Power Balance in the Microwave Superbeater . . . . . . . . . 20

3 Ray Tracing Geometry . . . . . . . . . . . . . . . . . . . . 21

4 Contour Plot of Outlet Temperatures from 1-D Code . . . . . . . . 22

5 Radial and Axial Profiles for the Base Case . . . . . . . . . . . 24

6 Seed Fraction Parametric . . . . . . . . . . . . . . . 25

7 Gas Pressure Parameciric . . . . . . . . . . . . . . . . . 26

8 Transpiration Cooling Mass Flux Parametric , . . . . . . . . 27

9 Microwave Padiation Intensity Parametric . . . . . . . . . . 28

\section{List of Tables}

1 Characteristics of the baseline case with and without radial electron losses $\ldots \ldots \ldots \ldots \ldots \ldots \ldots \ldots \ldots$ 


\section{Introduction}

The microwave superheater is a concept which can use the synchrotron radiation from a thermonuclear plasma to heat gas seeded with an alkali metal to temperatures far above the temperature of material walls. The idea is used in the innovative Compact Fusion Advanced Rankine (CFAR) cycle[1], although other blanket configurations could be substituted. Because of the need for copious amounts of synchrotron radiation, the microwave superheater is best suited for use with plasmas burning an advanced fuel such as $\mathrm{D}$-3 He.

The present report is concermed with the description and modeling of the microwave superheater. We perform a detailed examination of heaters in the laminar flon regime, appropriate for a small scale demonstration experiment. Section 4.3 suggests that scaling to larger superheaters is possible. Through parametzic analysis, discussed in Section 4, we determine the sensitivity of healer performance to changes in key parameters, such as gas pressure, seed fraction, and microwave intersity.

We have developed two steady-state codes which cauple fluid dynamics, radiation transport, and plasma physies to predict the performance of the microwave superheater. A relatively simple 1-D code calculates the arial profiles of the bulk gas properties. A more detailed 2-D code calculates both the radial and axial profiles of gas properties. Since issues of radial uniformity of the microwave heating are important, this report will primarily concentrate on results of the 2-D model. The complete set of equations used in the model are described in detail in Section 3.

We have considered experimental-sized superheaters operating in the laminar flow regime using helium seeded with lithium. The gas is heated by a monochromatic spectrum at $56 \mathrm{GHz}$ produced by a getotron. At reasonable pressures (0.1 to 1 atmospheres) and seed fractions ( $\left.\leq 10^{-4}\right)$ we have found that the radial uniformity of the heating is sufficient to allow the bulk outiet temperatures to reach nearly $3000^{\circ} \mathrm{K}$, when the inlet temperature is about $1200^{\circ} \mathrm{K}$ and the wall temperature is $1000^{\circ} \mathrm{K}$. The seed concentration and intensity of the microwave radiation must be carefully controlled to avoid either overheating or underheating. 


\section{Superheater Description and Design Issues}

In its simplest form, the microwive superheater is a cylindrical tube made of high temperature ceramic. The ceramic is transparent to the microwaves and serves as a window. The wall is maintained at a temperature which keeps microwave losses low, and may sequire transpiration cooling. Transpiration cooling involves the passage of a slip-stream of unseeded working flujd through tiny pores in the wall. Figure $l$ is a schematic diagram of the CFAR energy conversion system utilizing

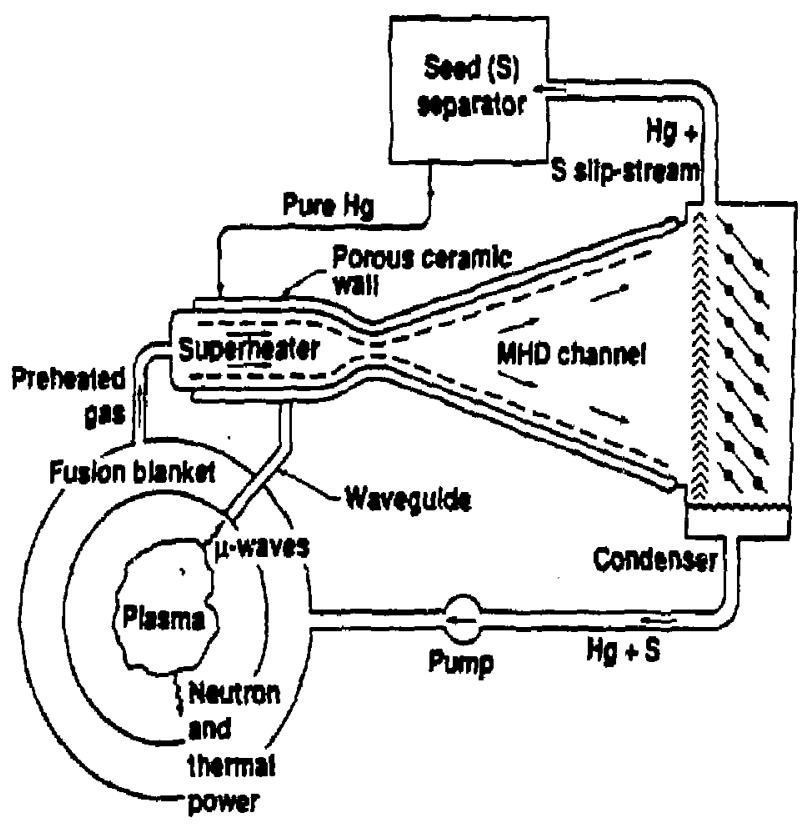

Figure 1: An Energy Conversion System Utilizing a Microwave Superheater

a microwave superheater. Our present plan is to employ a Rankine cycle using mercury as the working fluid. The fusion fuel cycle would probably be D-3He. Liquid mercury is boiled and partially superheated within a two-zone fusion blanket and enters the superheater at two locations. The majority of the vapor is seeded and is superheated conventionally by a high temperature pebble bed in the rear of the blanket to about $2000 \mathrm{~K}$ and enters the microwave superbeater for additional 
healing to about $30000 \mathrm{~K}$. Another stream of unseeded working fluid is heated in the front of the blanket to sbout $8000 \mathrm{~K}$ and is used to cool the porous ceramic wall. It is desirable that the wall temperature not exceed $1000-1500^{\circ} \mathrm{K}$ to avoid microwave absorption. The syachrotron rediation is piped through overmoded waveguides with small losses to a resonance cavity surrounding the superhezter structure. The microwaves pass through the ceramic wall, and beat the vapor.

The microwave superbeater is attractive because the heating is volumetric, al. lowing the gas to be heated to temperatures considerably higher than the wall temperature. However, the volumetric beat source during strong beating can be peaked neer the wall. Power deposited near the wall would be lost in the forms of an enhanced beat flux and will not contribute to a change in the bulk enthalpy of the gas. These concerns have motivated the development of a two-dimensional model which self-consistently calculates the radial and axial variation of the microwave beating source and the gas properties. This model will be described in more detail in Section 3.

The issue of radial uniformity must be addressed in the reactor- relevant regime. The working tluid would be metcury vapor seeded with cesium, at pressures of several atmospheres and mass flow rates which would place it in the turbulent flow regime. The spectrum would be characteristic of synchrotron radiation with a peak at approximately $1000 \mathrm{GHz}$ for an advanced fuel (D- ${ }^{3} \mathrm{He}$ ) tokamak. Section 4.3 presents some simple arguments which are used to scale to reactor-televant superheaters.

\section{Physical Model}

\subsection{Overview of Model}

The model we have developed for the study of microwave superbeating is comprised of the moment equations for the gas and electrons, the equation of mass transfer to describe the seed atorn "impurity" density, and the radiation transport equation. The continuity equation, momenturn equation, and energy equation[2] are solved for the main working fluid. The continuity and energy equ tions are solved for the electron fluid[3]. In the tro-dimensional model when transpiration cooling with fure gas is used, the radial and axial evolution of the seed alom concentration is found by solving the mass transfer equation[2]. 
The volumetric heating term from the microwaves is calculated as a function of electron and gas flud properties by two-dimensional ray-tracing. The inwardlydirected radiation intensity at the tube surface, $I_{0}$, is assumed isotropic and is treated as a parameter. For the reactor, $I_{0}$ can be adjusted by controlling the plasma chamber wall reflectivity of the synchrotron radiation and the number of superbeaters. In the experimental superheater, the power level of the grrotron output determines $I_{0}$.

The boundary conditions are specified as follows. Symmetry dictates that the radjal derivative of all properties vanish at the tube centerline. The gas temperature at the wall must be equal to the wall temperature which can be specified externally or calculated using some model (such as a energ balance for the wall material). The axial velocity at the wall is zero, and the radial relocity is that value consistest with the transpiration cooling mass flux. The concentration gradjegt of seed material is determined by relating it to the flux of pure gas flowing through the wall. The equiralence between the macroscopic Fourier heat flux and the microscopic heat flux for electrons including the effects of a wall sheat botential places a boundary condition on the electron temperature gradient at the wall[4]. The clectron density gradient boundary condition is obtained in a similar manner relating particle fluxes:3].

We have considered both a one and two dimensional model for the microwave superheater. The two dimensional model retains the radial and axjal dependence of the properties, whereas the one dimensional model includes only the axial variations. The one dimensional model is obtained formally by a radial average of the two dimensional model equations over an assumed set of property profiles. The propesty profies for this particular model are assumed uniform in radius. The volumetric heating term is evaluated with the average properties.

The one dimensional model, because of its relative simpliciry, is useful in mapping out large regions of parameter space. The model suffers however, because it canoot address the important issue of radial uniformity of the beating. The two dimensional model, on the other hand, is much more complex and considerably more computing is required to examine a given configuration. However, it has the capability to answer critical questions related to the radial aspects of the problen.

Figure 2 shows the power flow through a differential slice of the superheater tube. Mass and enthalpy flows into the volume through the entering main tube flow and through transpiration cooling of the walls. Power is deposited in the volume by heating due to the microwaves. Power can be lost from the volume by surface 
conduction and convection from the gas and electrons, and volumetrically from line radiation from electrons. The useful part of the microwave power, deposited by electron-neutral collisions, leaves the volume as incriased enthalpy of the gas.

\subsection{Gas Moment Equations}

The gas is described by the equations of conservation of mass, momentum, and energy [2]. The radially resolved equations are written in the boundary layer approximation, which requires that velocities (axial, $u$ and radial. $v$ ) and pressure, $P$, satjsfy certain orderings. These are $u \gg v, \partial u / \partial r \gg \partial(u, v)^{\prime} \partial x, \partial v / \partial r$; the stress tensor, $\overline{\bar{\partial}}$, is diagonal, with $\sigma_{x z}=-P$, and $\partial P / \partial \pi \approx 0$.

The continuity equation may be written:

$$
\frac{\partial}{\partial x}(\rho u)+\frac{1}{r} \frac{\partial}{\partial r}(r \rho v)=0,
$$

where $\rho$ is the gas mass density.

The gas momentum balance in an axisymmetric tube is given by:

$$
\rho u \frac{\partial u}{\partial x}+\rho v \frac{\partial u}{\partial r}+\frac{\partial P}{\partial x}=\frac{1}{r} \frac{\partial}{\partial r}\left(r \mu \frac{\partial u}{\partial r}\right),
$$

where the new variable is the viscosity, $\mu$. We use for $\mu$ the relationship appropriate for as ideal gas:

$$
\begin{aligned}
& \mu=\frac{2}{5} \mathcal{M}\left(\frac{\gamma-1}{R}\right) k, \\
& k=\frac{1}{3} \rho \bar{w} \lambda_{0 a 0} \frac{R}{M(\gamma-1)} \text {, } \\
& \tilde{w}=\sqrt{\frac{8 R T_{g a v}}{\pi \cdot M}}, \\
& \lambda_{\text {pas }}=\frac{m_{\text {gas }}}{p \pi \tau_{0}^{2}} \text {. }
\end{aligned}
$$

The parameter $\gamma$ is the ratio of specific beats, $M$ is the molecular weight of the gas, $R$ is the universal gas constant, and $k$ the thermal conductivits. In the relation for $k, \hat{w}$ is the mean thermal speed of the gas molecules, and $\lambda_{\text {gas }}$ is the mean iree path 
of the gas molecules. In $\lambda_{\text {gas }} m_{\text {gan }}$ is the mass of the gas molecule, and $r_{0}$ is the collision radius of the gas atom.

The energy equation for the gas can be nritten:

$$
\begin{gathered}
\rho u \frac{\partial \mathcal{H}}{\partial x}+\rho v \frac{\partial \mathcal{H}}{\partial r}-\frac{1}{r} \frac{\partial}{\partial r}\left(k+\frac{\partial T_{p s e}}{\partial r}\right) \\
-\mu\left(\frac{\partial u}{\partial r}\right)^{2}-u \frac{d P}{d x}-q_{e a l t}^{\prime \prime \prime}=0
\end{gathered}
$$

where $\mathcal{H}$ is the gas enthalpy, and $q_{\mathrm{coll}}^{\prime \prime \prime}$ is the source term frox collisional beating of the gas by microwave heated electrons, given by Eq. 12 .

When transpiration cooling using unseeded gas is emploged, a mass diffusion equation is solved for the radial profile of the seed materia' mass concentration, $\mathcal{G}_{\text {red. }}$. This equation is:

$$
\rho u \frac{\partial \mathcal{G}_{\text {sed }}}{\partial x}+\rho v \frac{\partial \mathcal{G}_{\text {eeed }}}{\partial r}-\frac{1}{r} \frac{\partial}{\sigma r}\left(r \Lambda_{\text {oeed }} \frac{\partial \mathcal{G}_{\text {seed }}}{\partial r}\right)=0
$$

The form of this equation is appropriate when $\mathcal{G}_{\text {ga }} \gg \mathcal{G}_{\text {recs. }}$. The mass diffusion coefficient, $\Lambda_{\text {eced }}$, is related to the viscosity, $\mu$, in the ideal gas and unity Lexis number (Prandtl $\#=$ Schmidt $\#$ ) limit by $\Lambda_{\text {ceed }}=\mu / \operatorname{Pr}$, witb $\operatorname{Pr}=\frac{2}{3}$ for an ideal gas. heater:

We now consider the boundary and inlet conditions for the gas in the super-

$$
\begin{aligned}
& p v\left(r_{w}, x\right)=\frac{\dot{m}_{\text {wall }}(x)}{2 \pi r_{w}}, \\
& u\left(\tau_{w}, x\right)=0, \\
& u_{1}^{\prime}(r, 0)=u_{0}(r) \text {, } \\
& T_{\text {gas }}(r, 0)=T_{D}(r), \\
& T_{\text {gas }}\left(t_{w}, x\right)=T_{\text {wall }}(x) \text {, } \\
& P(r, 0)=P_{0} \\
& \left.\Lambda_{\text {oo, }} \frac{\partial \mathcal{G}_{\text {metd }}}{\partial r}\right|_{r_{v}}=\rho v\left(r_{w:} x\right) \mathcal{G}_{\text {reed }}
\end{aligned}
$$


where $\dot{m}_{\text {wall }}(x)$ is the radial mass flux per unit length emitted from the wall during transpiration cooling, $u_{0}$ and $T_{0}$ are specified inlet radial profiles of $u$ and $T_{\text {pan }}$ respectively. Note that wall mass flux into the flow is considered negative.

\subsection{Electron Moment Equations}

Collisions are strong in this weakly.ionized plasma so the electron dist ribution func. tion remains Maxwellian, even during microwave heating. This justifies the use of monent equations derived from the electron Folker-Planck equation. Equations which describe the particle and energy balance for electrons are solved. These equations apply outside the very thin sheath region near the rall. The effect of the sheath potential drop at the wall, $\phi_{w}$, is included as a boundary condition on the electron heat and particle fux.

The electron particle balance outside the sheath region use the assumption that the radial flow is ambipolar and is given by [3]:

$$
\left.-\frac{1}{r} \frac{\partial}{\partial \tau}\left[r n_{e}\left(\frac{D_{a m b}}{2 p_{1}} \frac{\partial}{\partial r}\left(p_{e}+p_{i}\right)\right)\right]+\frac{\partial\left(u n_{e}\right)}{\partial x}+\frac{1}{r} \frac{\partial}{\partial r}\left(r u n_{e}\right)=a_{1} T_{e}\right)\left[\left(n_{c}^{*}\right)^{2}-n_{e}^{2}\right] .
$$

In this equation, $D_{a m b}$ is the ambipolar diffusion coefficieat, $p_{L}=n_{\mathrm{f},} k_{\mathrm{g}} T_{\mathrm{t}, \mathrm{i}}$ are the electron and ion pressures, $a\left(T_{e}\right)$ is the recombination coefficient. Our modeling so far has included the two-electron three body collisional recombination process. In the density and temperature range of the experimental-sized superheater, radiatjve recombination may not be negligible, but the complexity of the calculation for general parent and seed gasses prevents us from including it. For the three body process, $\alpha$ is given by (in MKS):

$$
\alpha\left(T_{e}\right)=1.09 \times 10^{-20} n_{e} T_{e}^{-\frac{9}{2}} .
$$

The term $\left(n_{e}^{*}\right)^{2}$ is related to the Saba equilibrium relation, and is given by:

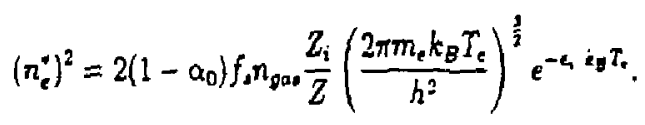

In this equation, $Z$ and $Z_{1}$ are the partition functions for the peutral and singlyionized atom, respectively. The variable $f$, is the seed fraction. $m_{\varepsilon}$ is the electron mass, $\epsilon_{i}$ is the ionization potential of the seed atom, $h$ is Planck's constant, and 
$\alpha_{0}$ is the degree of ionization of the seed. The limit when the diffusion losses are negligible, Eq. 7 reduces to $\left(n_{e}^{*}\right)^{2}=n_{e}^{2}$ which is the familiar Saba relationship. We bave found that including the diffusion terms in the electron particle balance is important to properly model the penetsation of the microwaves into the core region of the gas flow. The Saha relation overestimates the electron density near the wall and hence the amount of absorption there.

The electron energy balance forms the core of the plasma physics model of the mictowave superheater. It balances the input from microwave heating with collisional heating of the gas, radiation losses, and conduction and convection losses to the walls. This equation can be witten $\{3$ !:

$$
\begin{array}{r}
u \frac{\partial}{\partial x}\left[n_{\mathrm{e}}\left(\frac{3}{2} k_{B} T_{e}-\epsilon_{i}\right)\right]+v \frac{\partial}{\partial r}\left[n_{e}\left(\frac{3}{2} k_{B} T_{e}+\epsilon_{c}\right)\right]= \\
+n_{e}\left(\frac{5}{2} k_{B} T_{e}+\epsilon_{i}\right) \frac{1}{\rho}\left(u \frac{\partial \rho}{\partial x}+v \frac{\partial \rho}{\partial \tau}\right) \\
-\frac{1}{r} \frac{\partial}{\partial r}\left[r\left(\left(\vec{g}_{e}\right)_{r}-\frac{\epsilon_{s}}{e}\left(\vec{J}_{e}\right)\right)\right]-q_{r e d}^{\prime \prime \prime}-q_{c o l l}^{\prime \prime \prime}-q_{\mu}^{\prime \prime \prime} .
\end{array}
$$

The term $q_{\text {rod }}^{\prime \prime \prime}$ is the loss due to radiation. For the beaters using helium seeded with cesium or litbium, radiation is about a $10 \%$ effect. We use the worl of Gregory $[5 ;$, Lutz[6], and Holstein[7] to compute this term. The assumption of a Lorenzian shape of the radiation emission line is made for both the seed element and the parent gas. The general form for this term for a given species, $j$, for each emission line is 6 ; :

$$
\begin{aligned}
& q_{\text {rad }, j}^{\prime \prime \prime}=\frac{3.71}{\sqrt{r-T_{w}}} \Delta \nu_{j} \sqrt{\zeta_{0}}\left(B_{0}\left(\lambda_{j}, T_{t}\right)-B_{0}\left(\lambda_{j}, T_{g a j}\right) .\right. \\
& \Delta v_{j}=\Delta v_{\text {pres, }}+\Delta v_{\text {depps }} . \\
& \zeta_{0}=\frac{A f_{\text {oos, }, j} \pi_{\text {ops }}}{\Delta \nu_{j}} \\
& B_{0}(\lambda, T)=\frac{2 h c}{\lambda^{3}}\left[\exp \left(\frac{h c}{\lambda k_{B} T}\right)-1\right]^{-!} .
\end{aligned}
$$

The parameter $\lambda$ is the wavelength of the line, $\zeta_{0}$ is the inverse absorption length of the line evaluated at the line center, $\mathcal{A}=\frac{e^{2}}{2 m, m_{0} r}$, and $f_{\text {ox } j}$ is the absorption 
oscillator strength of the line. $B_{0}(\lambda, T)$ is the Planck furction. The line width $\Delta \nu$ has important contributions due to both Doppler and pressure broadening[8].

The collisional power lerm, qeoll, couples the electrons to the gas, and provides the power input to beat the gas. It is evaluated for the case where elastic collisions are dominant. This is a good approximation for parent gasses which are monoatomic, such as helium or mercury. This lem is of the form:

$$
\begin{aligned}
& q_{e d l]}^{\prime \prime \prime}=\sum_{h} \frac{2 m_{e}}{m_{h}} v_{e} / j n_{e} \frac{3}{2} k_{B}\left(T_{t}-T_{p o s}\right), \\
& v_{e f f}=n_{0} Q_{0} v_{e} .
\end{aligned}
$$

The parameter $v_{e f f}$ is the effective electron collision frequency. In $v_{e f f}, n_{0}$ is the neutral density, $Q_{0}$ is the collision cross section for electron-neutral interactions, and $v_{e}=\sqrt{\frac{8 s_{0} T_{s}}{m_{e} \pi}}$ is the mean thermal speed of electrons. The sum over the heavy species reduces to a single term for our model, as long as the seed fraction is not too large.

The electron heat flux vector, $\overrightarrow{q_{e}}$, is given by a Fourier law:

$$
\left(\overrightarrow{g_{e}}\right)_{r}=-\lambda_{e} \frac{\partial T_{e}}{\partial r},
$$

where $\lambda_{e}$ is the electron thermal conductivity, which includes collisions with both neutral and charged particles. It can be writtes[3]:

$$
\lambda_{e}=\frac{2.4}{\left(1+\frac{v_{e}}{\sqrt{2}+\rho)}\right)} \frac{k_{B}^{2} n_{e} T_{e}}{m_{e} \nu_{e} f f},
$$

where $\nu_{a}$ is the electron-ion momentum transfer collision frequency. The electron current is $\vec{J}_{e}$ related to the electron diffusion velocity, $\vec{v}_{\varepsilon}$ by:

$$
\vec{j}_{e}=e n_{t} \vec{l}_{e}
$$

and, in the ambipolar approximation, $\tilde{U}_{\epsilon}$ is given by:

$$
\left(\bar{U}_{e}\right)_{r}=-\frac{D_{\mathrm{amb}}}{2 p_{i}} \frac{\partial}{\partial \tau}\left(p_{e}+p_{i}\right)
$$

We conclude this subsection by describing the boundary conditions used for the electron balance equations. Th:se relationships involve the specification of the flux 
of particles or heat lost to the wall. From kinetic theory, including the effects of a sbeath potential, an expression can be derived for the particle and beat flux. Frow the fluid description of the electrons, these fluxes are related to the gradients of density and temperature at the wall through Fick's and Fourier's laws. The boundary conditions are obtained by realizing that these two descriptions must be equivalent for the fluid model to be valid. The conditions are:

$$
\begin{aligned}
-n_{\mathrm{e}} & \frac{D_{\mathrm{amb}}}{2 p_{\mathrm{i}}} \frac{\partial}{\partial}\left(p_{\mathrm{e}}+p_{\mathrm{s}}\right)=\frac{1}{4} F n_{\mathrm{e}} v_{\mathrm{e}} \\
& -\lambda_{\mathrm{e}} \frac{\partial T_{\mathrm{e}}}{\partial \mathrm{T}}=\frac{1}{4} F n_{\mathrm{e}} v_{\mathrm{e}} \cdot 2 k_{B} T_{\mathrm{e}}
\end{aligned}
$$

at $r=r_{w}$. The function $F$ takes into account the sheath potential. The form of $F$ we use assumes that the ceramic wall is not an electron emitier. This is a good assumption for the wall temperature range pie are considering. For this case, $F$ can be writtes:

$$
F=\sqrt{\frac{\pi \beta}{8}}\left[5+\ln \left(\frac{1}{2 \pi ;}\right)\right],
$$

where $\beta$ is the ratio of electjon to ion mass.

\subsection{Heat Source from Microwave Absorption}

The absorption process which is dominant at these frequencies and temperat ures is collisional danping. The directed motion of the electrons oscillating in the electric field of the wave is converted to random thermal energy of the electrons by collisions with all species in the plasma. The randomization is caused by the loss of coherence between particle and wave phases when the electron's velocity vector changes due to a collision. The microwave power absorbed by the electrons can be transferred to the gas through electron-neutral collisions, lost by line radiation, or electron thermal conduction and convection. Fortunately, for the experimental-sized superheaters operating in the laminar regime using helium working fluid seeded with lithium, we have found that most of the power goes into the gas.

The equation of radiative transfer in the absence of scattering and re-emsission is given by [9]:

$$
d I_{\nu}=-\kappa_{\nu} \rho I_{\nu} d \ell
$$


where in Chandrasekhar's notation $I_{\nu}$ is the intensity of the radiation at a given frequency, $\ell$ is the path length along a ray pointed in a giren direction, $\rho$ is the material mass density, and the quantity $\kappa_{2}$ is known as the mass absorption coefficjent. We ignore scattering in this treatment of the microware absorption problem, and the re-emission of radiation is treated in a separate term given by Eq. 11. The neglect of scattering is justified for plasmas near thermodynamic equilibrium.

In the notation which will be used in this report, the product $\kappa \rho$ will be replaced by $\frac{F}{\ell_{D}}$ where $\epsilon$ is the dielectric function and $\ell_{D}$ is the damping length based on collisional damping. Note that our treatment could be used to investigate heating of ionized gases by radiation in other frequency ranges just by supplying the proper damping length valid for that type of absorption mechanism. For our problem here, $\ell_{D}$ is given by :10]:

$$
\ell_{D}=\frac{c}{2 \omega}\left[-\frac{1}{2} \epsilon+\sqrt{\left(\frac{1}{2} \epsilon\right)^{2}+\left(\frac{2 \pi \sigma}{\omega}\right)^{2}}\right]^{-\frac{1}{2}} .
$$

where $c$ is the speed of light, $\omega$ is the rave angular frequencr. and $\sigma$ is the conducrivity:

$$
\sigma=\frac{e^{3} n_{e} \nu_{e f f}}{m_{e}\left(\omega^{2}+\nu_{e f f}^{2}\right)},
$$

For the weakly ionized gas in the magnetic field-free experiment al-sized superheater the dielectric function for the ordinary mode is used:

$$
\epsilon=1-\frac{\omega_{p e}^{2}}{\left(\omega^{2}+\nu_{e f f}^{2}\right)}
$$

Here, $e$ is the electron's charge, and $v_{e f f}$ is the effective collision frequency for the electrons. The parameter $\omega_{p e}^{2}=\frac{4 \pi e^{2} n_{n}}{m_{r}}$ is the electron plasma frequency. The largest contribution to $\nu_{e f f}$ in this parameter range is due to electron-neutral collisions.

The solution of Eq. (19) with the initial condition that the intensity at the tube surface at an angle $\theta$ be $I_{0} \frac{d \theta}{2}$ is straight forward and is given by:

$$
I(\ell, x)=\frac{I_{0} d \theta \sqrt{c}}{\pi \ell_{D}} \exp \left(-\int_{0}^{\ell} \frac{d \ell}{\ell_{D}}\right)
$$

Evaluation of this term will give the intensity of radiation along the ray path. The distribution of rays will be isotropic in angle because the microwaves have 
wavelengths much smaller than the dimensions of the cavity walls, and each ray bounces several times in the cavity before being absorbed or lost. To calculate the volumetric source of microwave power, the amount of power absorbed from a ray in a given direction when passing through a differential annular volume is determined, and divided by the differential volume. An integration over all ray directions and all locations around the tube circumference yields the expression for the volumetric source term, $q_{\mu}^{\prime \prime \prime}$ :

$$
\begin{aligned}
& q_{\mu}^{\prime \prime \prime}(r, x)=\frac{2 I_{0} \tau_{w}}{\pi \ell_{D}} \int_{\theta_{\varepsilon},(r)}^{\frac{2}{2}} \frac{d \theta \sqrt{\epsilon}}{\sqrt{r^{2}-r_{w}^{2} \cos ^{2} \theta}} \exp \left(-\int_{0}^{\ell\left(-r \cdot \frac{d \ell}{\ell_{D}}\right)},\right. \\
& \theta_{c r}=\arccos \left(\frac{r}{r_{w}}\right) \text {, } \\
& \left\langle(r, \theta)=r_{w} \sin (\theta) \pm \sqrt{r^{2}-r_{u}^{2} \cos ^{2} \theta},\right. \\
& d \ell= \pm \frac{r^{\prime} d r^{\prime}}{\sqrt{\left(r^{\prime}\right)^{2}-r_{u}^{2} \cos ^{2} \theta}} .
\end{aligned}
$$

The geometry ' the ray tracing and variable definitions are shown on Figure 3. The \pm in the Janobian and the $\ell$ expression is determined by whether a positive differential change in $r$ correspo ts to a positive or negative change in $\ell$. The point along the ray where this transition occurs is when $r=r_{\min }=r_{t} \cos \theta$.

This term for the volumetric source strength is local in the axjal coordizate, $x$, because only rays which lie in a plane of constant $x$ are considered. This is an approximation to the actual situation where rays originating from $x^{\prime}\left\langle x\right.$ and $\left.x^{\prime}\right\rangle x$ can be absorbed at $x$. Includiug these additional rays would couple all the axial locations in the moment equations and would add significant complication to the model. We feel the present local model gives a conservative first estimate of the absorption of microwaves in the gas and also contains all of the important physics required to address the radial uniformity questions.

The $q_{\mu}^{\prime \prime \prime}$ expression can be evaluated in the limit of $\epsilon \approx 1, \omega \gg v_{\varepsilon} f$, and a radistion intensity incident only in one direction, $I=I_{0} \pi \delta\left(\theta-\frac{\pi}{2}\right)$. The result is:

$$
q_{\mu}^{\prime \prime \prime} \approx I_{0} \frac{r_{w}}{r l_{D}}\left[\exp \left(-\int_{+}^{+*} \frac{d r^{\prime}}{l_{D}}\right)+\exp \left(-\int_{0}^{r_{*}} \frac{d r^{\prime}}{l_{D}}-\int_{0} \frac{d r^{\prime}}{l_{D}}\right)\right]
$$


where in this limit the damping length takes the simple form:

$$
\ell_{D}=\frac{c}{\nu_{e f f}}\left(\frac{\omega}{\omega_{R e}}\right)^{3}
$$

By examining Equs. 25 and 26, some qualitative features of the heating can be established. Notice first that the source can be decomposed into two factors: (1) a lacal absorption term $\propto 1 / \ell_{D}$ and (2) a term which describes the decay of the power flux $\propto \exp \{\}$ along a ray path. To have efficient beating of the core flow, not only does the local term have to be strong in the core, but the absorption along the ray path must not be too large. These two factors conipete xith each other in *aat short damping lengths correspond to strong local heating; but also to strong damping of the radiation intensity. If we could somehow keep the damping length long at the edge and shorten it toward the center, we could to achieve reasonably uniform heating.

The tadial profiles of electron temperature and density we self-consistently calculate with the two-dimensional code yield radial profiles of damping lengin which exhibit this tendency for a range of the incident radiation intensity. Two elements of the modeling which are important to properly calculate the iemperat ure and density profiles are the heat and particle fiux boundar, conditions at the vall for the electron temperature and density respectively, and the treatment of difusion losses in the electron particle balance. Both effects tend to lower the electron temperature and density in the vicinity of the wall. Section 4 will give some illustrations.

By examining Eq. 26, we can identify some of the parameters which are important to describe the strength of the microwave heating. We substitute the expressjons for $v_{e f f} . \omega_{p e}, P=n_{\text {gat }} k_{B} T_{\text {ga }}$ and normalize the damping length with tha tube radius, $r_{w}$ :

$$
\frac{\ell_{D}}{r_{w}} \propto \frac{\left(\omega T_{g a a}(0)\right)^{2}}{r_{w} \alpha_{0} f_{1} Q_{0} \sqrt{T_{s} P^{2}}} .
$$

The hesting will become stronger by increasing the gas presure, $P$, seed fraction $f_{0}$, degree of ionization, $\alpha_{0}$, or the collision cross section, $Q_{0}$. Higher frequencies will result in weaker heating, unless other parameters ars $i$ adjusted. Section 4.3 illustrates the use of this law to scale to a reactor-grade superbeater system. 


\section{Results of Calculations}

\subsection{One-Dimensional Model}

Figure 4 shows a plot of contours of constant outlet temperat ure as a function of gas pressure and seed fraction as predicted by the one dimensional superheater model. The gas is helium, with cesium seed material. The tube lengit is two meters, and its radius is fixed at $5 \mathrm{~cm}$. The inlet teinperature was consiant at $1100 \mathrm{~K}$. The $\ell_{D}$ varies over a large range in this figure. The $1-D$ model cannot be expected to be cortect when the damping length becomes much less than the tube radius. Therefore, we have drawn a contour of constant $l_{D}=0.05 \mathrm{~m}$ on the figure to show the maximum outlet temperature which can be believed. The main point of this plot is that outlet temperatures of nearly $3000^{\circ} \mathrm{h}$ can be obtained for a range of seed fraction-pressure combinations. The 1.D model can scan rapidly over paraneter space but cannot investigate the radial uniformity issues. We therefore concentrate on results generated from the more complete 2-D code.

\subsection{Two-Dimensional Model}

Table 1 shows the characteristics of an experimental sized microwave superheater. The case labeled without will be discussed later. The choice of the leagth and radius of the tube is somewhat arbitrary, but seemed reasonable for a small sized froof of principle experiment. We changed the seed material from cesium to lithium because th: conization potential for lithium is larger than for cesium, allowing operation at a higher pressure for the same degree of heating non-uniformity. In a real configuration there would not be enough unheated entrance region for the profiles to approach fully-developed ones, hence radially uniform initial conditions of gas velocity and gas temperature are imposed. The mass for rate is just under $1 \mathrm{gram} / \mathrm{sec}$, a value which can be easily delivered by a canister of heliurn. There is no transpiration cooling of the wall for the baseline case. For waves at $56 \mathrm{GHz}$, there is no problem in keeping the wall at $1000 \% \mathrm{~K}$, based on the results of the onedimensional model which has a simple energy balance for the wall.

The outlet gas temperature of $27500 \mathrm{~K}$ is obtained for ar inlet temperature of $1200^{\circ} \mathrm{K}$ using $10 \mathrm{~kW}$ of power. The pressure drops are aeqligible botb axially and radially. The seed fraction, $f_{1}$, is on the same order which is required for an MHD generator, a necessary condition for compatibility with the rest of the cycle. 
The single pass absorption fraction is about $33 \%$. The multiple-pass absorption efficiency will appraach unity, os long as the cavity wall remaitus bighly sefective and the ceramic walls transparent. The efficiency for conversion of microwave energy absorbed to enthalpy of the gas is $66 \%$. The remaining $34 \%$ is lost by line radiation and conduction and convection losses to the walls. To maintain a constant wall] temperature, this lost heat must eventually transfered to the chamber wall coolant.

Figure 5 shows some typical profiles of important calculated quantities for the base case. The first six subfigures are radial profiles at the tube exit, and the last two show axial profiles of the mean gas and electron temperatures, respectively. Figures 5b,e and $f$ illustrate the fact that for modeling the central region of the gas flow, a point model for the electrons would have been adequate, but for the edge region, the thermal conductivity and diffusion terms are important. Subfigure $e$ is the radial profile of the ratio of the electron density obtained by the Saha relation (ideal $\infty$ medium) to the actual electron density obtained by the electron particle balance. Subfigure $f$ is the degree of ionization of the seed, $\alpha_{0}$.

The reduced temperature and electron density due to these finite geometry boundary conditions improve the penetration of the micronaves to the center by increasing the damping length near the wall. (cf. Eqn. 25) The Figures $5 c$ and d show the non-uniformity of the volumetric heating term and the radjation emission term. The beating term is peaked because of the tradeoff discussed in Section 3.4. The radiation loss term is peaked at the edge because the plasma is optically thick to the helium and lithium line sadiation except for a fairly thin layer near the wall.

To demonstrate that the electron conduction and convection terms improve the gas heating, we considered the baseline case using a version of the 2.D code which did not include them. The results are shown on Table 1. For this case, the electrons were hotter at the edge by about a factor of two, and the heating non-uniformity was 10:1 compared to 1.7:1 for the base case including the fiaite geometry terms. The efficiency of converting the microwaves to heat was dramatica!ly reduced from $66 \%$ to $38 \%$, since steeper gas temperature profiles increased the conduction heat losses. The single pass absorption was increased to over $50 \%$ due to the stronger edge beating.

Parametrics around the baseline will now be considered. The figures of merit in most of the plots are the superheat $\Delta T_{\text {gas }}$ achievable and the ratio of the maximum to centerline volumetric heating source term $q_{\mu, \text { mas }}^{\prime \prime \prime} / q_{\mu}^{\prime \prime \prime}(0)$. The latter quantity gives a measure of the uniformity of the heating.

Figure 6 illustrates the effect of varying the seed fraction, f. By changing the 
seed fraction only $\pm 25 \%$ around the baseline can result in a difference of $400^{\circ}$ in the outlet temperature. There appears to be a saturation in the improvement of the temperature rise at higher seed fraction. Notice that the non-uniformity increases as $f$, is increased, although it too seems to saturate.

Figure 7 shows the pressure scaling of the baseline with the velocity changed to keep a constant Reynolds' number. The seed fraction was also scaled to keep the seed density constant in the paramelnic. For variations of $\pm 30 \%$ around the baseline pressure, the $\Delta T_{\text {gas }}$ can change by $550^{\circ}$. The degree of non-uniformity of the beating is enhanced as the pressure increases, because the damping length gets shorter due to the bigher electron-neutral collision frequency.

Figure 8 is a parametric of transpiration cooling mass flux. The beat flux, $q_{\text {cend: }}^{\prime \prime}$ from gas conduction losses is reduced substantially, but the dilution of the heated gas with cooler gas from the wall reduces the superheat temperature. Transpiration cooling for heaters of this smaller size and modest parametes range toes not appear to te necessary. If larger heaters have a beat flux which is bigher than for these cases or the microwaves beat the sall to a greater degree than we estimate here, transpiration cooling may be necessary. The answer to this question must wait for a detailed study of the larger superbeater.

Figure 9 shows a scaling of the superheat temperature, $q_{\text {cond: }}^{\prime \prime}$ and the $q_{\mu, \text { max }}^{m} / q_{\mu}^{\prime \prime \prime}(0)$ uniformity parameter when the incident radiation flux is varied. When $I_{0}$ is varjed by $\pm 20 \%$, the superheat temperatures are changed dramatically. Outlet temperatures of well over $3000^{\circ} \mathrm{K}$ are possible. Notice bowever that the conduction beat fux and the degree of non-uniformity of the heating are increasing dramatically as $I_{0}$ rises. Both these effects tend to reduce the rate of rise of $\Delta T_{p a s}$ as $I_{0}$ is changed. One might expect as the radiation intensity is increased further, the gain in the outlet temperature per unit intensity increase will be reduced. Calculations at higher intensity are difficult because of numerical problems in dealine with the very steap gradients at the wall.

The $I_{0}$ scaling illustrates the fact that careful adjustment of the power source will be necessary to avoid either underheating or overheating the gas.

\subsection{Scaling to Reactor Grade Systems}

An experimental-sized superheater as we have considered must scale to a larger, reactor-relevant systern. We have found that $\ell_{D}$ scales with important microwave and thermodynamic variables in a manner which is favorable to larger sizes. The 
reactor system wnuld use mercury working flujd, operate a pressures of sevesal atmospheres and mass flow rates of several kilograms/sec in tubes of radii of about half a meler. The radiation would have an intensity about an order of magnitude higher, produced by a plasma burning D. ${ }^{3} \mathrm{He}$ and be emitted in a synchrotron frequency spectram. The dependence of the source term and damping length on the microwave frequency, collision frequency, and electron density is central to understanding the prospects for scaling. An important scaling criterion is that the radially averaged damping length nomalized by the tube radjus be kept constant. This quantity is given in Eq. 27. Going to the higher pressures in mercury will reduce non-equilibrium effects present in helium because of the higber $Q_{0}(\times 3.7)$ and pressure $(\times 8.3)$. The inlet gas temperatures will typically be higher for the mercury channel $(x 1.6)$. The arerage frequency for the reactor beater will be much higher $(x 18)$. The $\alpha_{0} f$, product is the adjustable parameter to preserve $\frac{\ell_{2}}{r}$. For ther sealing ratios, we find that $\alpha_{0} f$, for the reactor should be about half the value for the present experimental-sized heater, well within values compatible with an MHD geverator. From this analysis it appears that the superbeater may be scaled to the full sized system. More work must be done to demonstrate this rigorously using the 2-D code in the turbulent flow regime using mercurs.

\section{Conclusions}

In this report, we bave presented calculations which suggest that high bulk outlet temperatures can be achieved with microwave superbeating in small proof-ofprinciple experiments. Quick scans of parameter space are arcomplished xiib a radially averaged set of roment equations. The issue of radial non-uniformity of the beating is addressed with a radially resolved 2-D code.

In the range of operation we have studied, the microwave beating is sufficiently uniform that bulk gas temperatures above $3000^{\circ} \mathrm{K}$ are possible when the wall temperature is at $1000^{\circ} \mathrm{K}$. Paranetric studies indicate that the beating becomes more non-uniform when either the pressure, seed fraction, or radiation intensity is increased. It is particularly important to be able to control the radiation intensity to avoid overheating or underheating the gas. For superheaters uith modest operating parameters, transpiration cooling will not be necessary. More work is needed to find out if reactor-sized superbeaters will need it.

Simple scaling arguments indicate that superheaters for reactors can be built 
with microwave absorption properties similar to the smaller sizes. This scaling must be verified by detailed calculations using the $2-\mathrm{D}$ code before anything definite can be claimed.

\section{References}

[1] B.G. Logan, R.B. Campbell, M.A. Hoffman, W.L. Barr, K. Yoshikawa, Y. Inuj, M. Ishikawa. and J. Umoto. "The Compact Fusion Advanced Rankine (CFAR) Cycle Concept". IEEE 12th Symposium on Fusion Enginetring, October 12-16, 1987.

(2) W.M. Kays and M.E. Crawford. Convective Heat and Mass Tronsfer. McGraw. Hill, New York, 2nd edition, 1980.

[3] M. Mitchner and C.H. Kruget Jr. Partially Ionized Gasses. Willey Interscience, New York, 1973.

[4] G.D. Hobbs and J.A. Wesson, "Heat Transmission Through a Langmuir Sheath in the Presence of Electron Emission". Plasma Physics, 9.p85, 1967.

[5] Chris Gregory. "Resonance Broadening of Cæsium". Physical Review, 61:p465, 1942.

[6] Michael A. Lutz. "Radiation and Its Effect on the Nonequilibrium Properties of a Seeded Plasma". AIAA Joumal, 5:p1416, 196i.

[i] T. Hoistein. "Imprisonment of Radiation in Gasses. II". Physical Reriew, 83:p1159, 1951.

[8] A.E. White. Introduction to Atomic Spectra. McGraw-Hill, New York, 1934. Chapter XXI.

[9] S. Chandrasekhar. Radiative Transfer, Dover Books Inc., New York, 1960.

[10] V.L. Ginzberg. The Propagation of Electromagnetic Waves in Plasmas. Pergammon Press, Oxdord, Znd edition: 1970. 


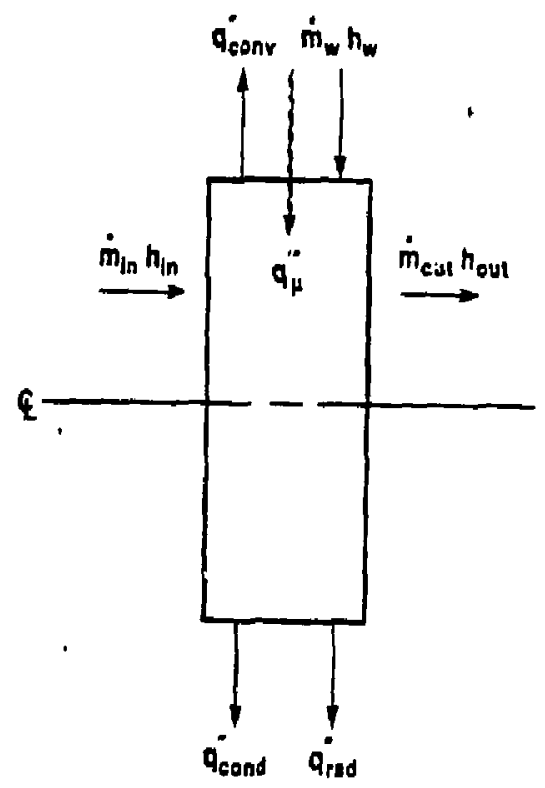

Figure 2: Power Balance in the Microwave Superheater 


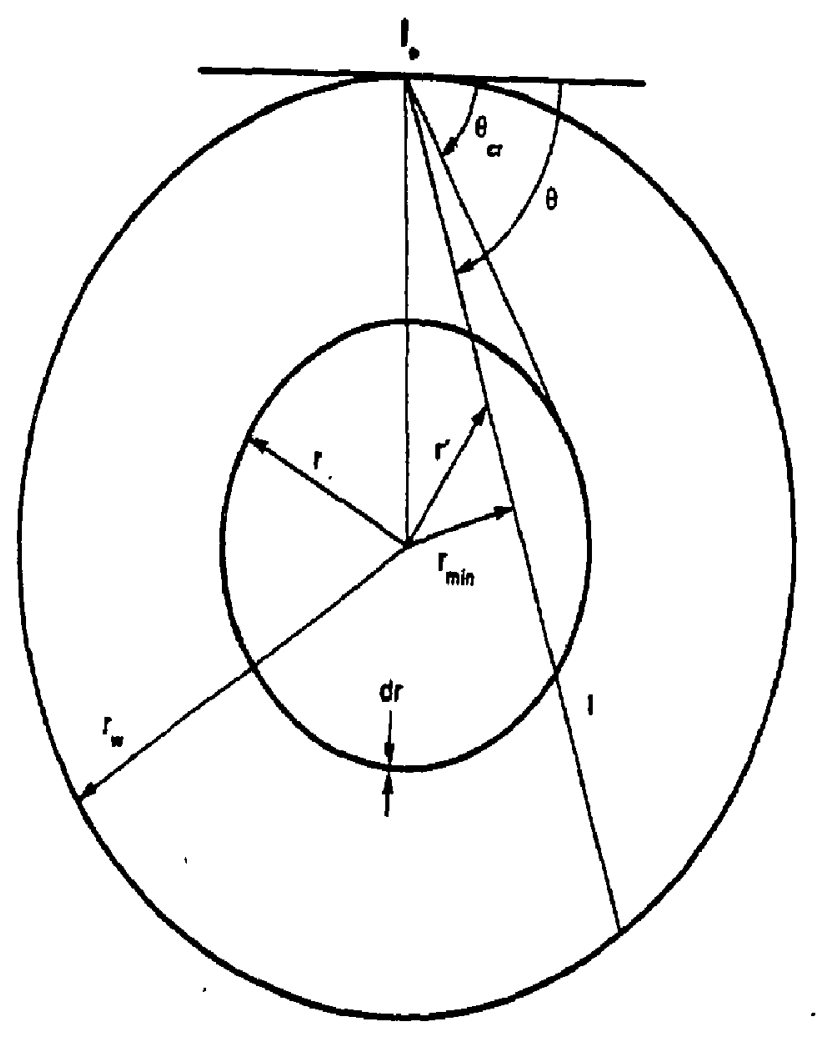

Figure 3: Ray Tracing Geometry 


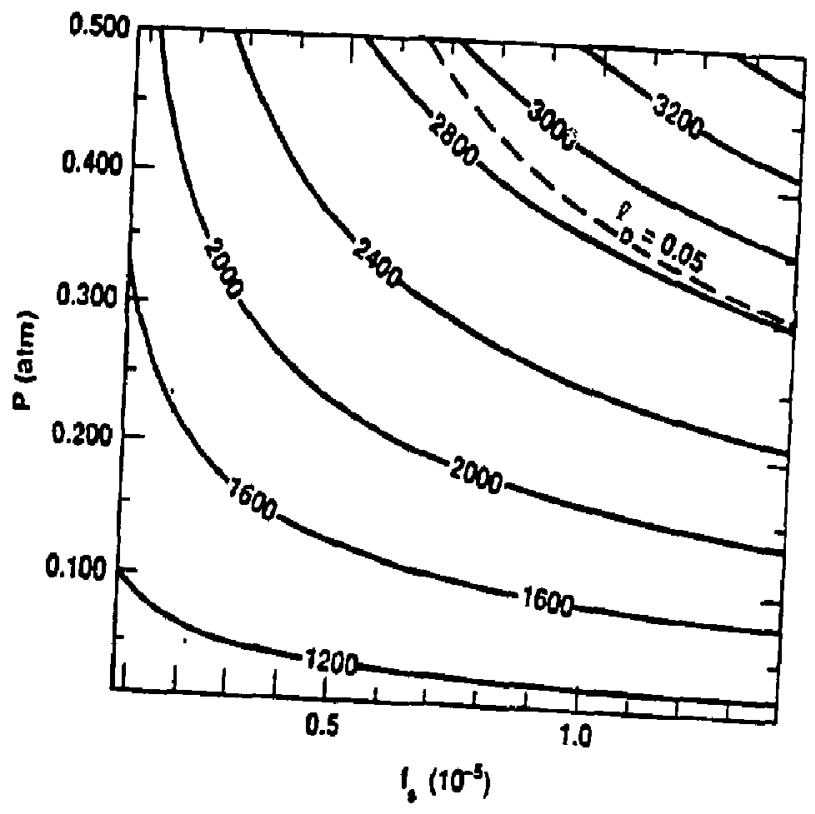

Figure 4: Contour Plot of Outlet Temperat ures from 1-D Code 


\begin{tabular}{|c|c|c|}
\hline Parameter(urit) & Baseline & Without \\
\hline Working Gas & helium & helium \\
\hline Seed Material & lithium & lithium \\
\hline Length $(m)$ & 1.0 & 1.0 \\
\hline Radius(m) & 0.05 & 0.05 \\
\hline Microwave Frequency $(\mathrm{GHz})$ & 56. & 56. \\
\hline Radiation Intensity $\left(10^{5} \mathrm{~W} / \mathrm{m}^{2}\right)$ & 1.0 & 1.0 \\
\hline Mass Flow Rate $(\mathrm{gm} / \mathrm{sec})$ & 0.86 & 0.86 \\
\hline Inlet Gas Temperature $\left({ }^{\circ} \mathrm{K}\right)$ & 1200. & 1200. \\
\hline Inlet Gas Velocity (m sec) & 9.0 & 9.0 \\
\hline Gas Pressure/atm $j$ & 0.3 & 0.3 \\
\hline Reynolds' Number & 960. & 960. \\
\hline Seed Fraction $\left(10^{-5}\right)$ & 0.8 & 0.8 \\
\hline Outlet Gas Temperalure( $\left.{ }^{\circ} \mathrm{K}\right)$ & 2750 . & 2600. \\
\hline Power Absorbed $(\mathrm{k} W)$ & 10.4 & 16.2 \\
\hline Heating Non-Uniformity & $1.7: 1$ & $10: 1$ \\
\hline Conversion Eficiency $(\%)$ & 66 & 38 \\
\hline One Pass Absorption(\%) & 33 & 51 \\
\hline
\end{tabular}

Table 1: Characteristics of the baseline case with and without radial electron losses 

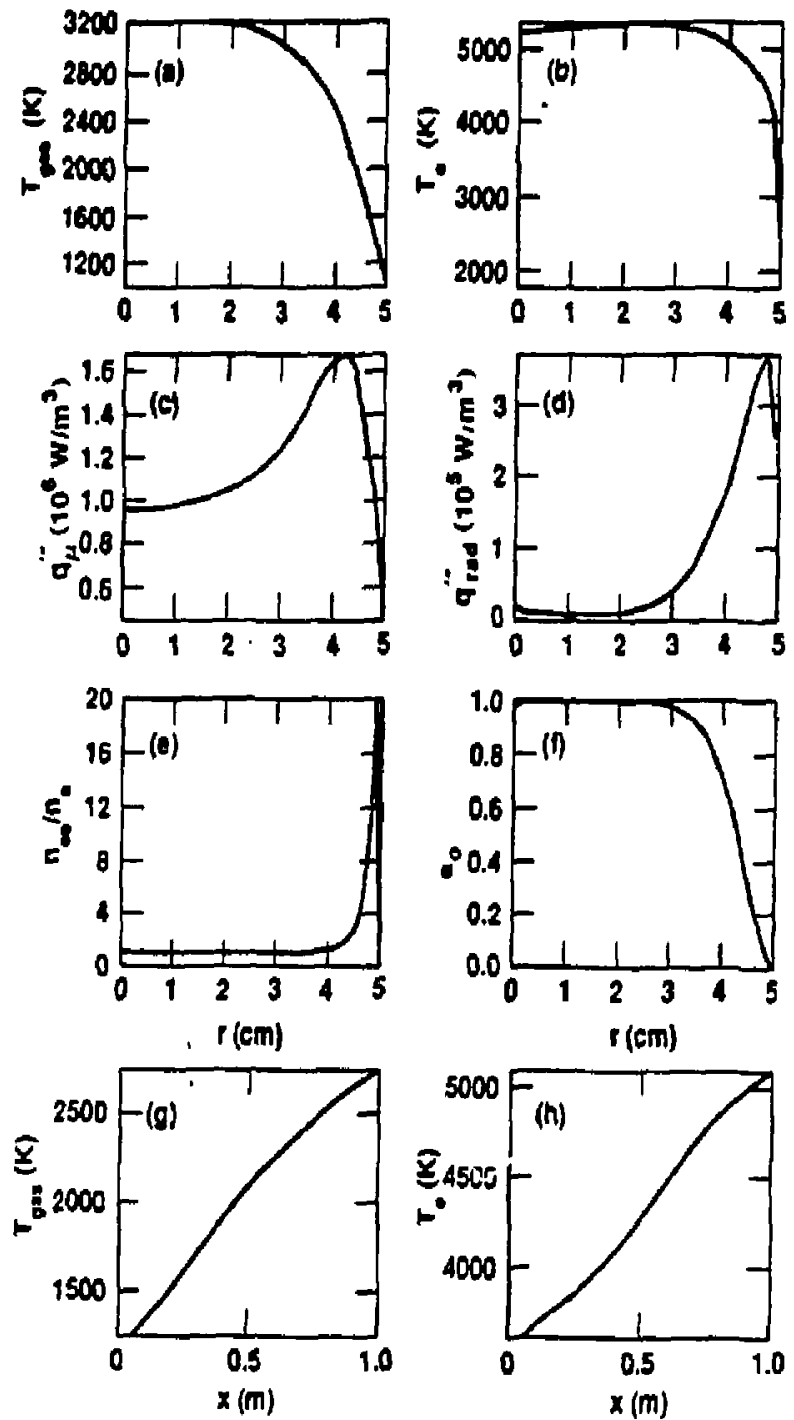

Figure 5: Radial and Axjal Profiles for the Base Case 


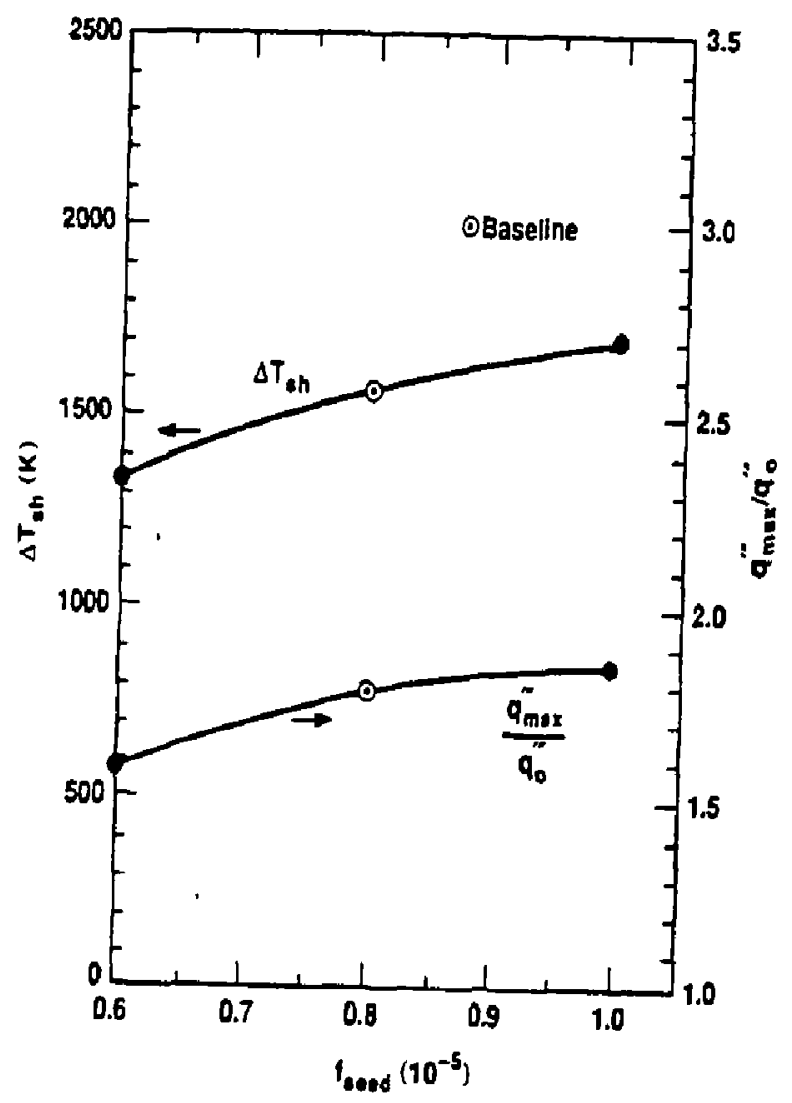

Figure 6: Seed Fraction Parametric 


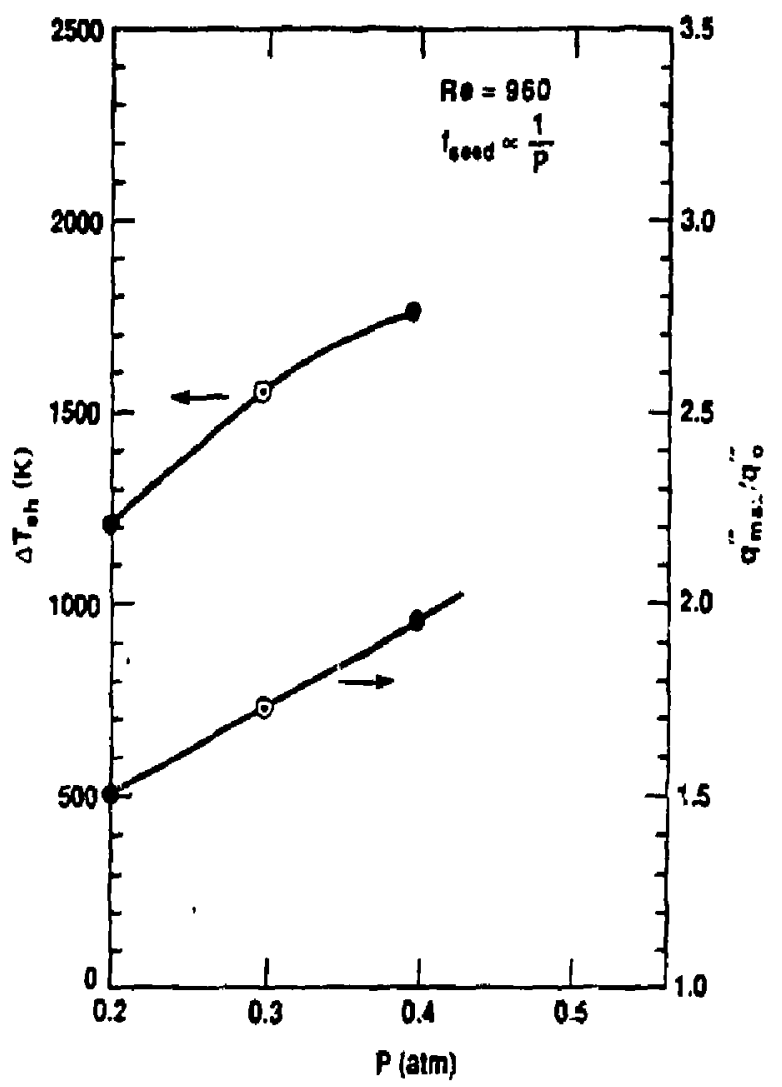

Figure i: Gas Pressure Parametric 


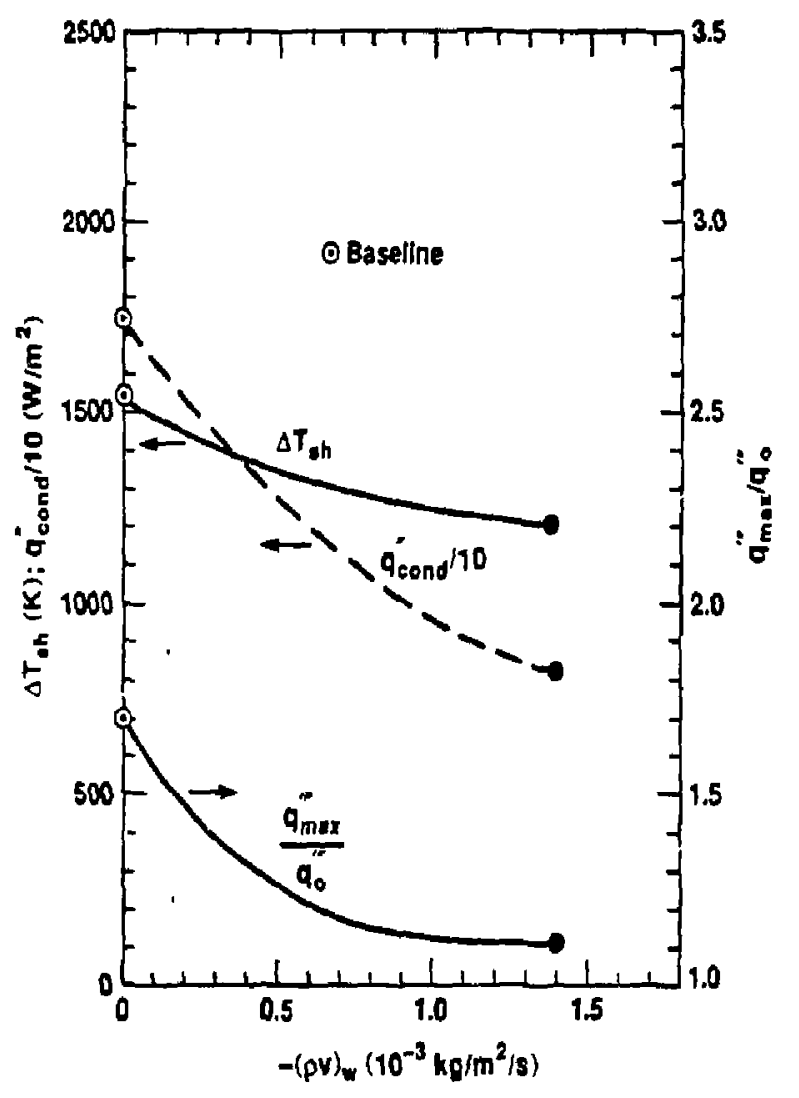

Figure 8: Transpiration Cooling Mass Flux Parametric 


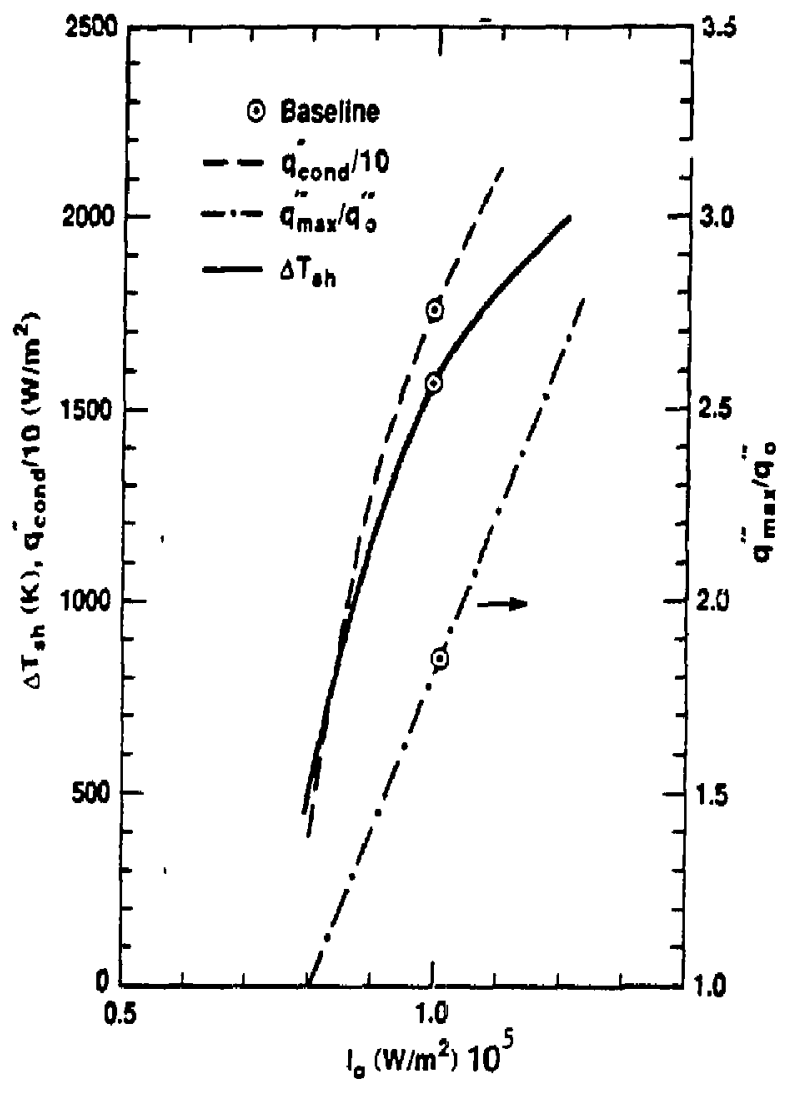

Figure 9: Microwave Radiation lntensity Parametric 
PART 3

TIME DEPENDENT MODELING

CONTRIBUTOR(S): D.T. BLACKFIEID 
TIME-DEPENDENT STUDIES

\subsubsection{INTRODUCTION - The Time-Dependent Systems Code (TTSC)}

The Iime-dependent Tokamak Systems Code (TTSC) solves radially averaged time-dependent particle and energy balance equations together with various engineering constraints. The physics and engineering modules are timedependent versions of the MUMAK [1] and TETRA [2] codes as they existed in early :987. These two codes were merged, made time-dependent and combined with an MHD equilibrium scaling routine [3]. The WHD scaling routine deteraines the required pololdal field (PF) and transformer coll currents (OH) to provide equilibrium and the necessary volts-seconds.

TTSC uses the steady-state plasma data from a TETRA output f1le and Einds a reasonable startup scenarto. ITSC determines auxillary heating and fueling requirements, volts-seconds capability and startup time, all features which MMAAR and IETRA, by theit tIme-independent natuze cannot readily address. In addition, TTSC provides an initial assessment of the required OH and PF coll waveforms and checks to see if $J_{\max }, B_{\max }$ and stress limits are exceeded.

ITSC has three basic modes of operazions. In the fully time-dependent mode, rime-varyling particle sources for each ton species and heating sources for all spectes (1ncluding elcctrons) are known and the density and energy equations are solved. On the other hand, the desfred density and temperature behavlor may be spectfded so the required time-varying particle and energy sources determined. Finslly, the density behavior way be prescribed and the requised parcicle source is calculated while a realistic power source is specified and the time-varying species temperatures determined. 


\subsection{2 .2 PHSICS}

The basic form of the time-dependent equations is

$$
\frac{d F^{\beta}}{d t}=\sum_{a} s_{a}^{\beta}-\sum_{b} L_{b}^{\beta} \quad \beta=e, D, T, a, H, O
$$

where $F$ is either the density $n$ or the energy $\frac{3}{2} n_{\beta} k^{k T} \beta$ and $s_{a}$ are sources and $I_{b}$ sinks. The $S_{a}$ and $L_{b}$ terms are modules from the MOMAR physics code which is described briefly in the appendices at the end of thls chapter.

ITSC can solve particle and energy equacions for each lon species. However, to save computer time since the fon-1on collision time is short, we assume that all fon specles cemperatures are the same and solve a global ion energy eạuation. In addition, since TTSC does not contain a wall model or an ispurity transport wodel, we assume that the impuricies (fncluding thermalized alphas) are a percentage of the total lon density. The percentage for eaci species tay be time-varying if specifled. Hence the densicy equarions for the impurietes are not solved. In addiciun we also assume that the ratio of deutertum to eritfum is fixed (normally this ratio is 1). Therefore, only a global fon densicy and fon and electron energy balance equacions are solved. The impurity densities are determined from the density of the deuteriumcrttium mixture while all ion spectes temperarures are the same.

The deuterlum-tritium density equation is as follows

$$
\frac{d n}{d t}=R_{\text {fueling }}-\sigma_{D} n_{I}\langle\sigma v\rangle_{D T}-\frac{n}{\tau_{p}^{1}}
$$

where $\mathrm{R}$ is a particle source term and

$$
\tau_{\mathrm{P}}^{1}=\tau \times \tau_{\mathrm{E}}^{1}
$$

where $C$ is a constant and $\tau_{E}^{1}$ is the global energy confinement time calculaced from the MUMAK transport routines. 
The electron energy balance equation is

$$
\frac{3}{2} \frac{d n_{e} T_{e}}{d t}=P_{\text {ohmic }}+P_{\text {aux }}+P_{Q}^{e}-\frac{n_{e} T_{e}}{T_{E}^{e}}=\frac{n_{e}\left(T_{e}-T_{1}\right)}{T_{E Q}}-P_{\text {rad }}+P_{\text {source }}
$$

where $P_{\text {ohmic }}$ is the ohoic heating source, $P_{\text {aux }}$ is an auxiliary heating term (usurily RF), $P_{a}$ is the Eraction of fast alpha power deposited in the electrons as they slow down, $\tau_{E}^{e}$ is a global electron energy confinement time, $T_{E Q}$ is the electron-ion equilibration time and $p_{\text {rad }}$ is a radiacion loss term (Bremsstrahlung and Synchrotron). The wodules which calculate these terms come from the MUMAK code and are documented in Ref. [1]. The electron and fon denstites are related through charge neutrality

$$
n_{e}=\sum_{\beta} \beta^{a} \beta \text { where } \beta=D, T, a, H, O
$$

If the electron densicy, $n_{e}(t)$, is prescribed as either an analytic function or a set of data poincs, then the fon species densities are

$$
n_{\beta}=\frac{f_{\beta_{e}}^{n_{e}}}{z_{\beta}} \quad \text { where } \beta=D, T, Q, H, O
$$

there $f_{\beta}$ are the concencrations of the lon spectes such that

$$
\sum_{\beta} f_{\beta}=1
$$

In this first verston of TTSC, these concentrations are constant in time. The $E_{\beta}$ can be adjusted so that the steady-state value of $z_{\text {eff }}$ used by MTMAK and TETRA is obtained

$$
z_{\text {eff }}=\frac{\left[z_{\beta}^{2} n_{\beta}\right.}{a_{e}}=\sum_{\beta} z_{\beta}{ }^{f} \beta
$$


Knowing the electron density and 1on species mix, the required lon particle source cerms can be obcained from Eq. (2)

$$
\mathrm{R}_{\text {fue } 1}^{\beta}=\frac{\mathrm{dn} \hat{p}}{\mathrm{dt}}+\frac{\mathrm{n}_{\beta}}{\tau_{\mathrm{P}}^{\beta}}+\mathrm{R}_{a} \quad \text { for D, T, } a, O, H
$$

where

$$
\begin{aligned}
R_{a} & =n_{D} R_{T}\langle\sigma v\rangle_{D T} \text { for } D \text { and } T \\
& =-B^{n_{T}}\langle\sigma v\rangle_{D T} \text { for alphes } \\
& =0 \quad \text { for impurities }
\end{aligned}
$$

and $\frac{d n}{d t}$ is determined from the specified analytic expression for $n_{e}(t)$ or by fitting $n_{e}(c)$ daca points to cubic splines.

Assuming that all the fon species have the same temperature, a global ion energy balance equation can be solved to obtain the ion temperature

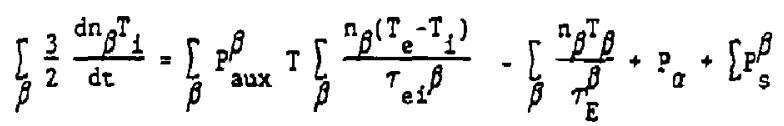

where $P_{a u x}$ is an auxillary heating source (usually $\left.R F\right), T_{E I}^{\beta}$ is the ionelectron equilibration term for 10 spectes $\theta, \tau_{E}^{p}$ is the global energy confinement time for species $\beta, \mathrm{P}_{Q}$ is the fraction of alpha powez depos:=- in the jons aud $\mathrm{P}_{S}$ is an addiclonal energy (source or sink) which is used wher: tie fon :emperature is prescribed.

If $T_{e}(E)$ and the ratso of $T_{e}$ to $T_{1}$ prescribed, then Equations ( 4 , may be solved to obealn the requized energy sources

$$
\begin{aligned}
& P_{\text {source }}^{e}=\frac{3}{2} \frac{d n_{e} T_{e}}{d t}-P_{\text {ohmle }}-P_{\text {aux }}-P_{\alpha}^{e}+\frac{n_{e} T_{e}}{T_{E}^{e}}+\frac{n_{e}\left(T_{e}-T_{1}\right)}{T_{e 1}}+P_{\text {rad }} \\
& P_{\text {source }}^{\beta}=\frac{3}{2} \frac{d n_{\beta} T_{1}}{d t}-p_{\text {aux }}^{\beta}-P_{\alpha}^{\beta}+\frac{n_{\beta}\left(T_{e}-T_{1}\right)}{T_{e 1} \beta}+\frac{n_{\beta} T_{\beta}}{\tau_{E} \beta}
\end{aligned}
$$


where $\frac{d n}{d t}$ is decermined from the analytic expressions for $n(t)$ and $"(t)$ or $b y$ using cubie splines.

\subsubsection{INITIAL CONDITIONS}

The initial plasma current is specified (typically $200 \mathrm{ks}$. The Initial density is taken to be a fraction of the Greenwald density limit given as

$$
n_{e}=\frac{1 \times 10^{14 E_{e} I_{p}}}{\pi a^{2}}
$$

where $f_{e}(1$ (cyptcally 0.2$)$. Using Eq. (13) and the user supplied $f_{\beta} f_{f}$ Eq. (6) :he initial fon densities ase determined. To find the ion and election densities, the lon and electron extergy balance equations are solved assuning

$$
\frac{d \beta^{T} \beta}{d t}=0 \quad \beta=D, T, \alpha, H, O, e
$$

We also force the ratio $\frac{T_{1}}{T_{e}}$ to be a ser supplied fnitial ratio

$$
\text { RATTIE }=\frac{T_{1}}{T_{e}}
$$

We slso allow ne to adjust somewhat and solve the charge balance equation

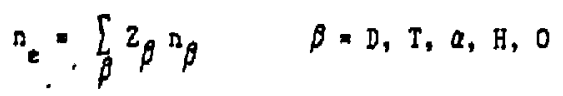

For these four equations, the corresponding fout variables are $T_{e}, T_{i}, n_{e}$ and $T_{\text {MIN }}$ where $\tau_{\text {MIN }}$ is the minimum energy confinemenc time used in the energy belance equations. The zadial transport routines come from the MUMAl code which assumes a steady-state fuil-sized plasma. The $T_{E}$ calculated from these routines for the Initial plesma is usually quite small and greatly increases List aunt " cotputer time reeded to reach stendy-state. Therefore, ITSC cosumes that 


$$
T_{\mathrm{Z}}^{P} \geq \tau_{\mathrm{MIN}}
$$

where $\tau_{\text {MIN }}$ is adjusted to solve the Inttlal energy balance equations. A nonlinear equation solver KYBRID [4] is used to solve the four equations (12, 35, 16). The Initial value for $n_{e}$ comes from Eq. (13) while those for $T_{e}$ and $\tau_{1}$ come from Eq. (15) and the following equation

$$
\beta=E_{\beta} \beta_{\text {IM }}
$$

where $f$ is a user supplied number $\leq=1$ (fnitially 0.005 ) and $\beta_{\text {LIM }}$ is the Yamazak1 beta 11mit with a coeffictent of 0.047 . When external energy and/or particle sources are prescribed, we assume that the global particle and energy conflsement times obtained from the MUMAR model degrade exponentially when efther the beta or density lifits are exceeded. This prevents thermal runaway when the fusion power becomes significant. When efther the density of cemperature time-profiles are specteled and the required sources calchiaced, at sceady-state, the sources way be negative. This can be interpreted as an enhatcement in radial transport required to prevent chermal sunaway.

\section{$\because 12.4$ MID EQUILIBRIUM SCALING}

Javing obtatned the intifal $T_{f}, T_{e}, n_{1}, n_{e}$ and plasma current, the PF and $\mathrm{OH}$ coll currents need to be adfusted to provlde MHD equilibrium and the proper amount of Elux linkage. A unique featuse of TISC is the capability of link1ng the $P F$ and $O H$ coll waveforms with plasma performance. At each point In : Ime, the $O H$ and $P F$ coll currents are adjusted to provide MHD equilibrium and correcr amount of volts-seconds. The number, sizes, and locations of the PF and OH colls come from the output of the TETRA steady-state nonlinear optimization systaws cod discussed in Chapter.

Before the plasma is initiated, for a given of currenc, the remaining PI cosls current: are adjusted to produce (In a lesst squared sense) a zero 
vertical magnetic field at a number of equally spaced grid points along the midplane (from 3 to 32 ). To decermine the of current, a guess for the inltial OH current is supplied and the resulting $P F$ coll curzents determined. Bax and $I B_{\max }$ a:e calculated at the top and bottom of each $P F$ coil and at the top, botton and center of the transformer stack. The initial guess is then scaled so that the currents in the $\mathrm{OH}$ and $\mathrm{PF}$ colls do not exceed the $\mathrm{B}_{\max }$ and $\mathrm{JB}_{\max }$ limits (typlcally $14 \mathrm{~T}$ and $500 \mathrm{MAT}$ ) while being as large as possible. This will allow the OH coll swing to produce the largest amount of volts-seconds. Scarting from these initiation coll currents, when the pissma is present, the co11 curtents are then adjusted to provide MiD equilibrium and the required voits-seconds. To obtain these currents, first the vertical field at the midplane grid points (from 3 to 32 ) is calculated using the plasma conditions (size, position, poloidal beta, cursent, elongation and Inductivity) and the PF and OH coil currents and locstions from a separate 2-D MHD equilibrium es lculation. These reference set values are abtained from TETRA or directly from the 2-D MHD code NEQ [5]. This reference set provides the vertical field which the TTSC MHD routine then uses to scale the coll currents. For a given OH curzent, the PF coll currents are adjusted so that the verticol field at the grid points on the midplane match in a least-squared sense those values obtained from scellng the reference set vertical field for the new set of plarma conditions generated by ITSC. The OH current is adjusted so that the complete $P F$ and $O H$ coll sets provide the amount of volts-seconds required by the plasme at that polnt in time. At each time step, the new plasma conditions and volts-seconds requirement are given to the Mys scaling routine which then returns the requized old r.ad PF coll currents.

In addition, at each time step, $B_{\max }$ and $J B_{\max }$ are determined at the top and bottow of ach PF coll and at the top, bottom and senter of the scensformer stack. The mexs $Z_{T 2 x}$ and $\mathrm{JB}_{\max }$ for the entire coil set over 
the entire simulation is recorded as well as the coll location where this occufs in order to plnpolnt a possible stress probleth. In addition, at the end of the simulation, usually 2-3 seconds into the current flattop, and presumably, but not necessar1ly, when the plasma is at steady-state operating co-ditions, the PF and $\mathrm{OH}$ coll currents are linearly extrapolated to the time where efther the $\mathrm{B}_{\max }$ or $\mathrm{JB}_{\max }$ 11mit (whichever comes first) is met. This shen deterines the maximum burn time and volts-seconds capab1lity of the given magnet set for the assumed startup scenario. If elther the $B_{\max }$ or $\mathrm{J}_{\max }$ limit is exceeded at some polnt during the startup, this is noted along with the coll location and current value. The burn time and volts-seconds capabtlity is then glven as the values obtalned by TISC at the end of the 51mulation.

\subsection{2 .5 ENGINEERING}

The radial build and $P F$ and $O H$ coll losations and sizes come from the TETRA code. GIven the PF and OH coll cur:ar, 5, an 2 tidate of the actual coil stresses can be obtained. Th1s will be done whth the new version of TETRA is Incorporated into TTSC.

The aux111ary power inputs can be adfusted to minimize the amounc of volt5-seconds used in stertup without exceeding the beta limit or the capability of the auxility heating power supplies.

\subsubsection{FOSSIBLE STARTUP SCENARIOS}

For this firse version of TTSC we have examined varlous startup scenarfos for pulsed nnazsidu shere $R F$ is used as a heating source but not as a eurrent disive source. We have also assumed that the plasma density ramp is 
prescribed while the auxillary power (presumably RF) source to the electrons is specified. The resulting particle sources (or sinks) and electron and ion temperatures are determined. The piasma current is assumed to be a plecewise continuous linear tamp based on DIII-D data [5] and shown In Figure 1 . The electron density is prescribed to follow the plasme cursent as displayed in Figure 2 there we have fixed $z_{\text {eff }}$ at 1.32 . The general TIBER pulsed-mode parameters are give in TABLE I while TABLE II shows the assumed initial plasma corditions.

Figure 3 shows the prescribed RF auxiliary heating power waveform, in this case a maximuin of $20 \mathrm{WW}$ to the electrons. TABLE III shows the effects of varying the maximum amount of $R F$ power. For $R^{F}$ powers less than $8 \mathrm{MW}$, the plasma does not 1gnite. For RF powers from 8-10 WW the plasma 1gnites but well after the current flatiops. To igntie the plasma and reach steady-state when the current flattops requires at least $15 \mathrm{WW}$ of RF power. Increastng the $\mathrm{RF}$ power from $10 \mathrm{MW}$ to $20 \mathrm{WW}$ saves over 1 volts-seconds which transiates to $14 \mathrm{~s}$ of increased burn time.

To get a faeling for the capabilities of TTSC we examine in detall a possible staz: ip scenarto assuming a maximum of $20 \mathrm{WW}$ of $\mathrm{RF}$ power deposited in the eiections with the heafing profile stow in Figure 3 . Figures 4 and 5 show the resulting electron and fon tewperatures. The inttial change in slope in the cerperature curves near 4 seconds corresponds to a change in confinement due to a change in the assumed slope in the current rampup. The second change in the temperature slopes near 9 seconds follows the exponential enhancement if radial losses when the beta limit is exceeded. The plasma beta and bete limit (dashed curve) are shown in Figute 6 . The Elnal change in slope occurzing neat 17 seconds results frow the assumed change in slope in the plesw curtent due to fiattoping. The entrgy confinement time is a function of density, temperature, pleswa curront and auxiliary power 
(Including alpho power) and is plotted for the electrons in Figure 7. There are several competing effects. As the density, temperature and plasma current increase, $T_{E}^{e}$ increases. However, as these increase, $P_{q}$ increases, which decreases $T_{E}^{*}$ Also $P_{\text {ohmic }}$ decreases in the which tends to decrease the rate at wisch the electron energy increases. These effects, together with the exponential enhancement in losses when the beta limit is exceeded produces the temperature zurves shown in Figures $4-5$.

The reference magnet set which provides a 2-D MTD equilibrium durting steady-state is shown 2i. Figure 8. TISC represents this case as 7 sets of $p_{1}$ rodls and an OH stack made up of 4 coils all programed with the same current. The numbering system for the coils can also be seen In Figure 8. Point 16 corresponds to the top of the $\mathrm{OH}$ stack while 16 is at the center. Figure 9 shows the voi s-seconds required by the plasma. This volts-seconds requirement can be divided into an inductive part, primarily a function of plasta size and eurrent (Figure 10), and a resistive part (Figure 11), a Eunction of plaspa density and temperature. Assuring a full stzed plasma startup, the Induetive part of the total volts-seconds requirement is independent of the starzup scenario. The startup scenario can greatly affect the resistive pa:t. Thu less auxiliary heating, the longer the plasma takes to reach steady-state and the greater the resistive volts-seconds corsumed, as shown in TABLE III. However, In a reasonable startup scenerio, the resistive part may anount to less than $10 \%$ of the cotal volts-seconds consumed so there reaches a point of diminishing recurn as far as facreasing the amount of auxiliary hearing. To provide this volts-seconds, the $P F$ and $O A$ colls aze charged so as to swing frow a $-27.66 \mathrm{~V}-\mathrm{s}$ to $22.79 \mathrm{~V}-\mathrm{s}$ shown in Figure 12. The OH and PF cotls are scring so as to prevent $B_{\max }$ and $\mathrm{JB}_{\max } 11$ mits from being excoejed. The $O H$ coll scack current waveform is shown in Figure 12 while the $B_{\text {max }}$ and $J B_{\text {max }}$ at the end of the OH stack is shown in Figures 13-14. 
Figures 15-21 show the current waveforms for the othet PF coll sets 1dencifled In Figur2 8. The ratter strange shape in many of the current waveforms between 4 and 8 seconds is a result of changes in bets pololdal, shown in Figure 22. For fixed plasma size, the scaling is a sensitive function of polo1dal beta,

In addition to examining $B_{\text {max }}$ and $\mathrm{IB}_{\max }$ for the OH stack, we also examine them for each PF coll set. In this particular case, the $B_{\text {mex }}$ at point 16 limited the burn time. When the slope of $B_{\max }$ for the steady-state condic1ons in Figure 13 was axtr=polated then the $B_{\text {rax }}$ 11m1t of 14 T was seached for a burn time of 321 seconds wh a toral volts-seconds consumed of $74.8 \mathrm{~V}-\mathrm{s}$. These numbers are somewhat larger than the baseline paramerers because we do not look at the stresses in the OH stack which way be exceeded before the $B_{\text {max }}$ ilmit is met. In the next version of TTSC we hope to 1ncorporate some analytic stress models. During steady-state, the plasma has 2 loop voltage of $0.072 \mathrm{~V}$. Therefore, for each volts-seconds saved during startup, the burn time can be extended approxinately 14 seconds. In addition, $15 \mathrm{JB}_{\max }$ was the 11aft, then this limit would be zesched for a burn time of 30617 seconds. In charging the co1ls to zero ut the verticel field at plasma initiation, the largest $B_{\max }$ is at the top of coll 4. However, as the coll currents change to follow the changing plasma conditions, the highest $B_{\max }$ polnt quickly switches to center of the transformer stack.

\subsection{2 .7 CONCLUSIONS}

We have developed a O-D tide-dependent physics-engines:ing code thich can guickly examine various startup scenarios and, when coupled to the steadyotate nonlineaz optimization rokamak syatems code IETRA, ascertain if the "optimal" stendy-atate operating conditions are "achievable". TTSC can 
estimate volts-seconds requirements and capabilities and auxiliary heating and fueling requitements. In addition, TTSC can address potential magnet stress problems by examining $B_{\text {max }}$ and $\mathrm{JB}_{\max }$ at various coll locations. TISC has shown the effectiveness of auxiliary power in reducing the volts-seconds requirement during startup and has found a resonable startup scenario for the pulsed-operation mode of TIBER. In addition, TTSC can estimace the burn time and volts-seconds capability of the magnet set.

The next version of TTSC w1ll include the most up-to-date physics and engineering rout ines fro MDMAR and TETRA. We also hope to address the effect of RF current drive (in particular, lower-hybrid) on the volcs-seconds requisement and on the MED equilibrium scaling. We also intend cals ilating stresses in the $O H$ and $P F$ codls to decermine the burn time and volts-seconds capabillty. We w111 a.1so use ITSC to exanfine expending radius startup scenarios, since presumably, at very low densities the plasmi will be swaller and more clraular. Finally we will examine the effect of changing $Z_{\text {eff }}$ from approximately 5 to the steady-state value of 1.32 on volts-seconds consuned duIing startup. 


\section{References for Section 2.12}

[1] M.E. Fenstermacher LLNL Report UCID-21038 (Apr11 22,1987); Section 2.4 of this report

12] I, Reid et al, Section 7 of this report

[3] D. Strickler FEDC/ORNL Private comunication (1986)

[4] B.S. Garbow, K.E. Hillstrom end J.J. More, Argonne National Laboratory, Argonne, Il, Minpack Project (March 1980)

15] S. Ej1ma, I. Loo, J. Luxon, T.A. Osborne, R.D. Stav, T.S. Teyler, APS paper 6R2, Bull, of Am. Phys. Soc. Vol. 31, No. 9 (Oct. 1986) p. 1532 
Table 1 shows the inftial plasme conditions.

TABLE I

\section{TIBER PARAYETERS}

\begin{tabular}{|c|c|}
\hline$R_{0}(\mathrm{~m})$ & $\begin{array}{l}3.0 \\
0.833\end{array}$ \\
\hline 6 & 2.4 \\
\hline & $\begin{array}{l}5.55 \\
8.0\end{array}$ \\
\hline$q^{p}\left(\times 10^{20} \mathrm{~m}^{-3}\right)$ & $\begin{array}{l}1.78 \\
1.32\end{array}$ \\
\hline$\beta_{1 \text { im }}^{\text {eff }}$ (75\% of $p_{\mathrm{Yam}}$ ) & .050 \\
\hline$\frac{d}{d t}(V-S)$ & .072 \\
\hline startup (s) & $\omega 17$ \\
\hline
\end{tabular}




\section{TABLE II}

AT PLASMA INITIATION (t $=3$ s)

$\begin{array}{ll}I_{\mathrm{p}}(\mathrm{MA}) & 0.200 \\ \mathrm{n}^{\mathrm{e}}\left(\mathrm{x} 10^{20} \mathrm{~m}^{-3}\right) & .018 \\ \left.\mathrm{~T}_{\mathrm{e}}^{\mathrm{keV}}\right) & .13 \\ \mathrm{~T}_{1}^{\mathrm{e}}(\mathrm{keV}) & .08\end{array}$


TABLE III

TIBER WITH CW RF HEATING

At $t \sim 27 s\left(t_{\text {flattop }}+10 s\right)$

$\begin{array}{lccccccccc}\text { CASE } & R F \text { POWER } & T_{\mathrm{e}} & T_{1} & \beta & P_{\text {FUS }} & T_{\text {WALL }} & \mathrm{V}-\mathrm{S} & V_{\text {RES }} & T_{E}^{\mathrm{e}} \\ & (\mathrm{MW}) & (\mathrm{keV}) & (\mathrm{keV}) & & (\mathrm{MW}) & \left(\mathrm{MW} / \mathrm{w}^{2}\right) & (\mathrm{VS}) & (\mathrm{VS}) & (5) \\ 30.00 & \sim 0 & 1.49 & 1.49 & .0083 & 1.27 & .005 & 56.8 & 12.78 & 13.9 \\ 30.08 & 8 & 6.14 & 5.81 & .0343 & 150 & .621 & 47.9 & 3.98 & 3.7 \\ 30.10 & 10 & 8.78 & 7.83 & .0491 & 297 & 1.23 & 47.0 & 3.00 & 2.94 \\ 30.15 & 15 & 9.20 & 8.05 & .0515 & 314 & 1.30 & 46.1 & 2.05 & 1.97 \\ 30.20 & 20 & 9.82 & 8.04 & .0519 & 313 & 1.30 & 45.7 & 1.71 & 1.07\end{array}$


LIST OF FIGURES

(1) Assumed plesw current waveform. Initlal value of $200 \mathrm{kA}$, Initial slope is $1 \mathrm{MA} / \mathrm{s}$ changing to $\frac{4}{9} \mathrm{MA} / \mathrm{s}$ after reaching I $\mathrm{MA}$

(2) Assumed radially-averaged electron density zamp

(3) Assumed auxiliary power source waveform (RF with all the power deposited in the electrons

(4) Radially-averaged electron temperature assuming the auxiliary power source in Figute 3.

(5) Radialdy-averaged ion temperature assuming the auxlliary power source in Figure 3 with all ion species having the save value.

(6) Plasma beta including fast alphas (5011d line) and $75 \%$ of the Yamazaki beta limit (dashed Iine). Energy confinement time is exponentially degreded when the soltd curve is above the dashed line.

(7) Global electron energy confinement time.

(8) Reference PF and OH coil set used by ITSC and TETRA. This plot is generated by the FEDC/ORNL 2-D MHD equilibrium code NEQ. The numbers by the colls corzesponds to the TTSC numbering system.

(9) Voles-seconds consumed by the plasma.

(10) Inductive volts-seconds consumed by the plasma, a function of plesma current.

(11) Resistive volts-seconds consumed. This is may vary greatly with differing startup scenarios. Is a function of changing plesma condicions.

(12) Volts-seconds provided by the PF and OH colis. At each time-step, the volts-seconds provided by the colls equals that required by the plasma. 
(ij) Ori transiormer stack current wavejorm. indtiai peak limiteo by $B_{\max }$ 11mit.

(14) $B_{\max }$ at point 16 , the center of the Ofl transformer stack at an I location of $0.6 \mathrm{~m}$.

(15) $J B_{\max }$ at point 16 , the center of the OH transformer stack at an $I$ locarion of $0.6 \mathrm{~m}$.

(16) Current waveform in PF coll 1 located at $z=0.8$ m and $z= \pm 1.2 \mathrm{~m}$

(17) Current waveform in PF coil 3 located st $I=0.8$ m and $z= \pm 2.0 \mathrm{~m}$

(18) Current waveform in $P F$ coll 5 located at $z=0.8$ al and $z= \pm 2.8 \mathrm{~m}$

(19) Cusrent waveform in $\mathrm{PF}$ coll 7 located at $I=1.8 \mathrm{~m}$ and $z= \pm 4.25 \mathrm{~m}$

(20) Currene waveform in PF coil 9 located at $I=4.1 \mathrm{~m}$ and $z= \pm 4.25 \mathrm{~m}$

(21) Current waveform in $P F$ coil 11 located at $I=6.2$ w and $z= \pm 3.2 \mathrm{~m}$

(22) Current waveform $1 \mathrm{PF}$ coil 13 located at $r=6.2$ m and $z= \pm 1.5 \mathrm{~m}$

(23) Poloidal bete

(dj708240/tiber) 
PLASMA I

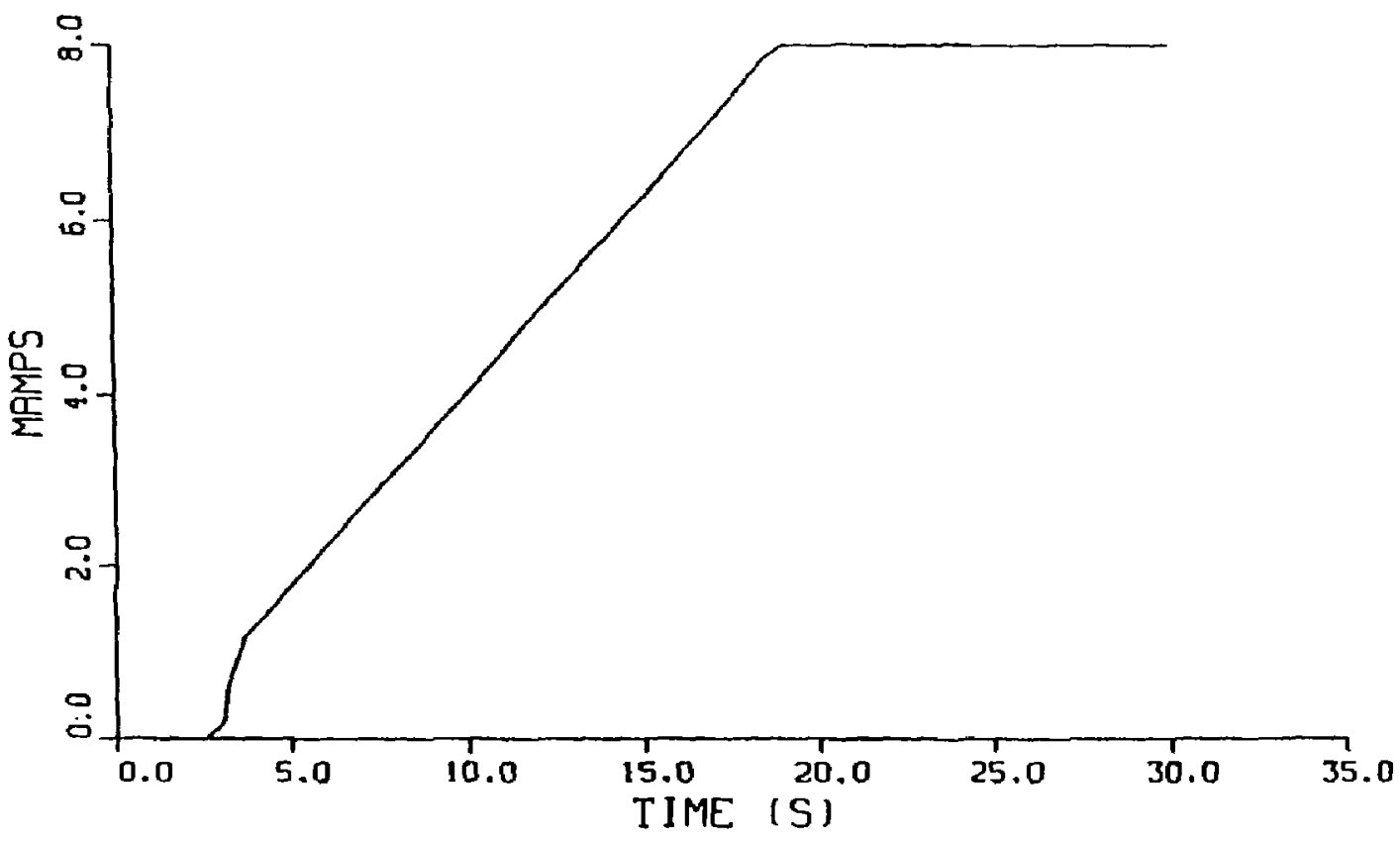

$$
0.000 \quad 7.995
$$

(1) Assumed plasm current waveform. Inttial value of $200 \mathrm{kA}$. Initial slope 18 MA/s changlng to $\frac{4}{9} \mathrm{MA} / \mathrm{s}$ after reaching $1 \mathrm{MA}$ 


\section{DENS I TY}

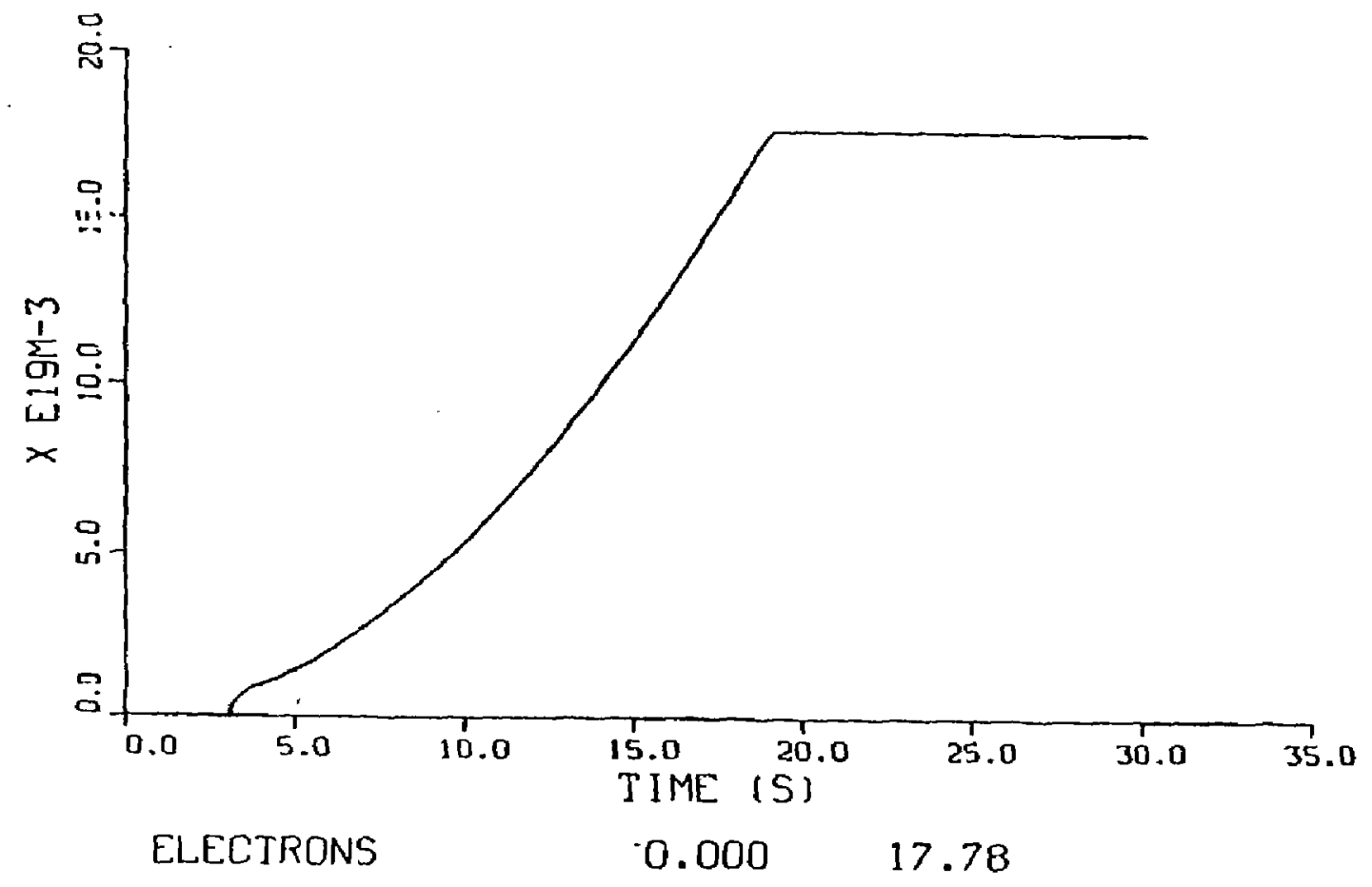

(2) Assumed radialiy-averaged electron density ramp 


\section{RF}

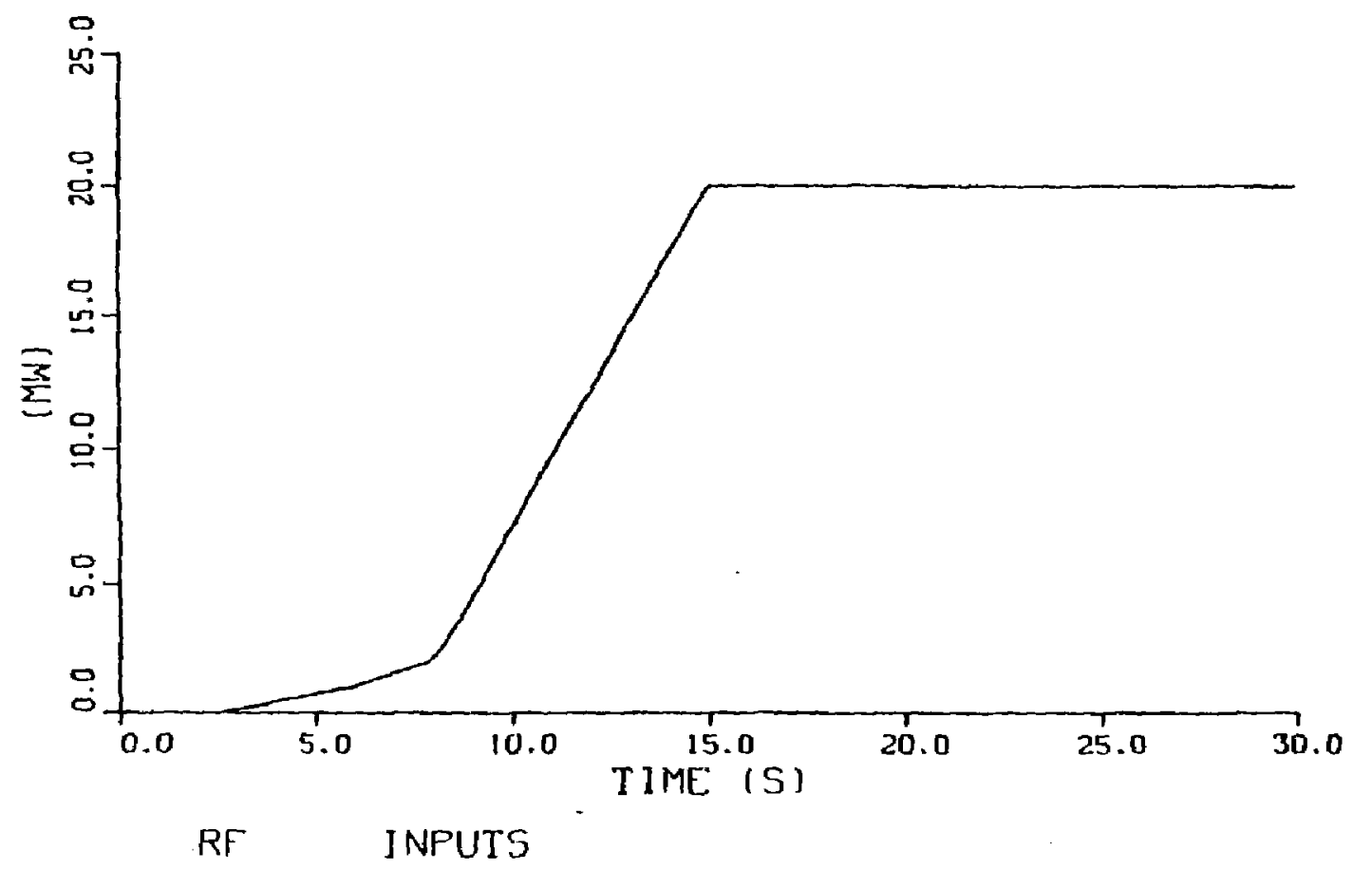

(3) Assumed auxtitary power source waveform (RF with all the power 
TEMP.

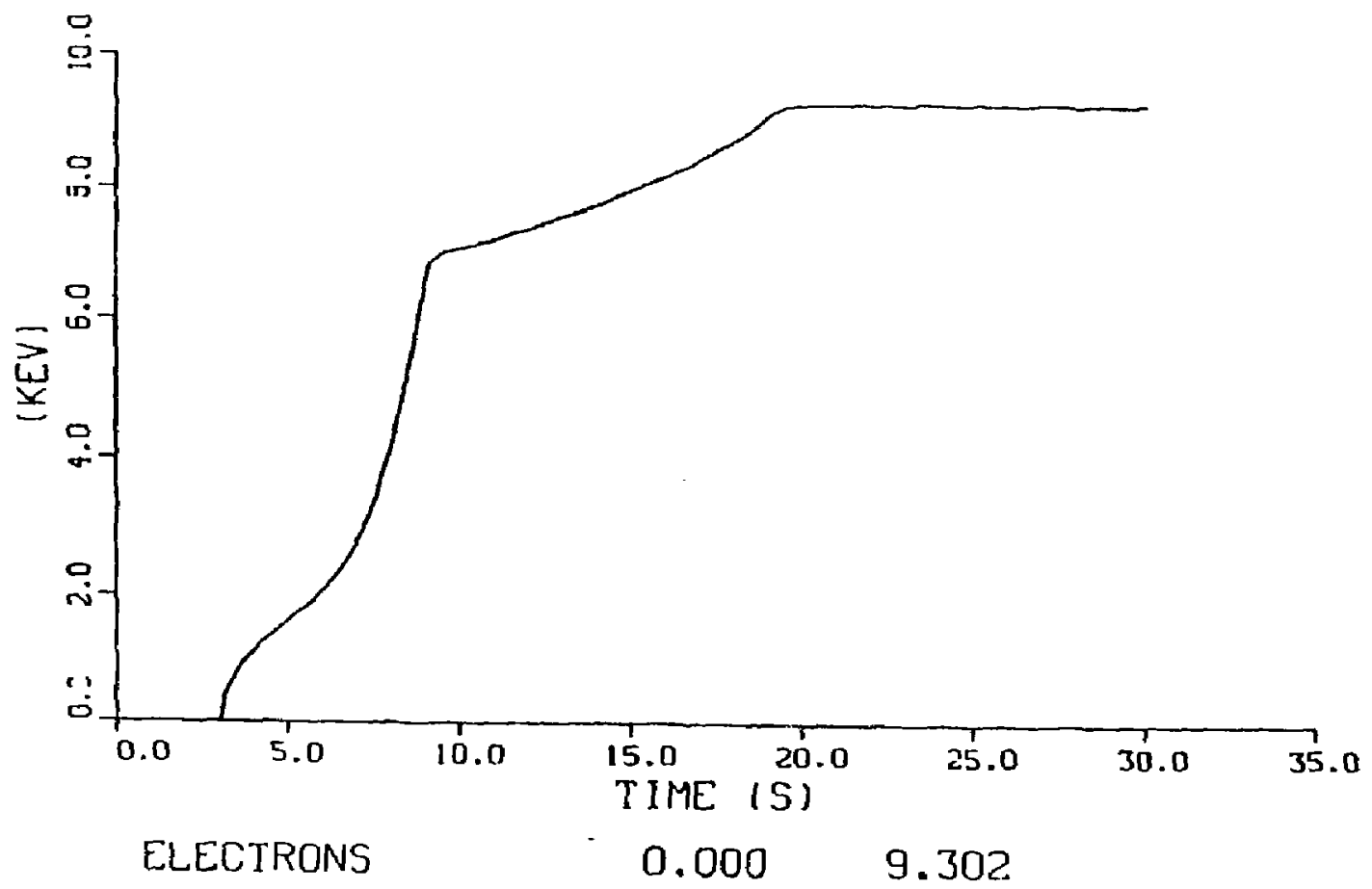

(4) Radially-averaged electron temperature ossuming the auxilfary power source in Figure 3. 


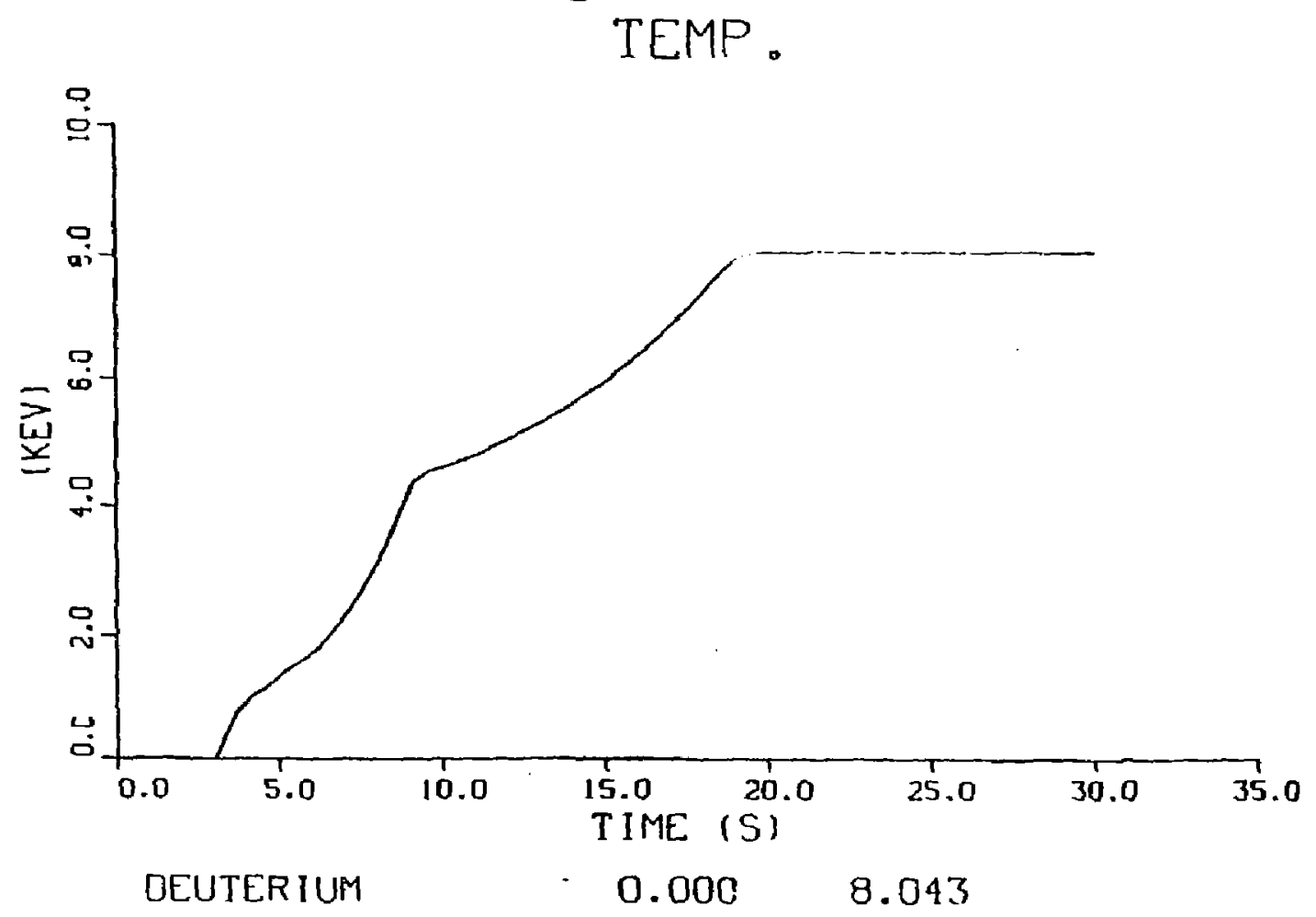

(5)

Radially-averaged fon temperature assuming the auxiliary power source

in Figure 3 with all ion specfes having the same value. 


\section{BETA LIMIT}

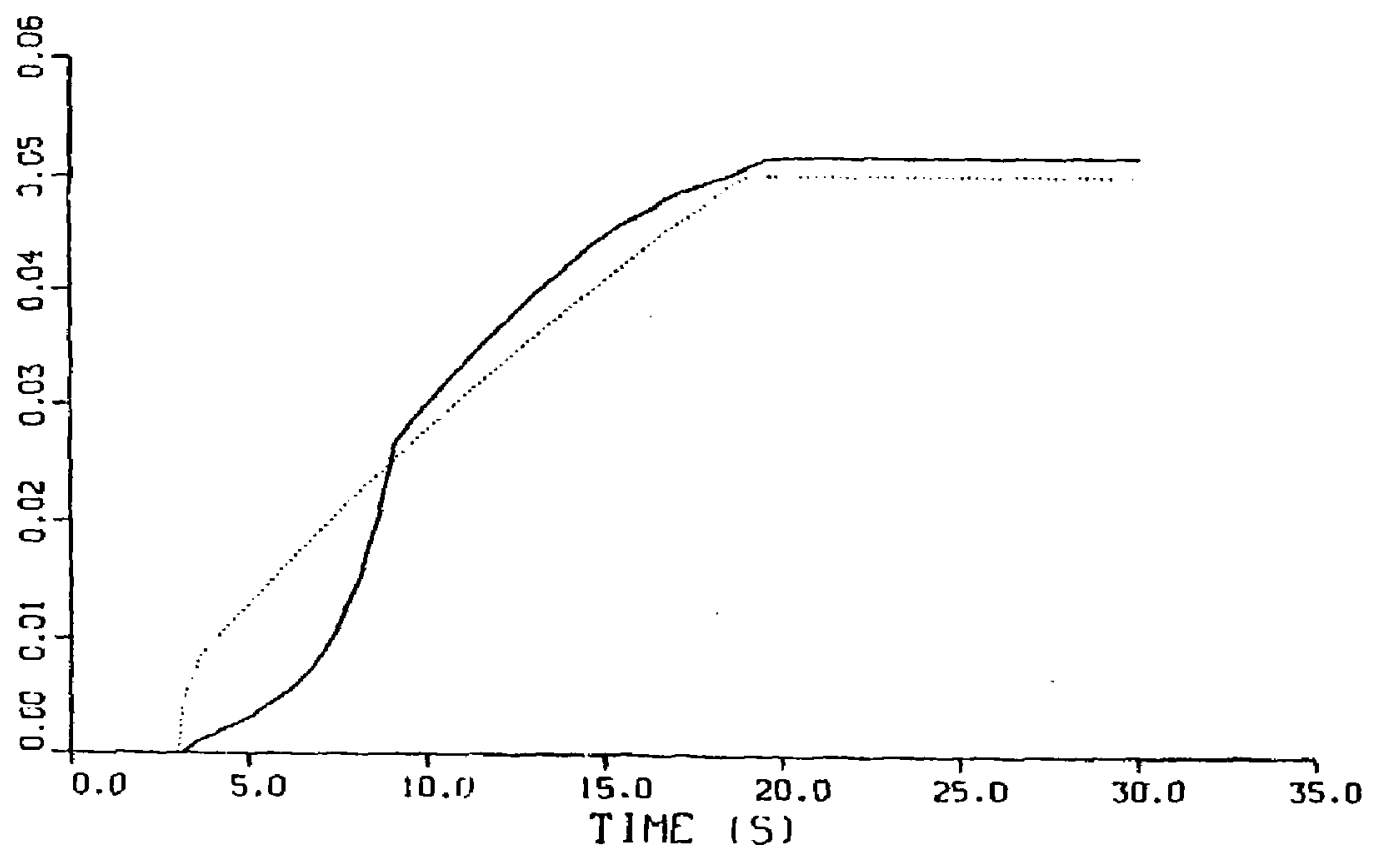

\section{$0.0000 \quad 5.1860 \times 10^{-2}$ DOT - LIMIT}

(6) Plasug beta Including fast alphas (solid 11ne; and 757 of the Yamazaki

beta limt (dasted line). Energy confineant time is exponentially

degraded when the solid curve $1 \mathrm{~s}$ above the dashed Itre. 


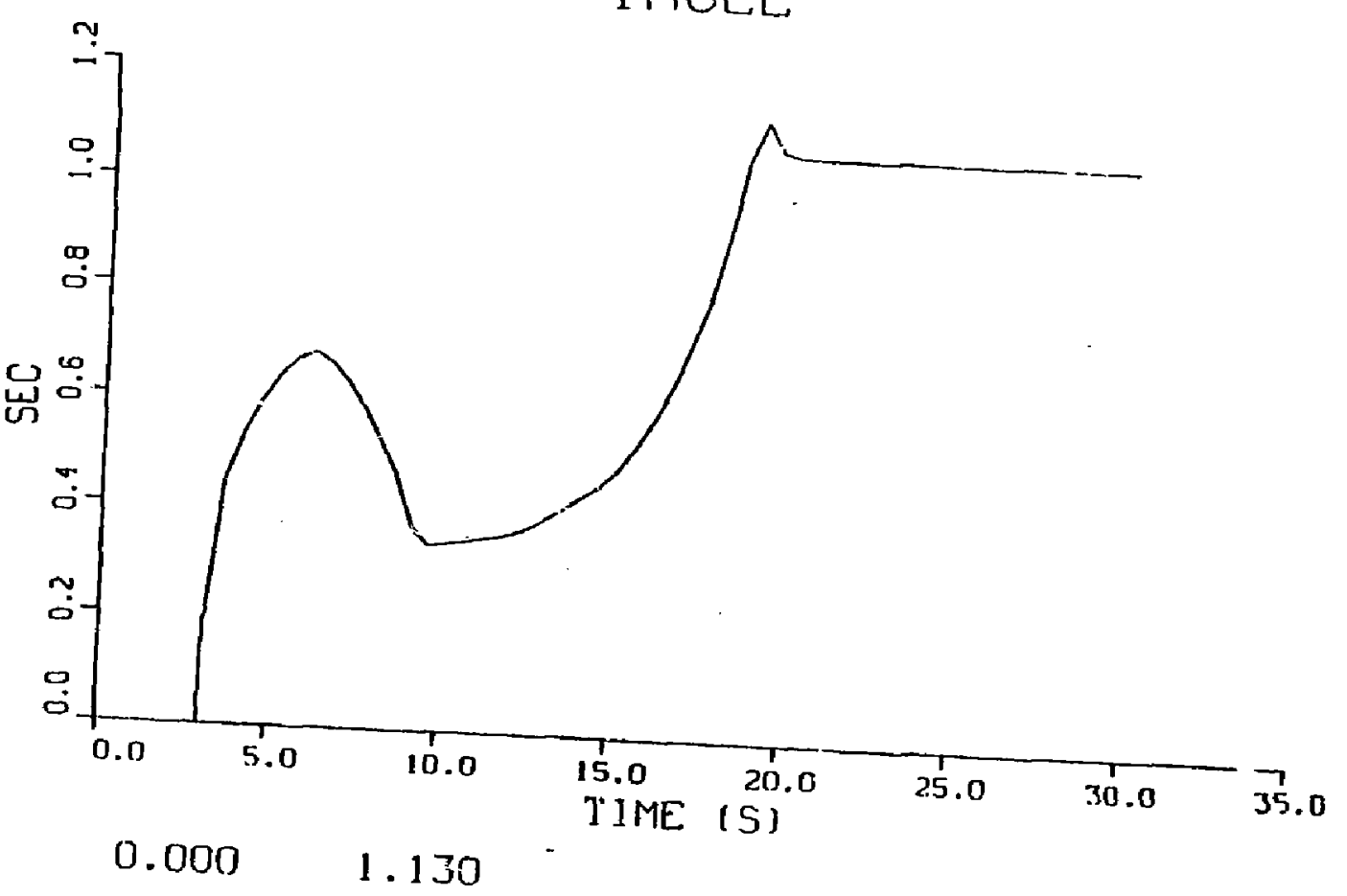

5
0
0
$\frac{1}{y}$
0
20
$\frac{2}{80}$
$c$
8
0
0
0 
(8) Reference FF and OH coll set used by ITSC and TETRA. This plot is generated by the FEDc/ORNL 2-D MllD equilibrtum code NEQ. The numbers by the colls corresponds to the TTSC numbering system.

\section{TIBER-I I Model k69c}

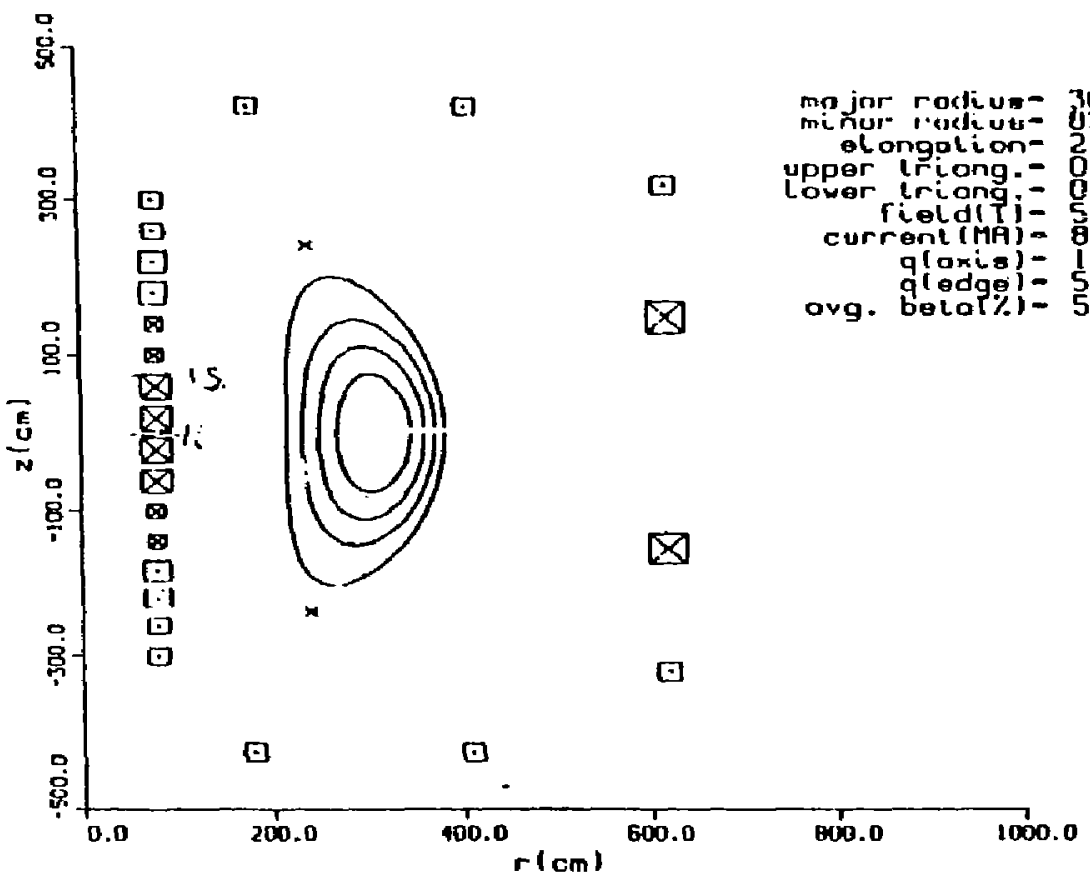


UCD-21550 2.1/2 Se 37

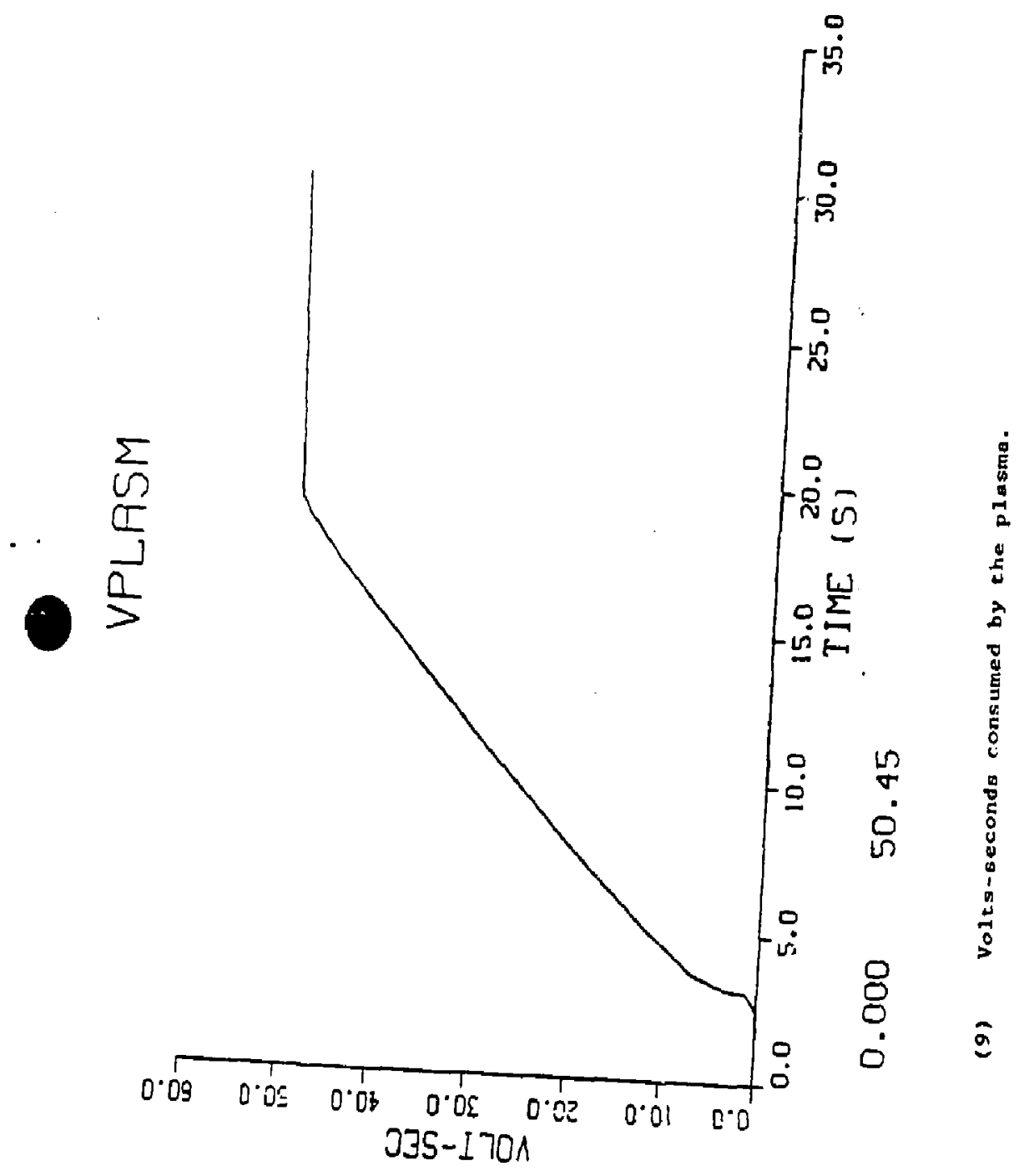

I 


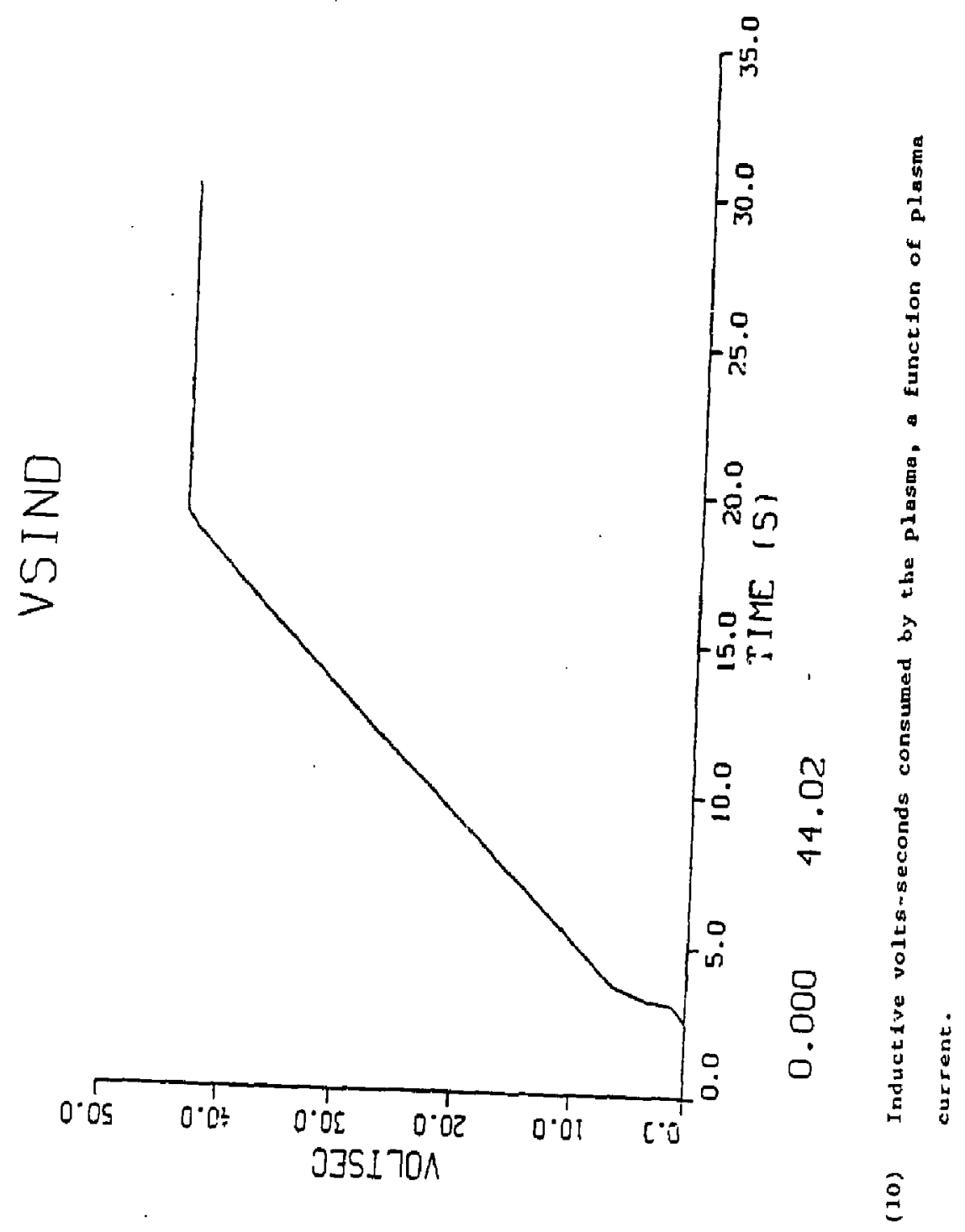




\section{UGD-21550 2.12 Sep8 87}

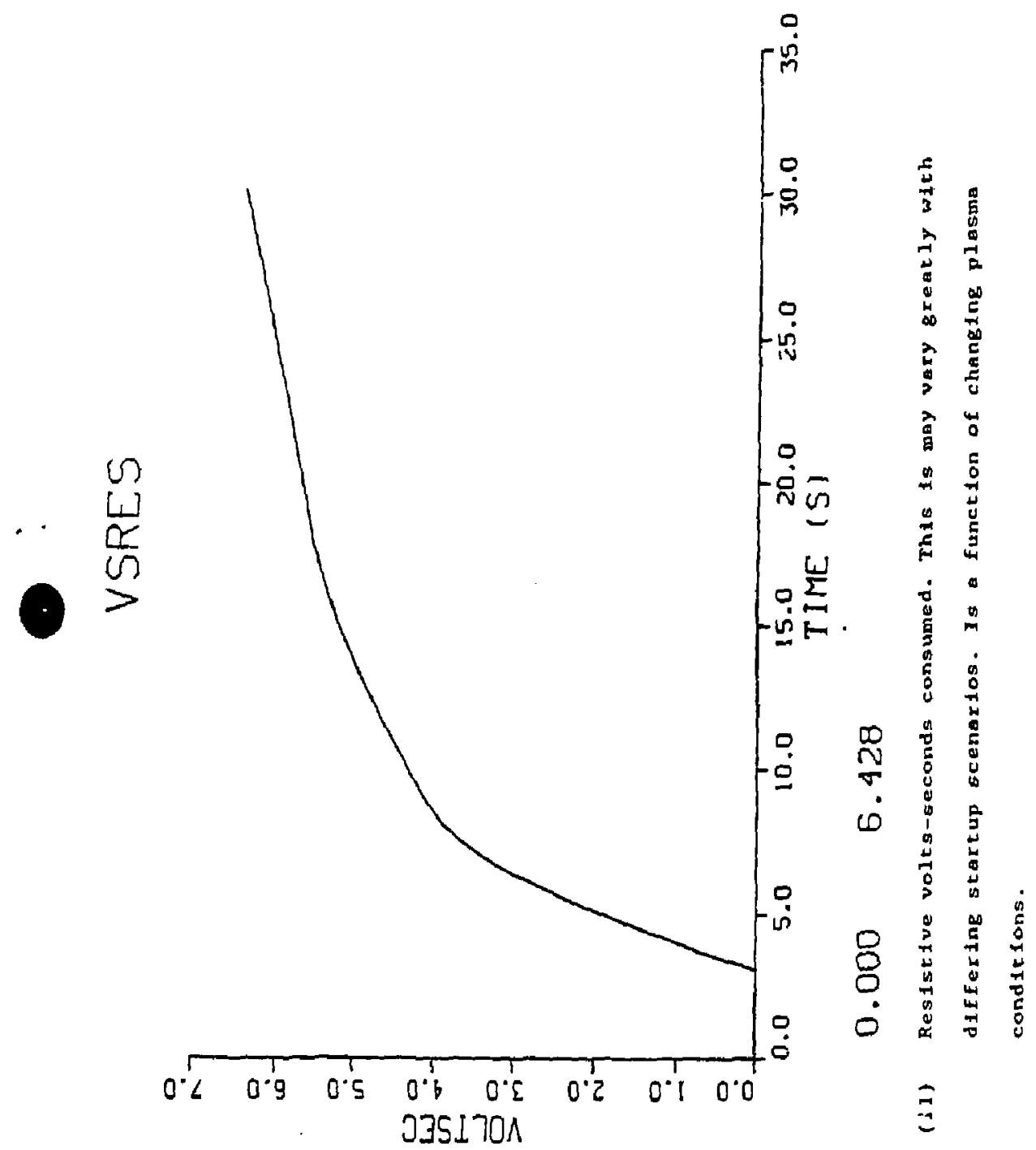




\section{RVOLTSZ}
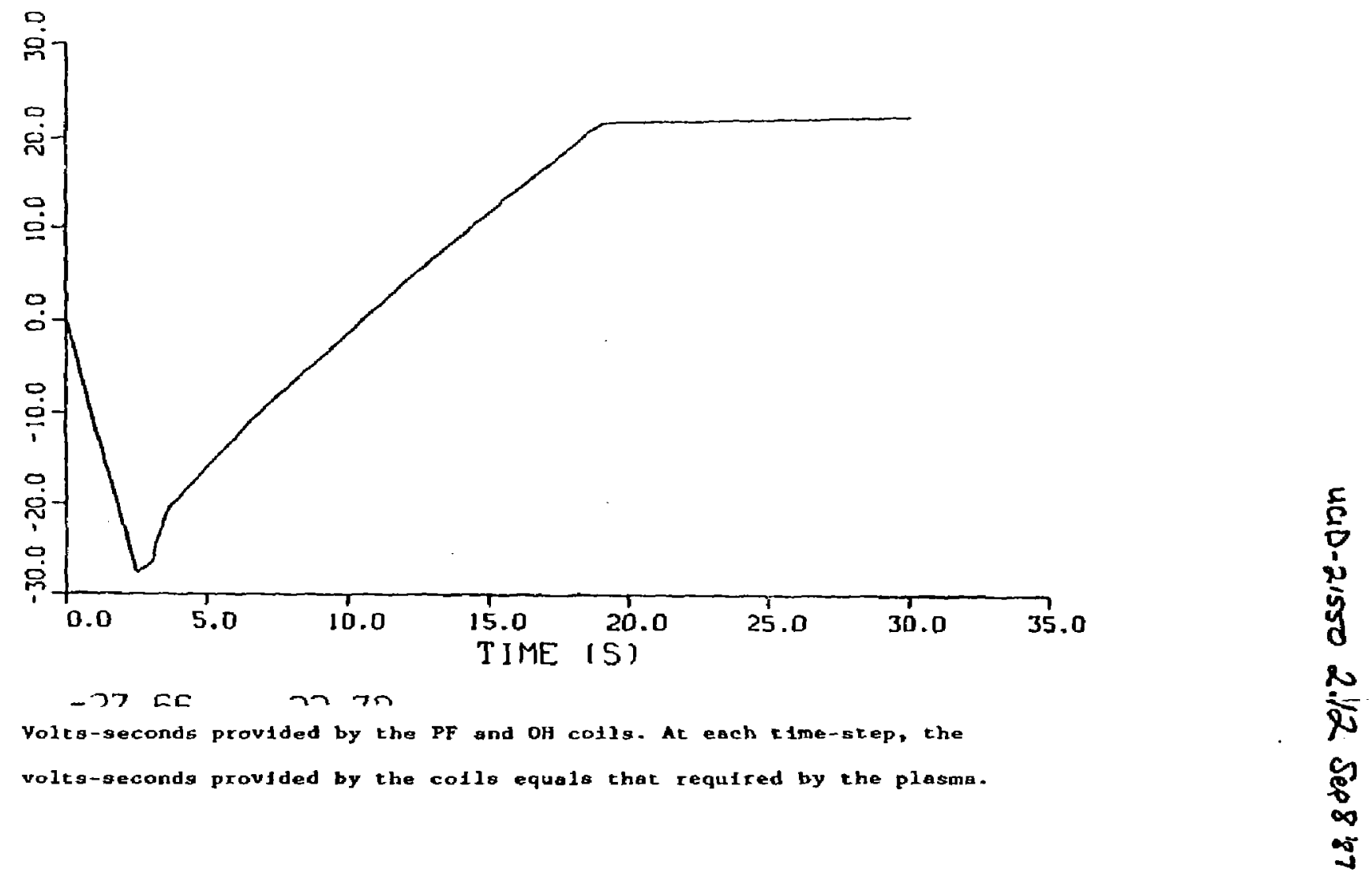

(12) Volcs-seconds provided by the PF and oH cotls. Ac each rime-siep, the

volts-seconds provided by the colls equale that required by the plasma. 


\section{UCID-21550 2.12 Sep 857}

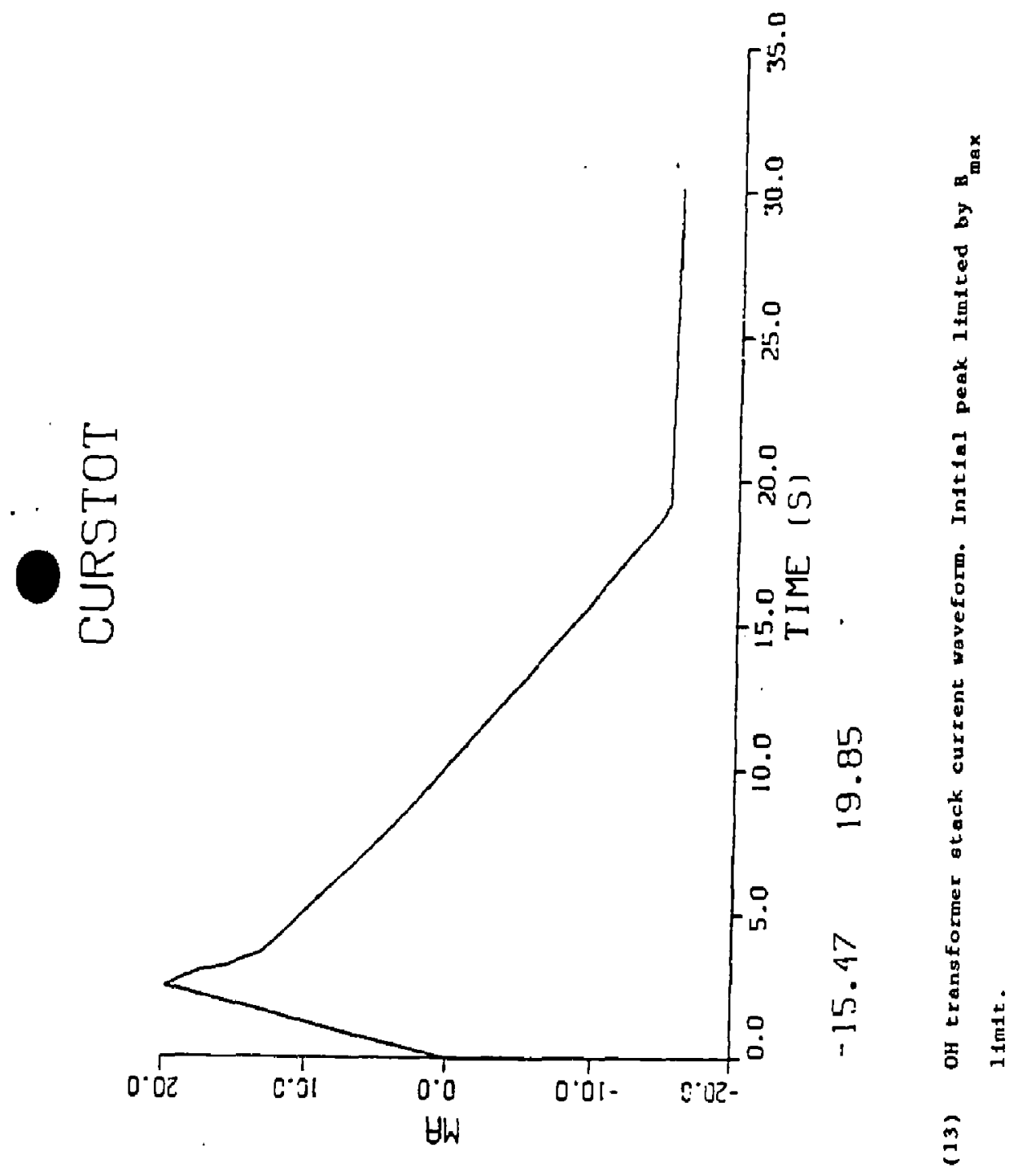




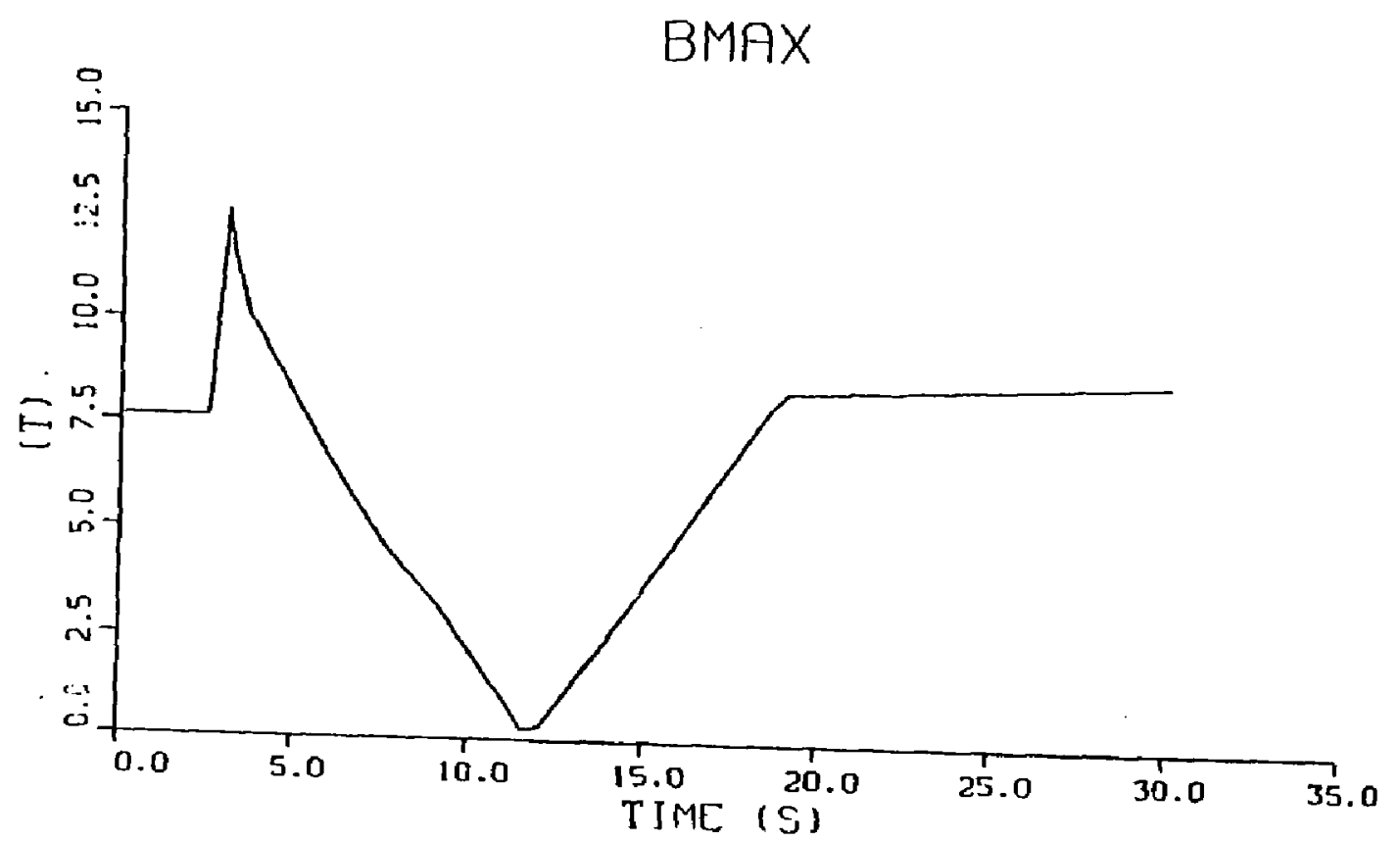

$$
\begin{array}{lll}
\text { PF COIL-16 } & 2.661 \times 10^{-1} & 1.270 \times 10^{\prime} \\
\text { RAOH } 0.600 & \mathrm{ZHOH} 0.000 &
\end{array}
$$

(14) B Bax at point 16, the center of the oH trangformer otack at an $x$

location of $0.6 \mathrm{~m}$. 


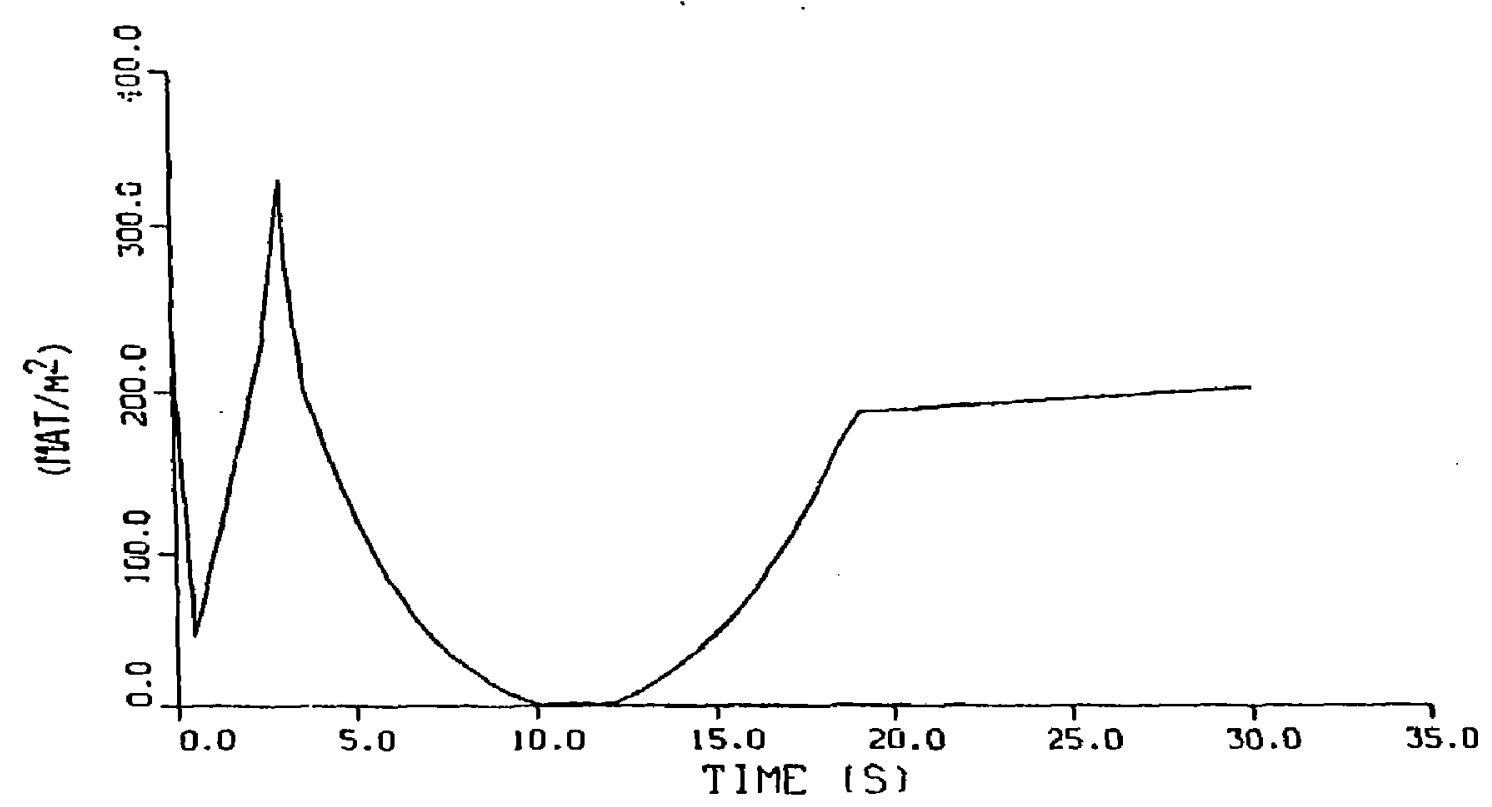

$$
\begin{array}{lll}
\text { PF COLL-16 } & 3.974 \times 10^{-1} & 3.309 \times 10^{2} \\
\text { RAOH } 0.600 & \mathrm{ZHOH} 0.000
\end{array}
$$

(15) $\mathrm{JB}_{\max }$ at point 16 , the cente: of the of transformer stack at an $r$ location of $0.6 \mathrm{~m}$. 

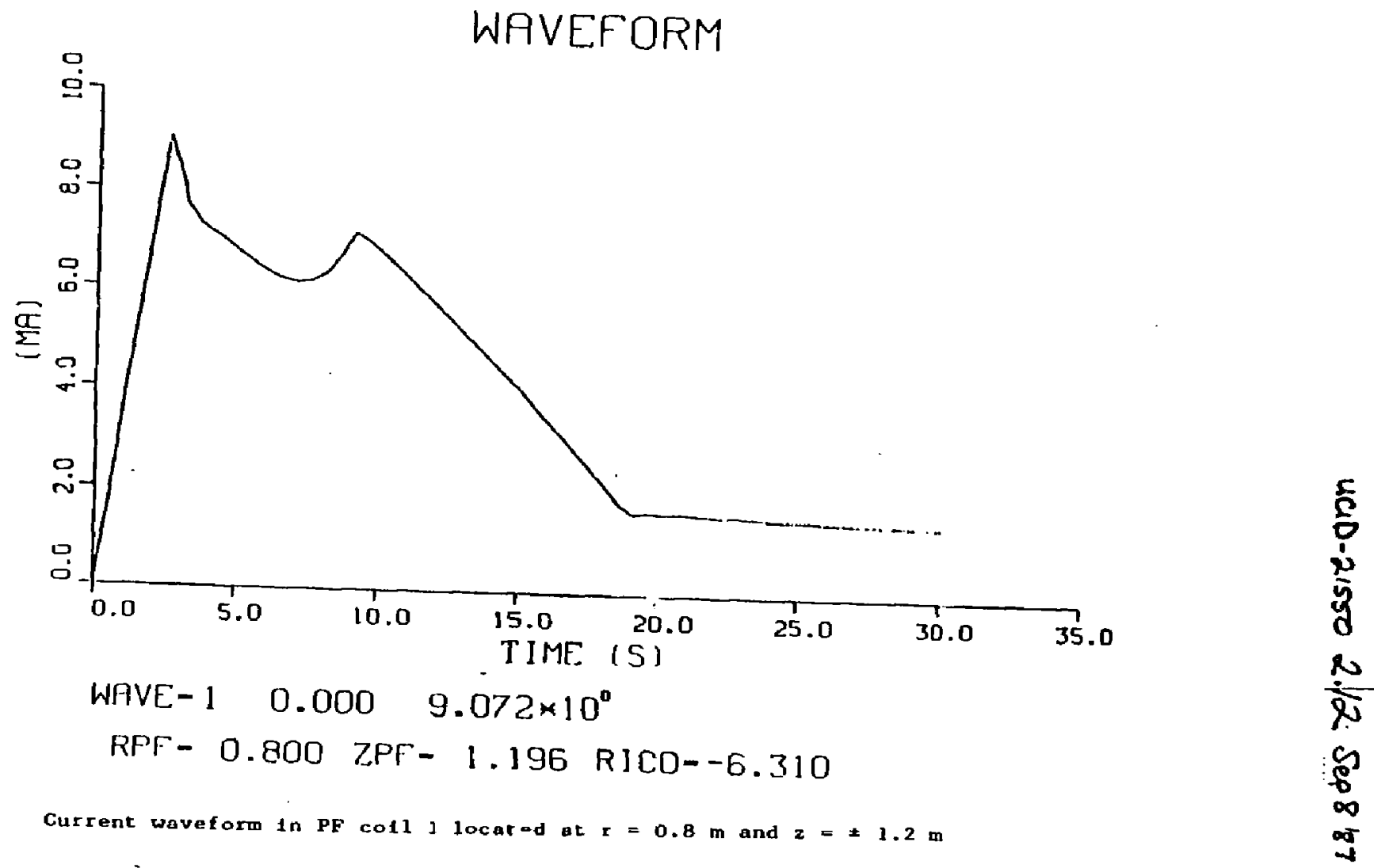

(16) Current waveform in PF coll 1 locarad at $r=0.8 \mathrm{~m}$ and $z= \pm 1.2 \mathrm{~m}$ 


\section{UAD-21550 2.12 Sep 887}

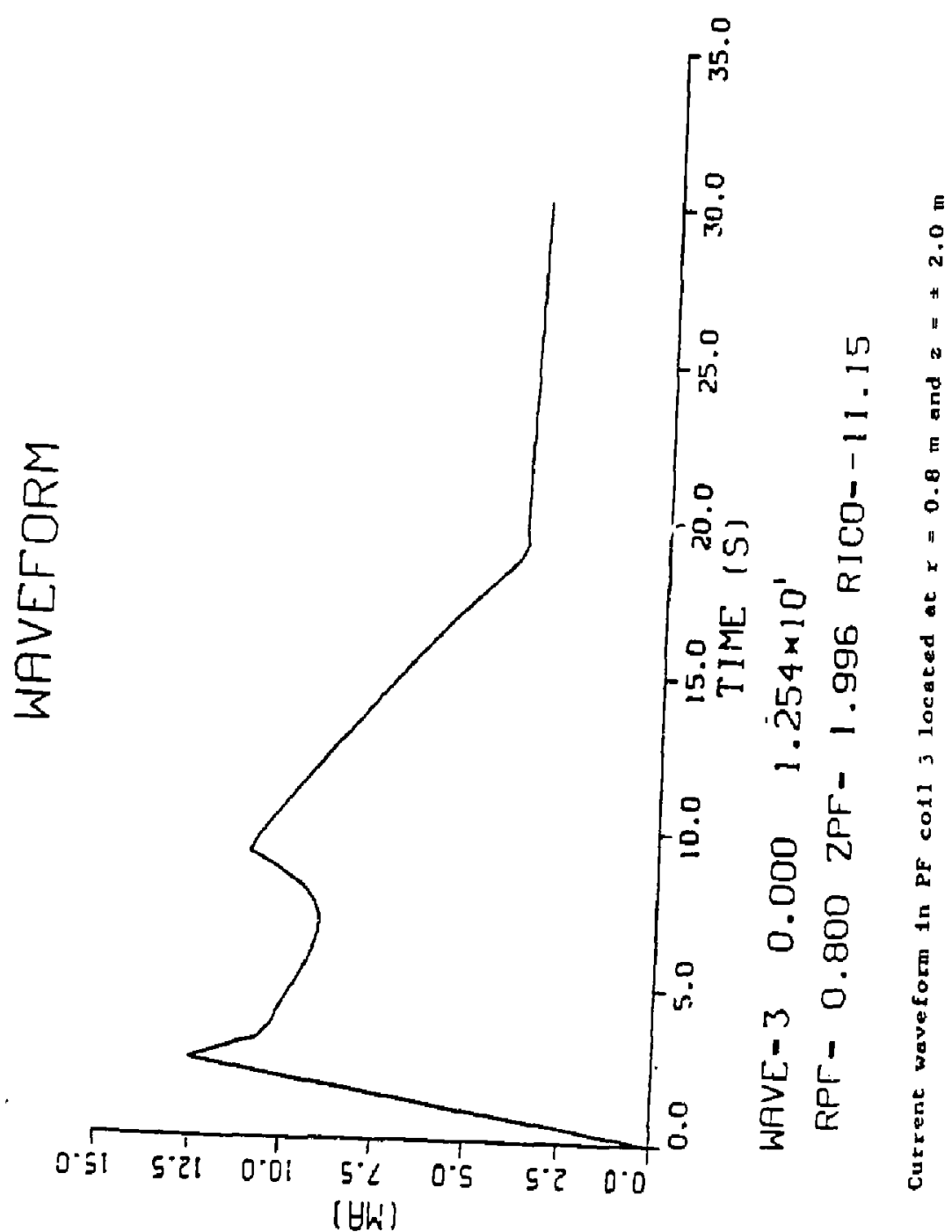

$\hat{\Xi}$ 


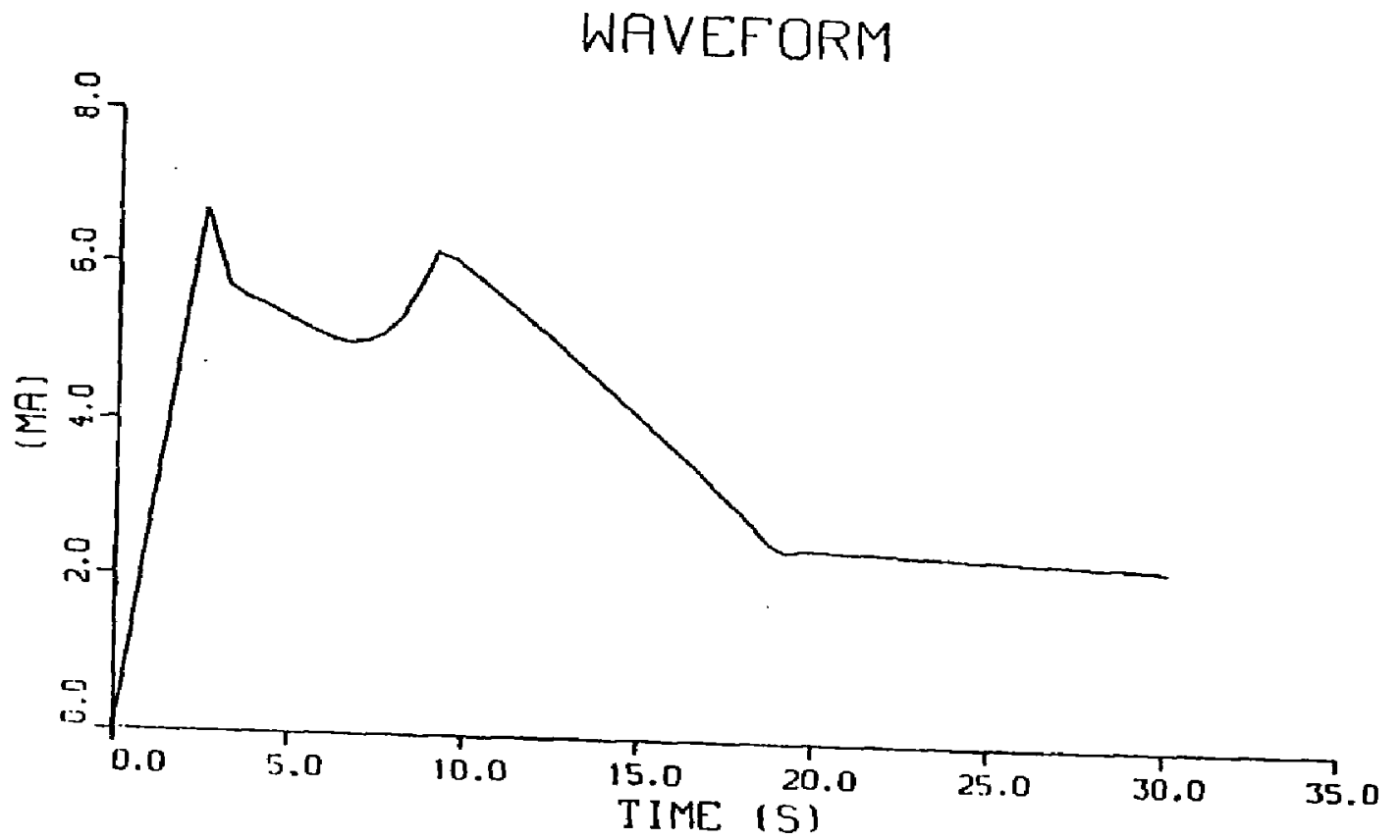

$$
\begin{aligned}
& \text { WAVE }-5 \quad 0.000 \quad 6.709 \times 10^{\circ} \\
& \text { RPF }=0.800 \text { ZPF }-2.796 \text { RICO- }-6.131
\end{aligned}
$$




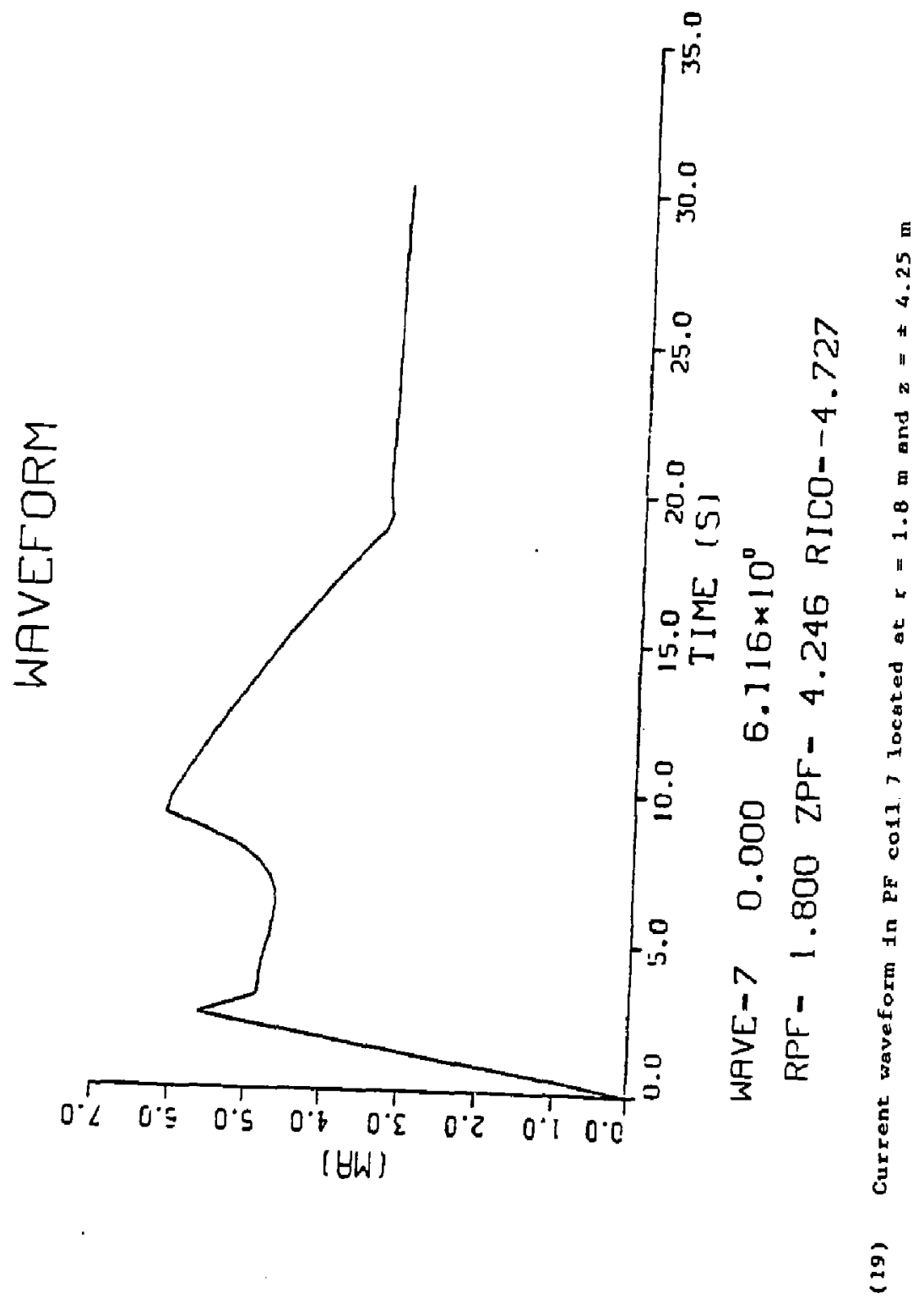




\section{WAVEFORM}

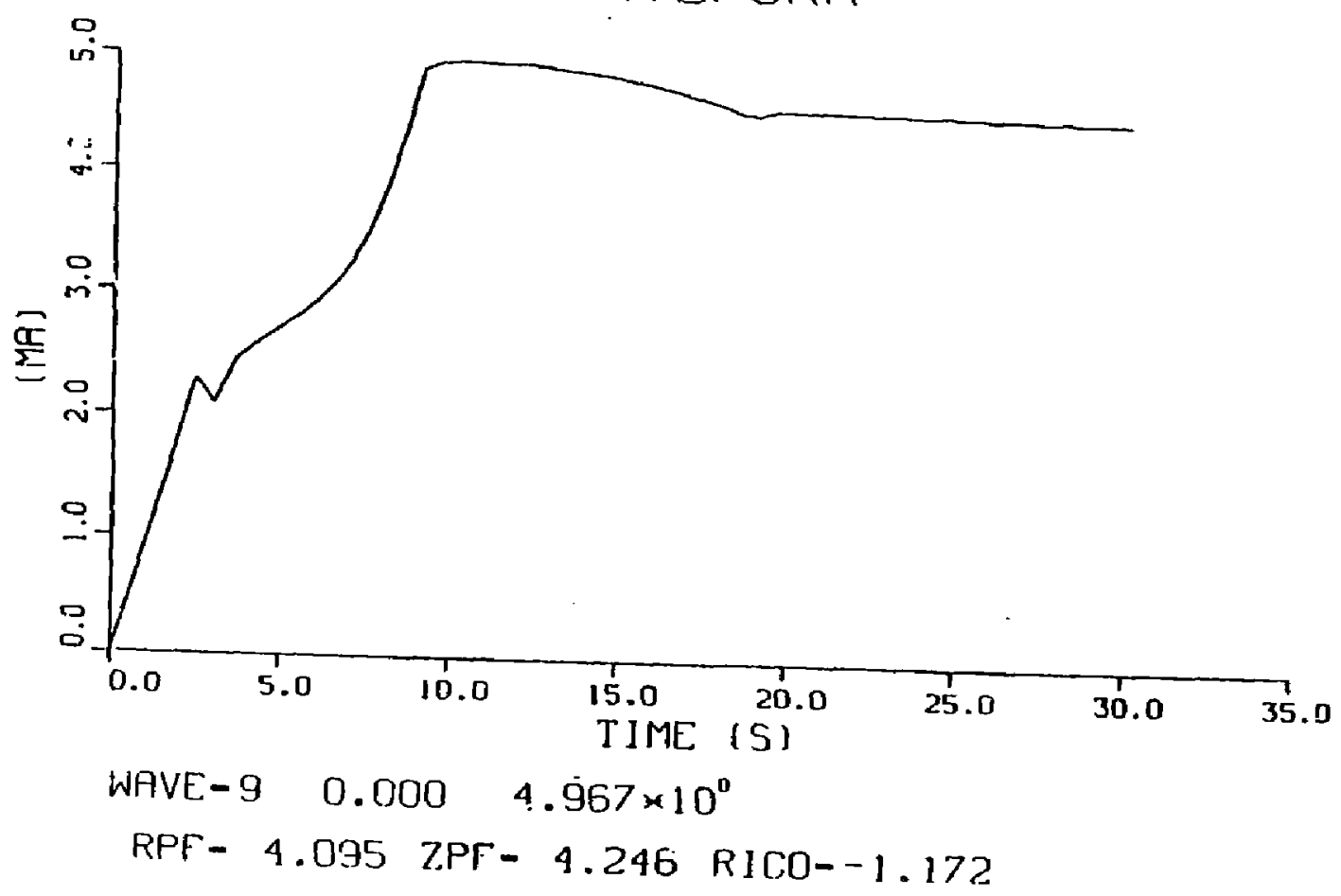

(20) Current waveform In PF coll g located at $r=4.1 \mathrm{~m}$ and $z=4.25 \mathrm{~m}$ 


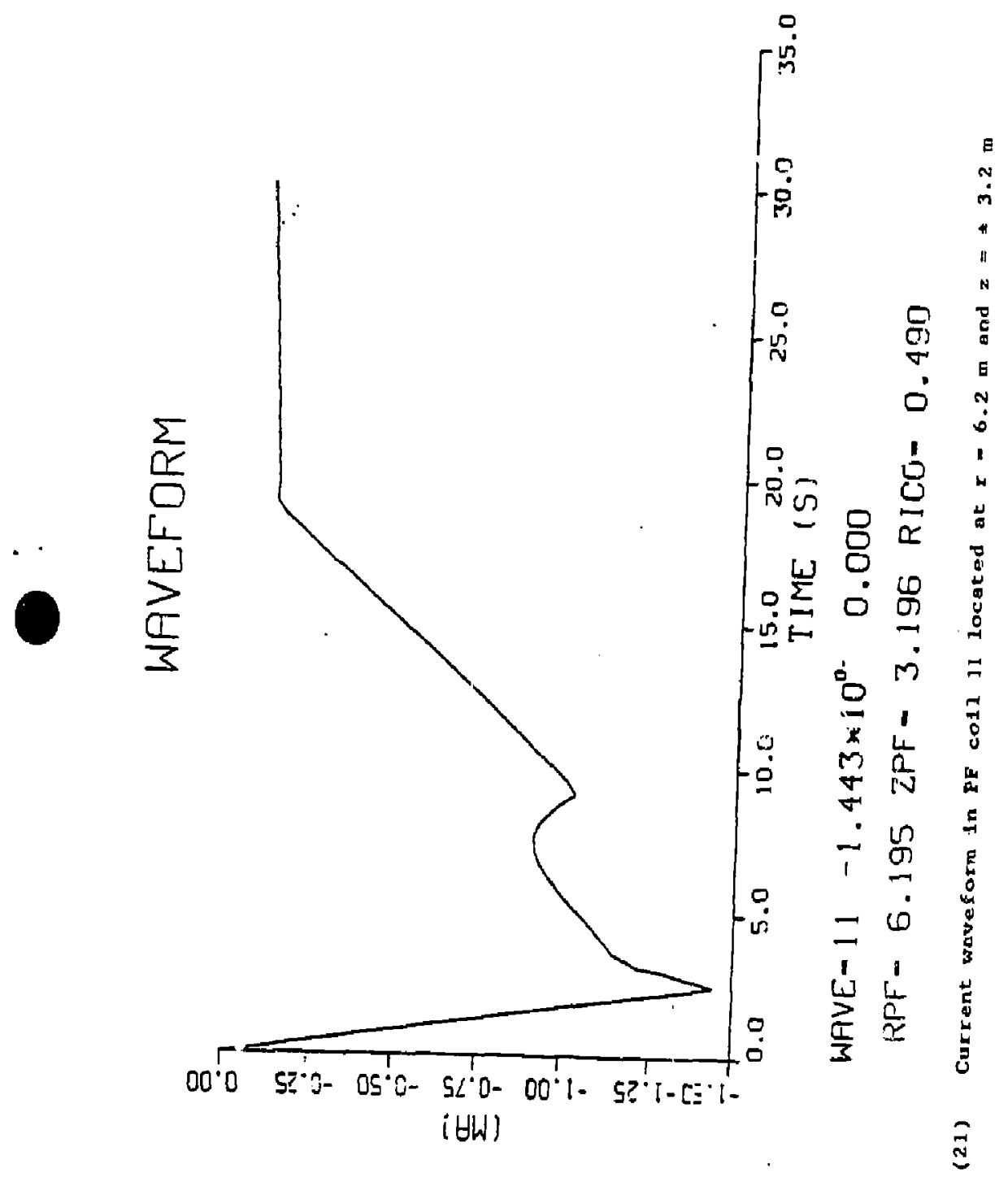




\section{WAVEFORM}

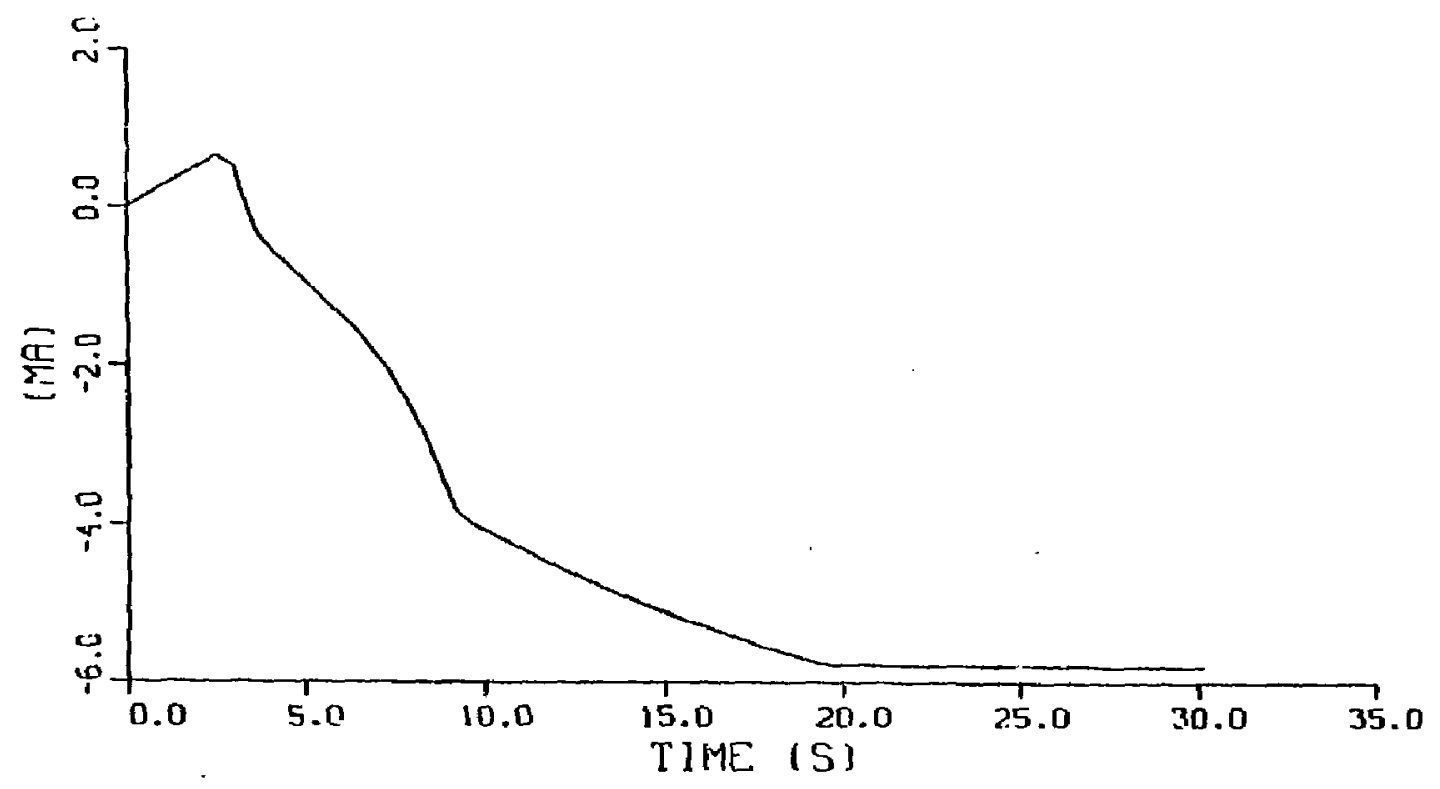

$$
\text { WAVE }=13-5.802 \times 10^{\circ}-6.777 \times 10^{-1}
$$

$$
\text { RPF }=6.195 \text { ZPF }-1.496 \text { RICO- }-0.312
$$




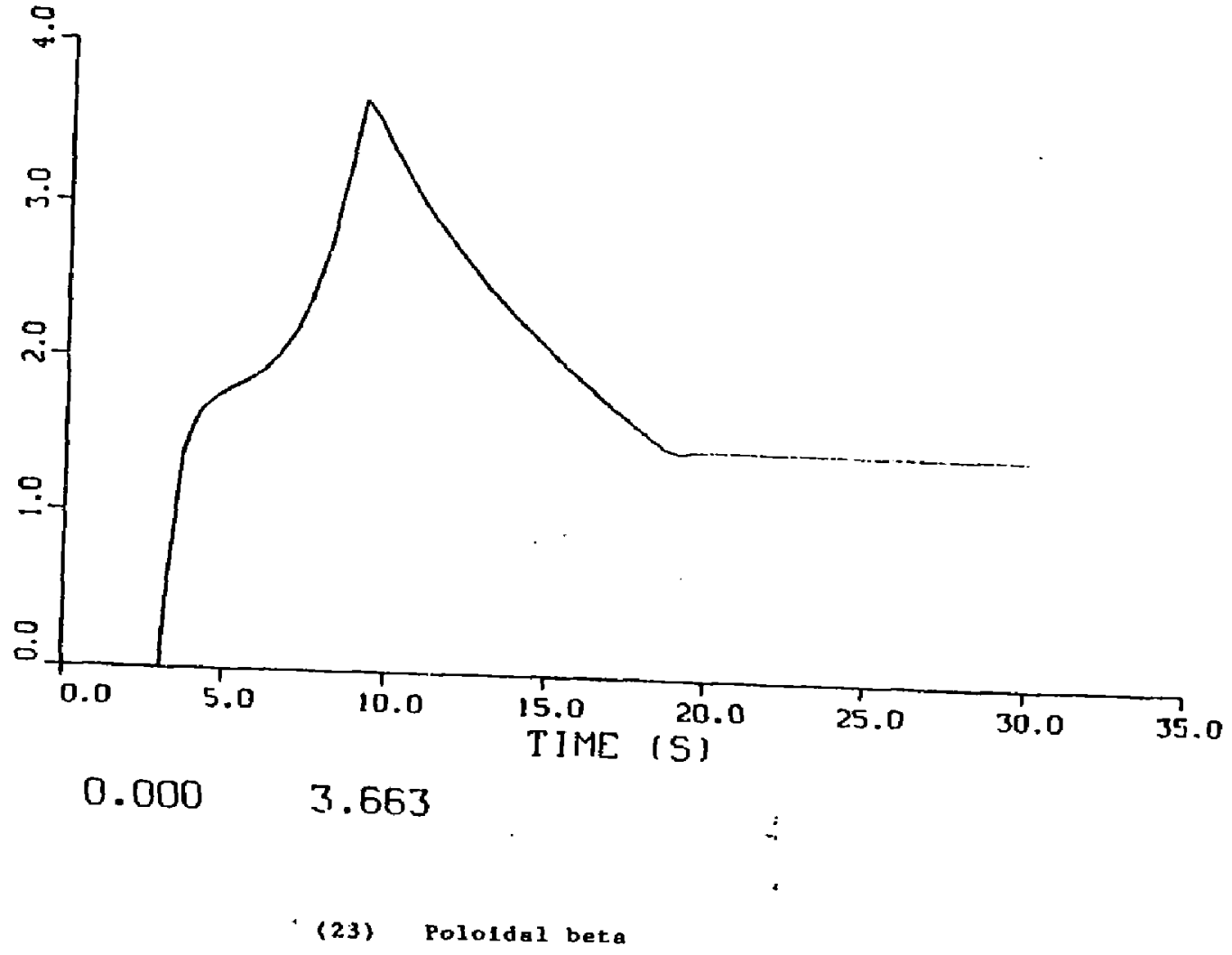




\section{PART 4}

FREE ELECTRON MASER (FEM) FOR IIBER II

$\begin{array}{ll}\text { CONTRIBUTORS: } & \text { H. BOEHMER } \\ \text { B. HAUSS } \\ \text { M. LAMPEL } \\ \text { H. AGRAVANIE } \\ \text { R. CAMPBELL } \\ \text { T. CHRISTENSEN } \\ \text { T. SAMEC } \\ \text { T. SMITH } \\ \text { C. WAGNER }\end{array}$




\section{FINAL REPORT}

\section{FREE ELECTRON MASER FOR TIBER-II}

\section{Electron Cyclotron Heating Requirements in the TIBER-Il Reactor.}

The electron cyclotron heating (ECH) requirements are based on a scenario discussed by Smith, Logan, and Kritz 1 . They show, that the same launching geometry can help the reactor operation in two ways: 1) Facilitating the initiation of burn by localized core heating during reactor startup and 2) suppression of the disruptions and decrease of transport by controlling radial electron temperature and current distribution. Second harmonic absorption is preferred over fundamental ECH because of the better accessibility of the resonance layer at high densities and because targeting of a specific heating area is less affected by density fluctuations which can scatter the microwave beam into an appreciable solid angle. The authors of Ref. 1 show that in the TIBER-Il configuration, an extraordinary mode signal at $450 \mathrm{GHz}$ launched at a polar angle of $\theta=50^{\circ}$ and azimuthal angle of $\Phi=285^{\circ}$ (cylindrical cordinate system coaxial with the tokamak axis of symmetry) $99 \%$ of the incident power is absorbed in the region outside the $q=2$ lux surface. The code calculations show that now power reaches the center of the plasma.

The less desirable choice of fundamental absorption of a $225 \mathrm{GHz}$ signal, launched in the ordinary mode polarization, is also considered. Calculations of the toroidal curtent profile with and without ECH shows that a $10 \mathrm{MW}$ power level at $450 \mathrm{GHz}$ reduces the radial current gradient near the $q=2$ surface to an extent that is expected to positively influence disruptions and plasma transport. Because of fluctuations in the current profile, the radial point for optimum profile control with $\mathrm{ECH}$ can vary on a timescale of several msec. Therefore, the microwave source should be fast tunable over $5-10 \%$ in frequency in order to be able to move the point of absorbtion to ancther cyclotron resonance layer.

The $10 \mathrm{MW}$ microwave power considered above can be subdrivided in a number of ways between several individual sources. Using one single source is undesirable because of high local power loading both in the source and transmission system but also because of lack of redundancy. A set of 6 sources, one of which a spare, would limil the individual power to a convenient $2 \mathrm{MW}$ and would guarantee continuous operation in case of a failure in one unit. 
Both fundamental and harmonic operation are an option in the ECH scenario considered above. It is highly desirable that both frequencies can be generated with the same sources with only minor modifications.

In conclusion, the design requirements for the mierowave sources for ECH in TIBER-II can be listed as shown in Table I. 


\section{TABLE J}

Frequency: $450 \mathrm{GHz}$ (harmonic heating)

$225 \mathrm{GHz}$ (fundamental heating)

both frequencies should be generated

with the same sources with only minor

modifications.

Total Power: $10 \mathrm{MW}$

Power/Module: $2 \mathrm{MW}$

Dynamic frequency tuning range: $5-10 \%$

Polarization: Linear

Mode: gaussian

Duty Cycle: C.W. 


\section{ECH Source Design Philosophy and Beam Layout}

The Free Electron Maser (FEM) is idealy suited as a source for ECH in TIBER-II and other Tokamaks ${ }^{2}$. Since no frequency determining cavities and/or magnet fields are necessary, the FEM does not have the frequency and power limitation of other devices. The approximate wavelength sealing law of

$$
\lambda=\frac{\lambda}{2 \gamma^{2}}
$$

where ${ }^{\lambda_{w}}$ is the wiggler wavelength and $r=\left(1+E_{b} / m c^{2}\right)$, shows that the output wavelength $c$ an be varied with the electron beam energy $E_{b}$. This makes it possible to operate a given FEM at different output frequencies. Furthermore, since the beam energy is high, the FEM is inherently a high power device. The beam extraction efficiency depends critically on the beam quality (energy spread $\Delta \mathrm{r} / \mathrm{\gamma}$ and emittance $c$ ). High quality beams can be generated optimally

with eletrostatic accelerators which operate in the D.C. mode. They also allow beam energy recovery of the spent beam which results in a high total efficiency, low power loading of the beam collector and allow the use of a low current; low cost high voltage power supply.

The FEM interaction is broad band. The device, therefore, can either be operated as a broad band amplifier or, with a frequency selective feedback loop, as a fast tunable amplifier. The latter option is important for fusion relevant frequencies, since no broadband tunable oscillators are available at any power level.

Figure 1 gives a schematic description of a high power, high freqency FEM for TIBER-II. The electron beam, generated by the electron gun, is accelerated to the required high voltage deflected into and out of the interaction region, represented by the magnetic wiggler, by achromatic bends which can deflect the beam independently of energy within the required limits. The highly overmoded interaction waveguide is straight. Frequency tuning over the gain bandwidth of the FEM is accomplished with a tunable longitudinal laser like cavity.

3. FEM parameter selection and interaction modeling.

Equation 1 shows that it is desirable to choose a short wavelength wiggler in order to limil the beam voltage. On the other hand, the wiggler field scales with $\exp (-g / x)$, where $g$ is the gap width between wiggler pole faces. This gap has to 
accomodate the electron beam and microwave transport tube, usually a rectangular otermoded waveguide. It is then understandable that the gap and therefore the wiggler wavelength can not be made arbitrarily small both because of the finite electron beam size and the microwave power loading of the raveguide wall.

Other constraints that enter the parameter selection are current limitations due to space charge blow-up of the propagating beam, equilibrium radius in the wiggler section due to finite beam emittance and electron to microwave beam filling factor.

The operational parameters selected for the TIBER-I FEM are listed in Table Il. As will be shown below, all parameters are conservative and well within the limit of present technology limits. For the input power level it is assumed that about - $30 \mathrm{~dB}$ of the output power enters the system through a feedback loop.

The TRW FEM interaction code was used to predia șstem performance for the conditions listed in Table II. The left panel in Figure 2 a demonstrates for the $450 \mathrm{GHz}$ case the axial wave growth in terms of the beam extraction efficiency. Nonlinear wave saturation and therefore maximum interaction occurs at $L=160$ $\mathrm{cm}$. The beam extraction efficiency at that point is $3.5 \%$. The right panel of figure 2a shows the single pass gain as a function of frequency. Peak gain is 1400 which means that less than $30 \mathrm{~dB}$ of the output power needs to be recycled in a feedback loop for oscillator operation. Fast tunability can be achieved for constant beam parameters since the $3 \mathrm{~dB}$ width of the gain curve is $7.2 \%$. By lowering the beam voltage to $1,88 \mathrm{MV}$, the system can be operated at $225 \mathrm{GHz}$ while leaving the other system parameters constant. Figure 2b) shows, compared to the $450 \mathrm{GHz}$ case, that the beam extraction efficiency is slightly enhanced to $3.8 \%$. Since simultaneously the beam power decreased, the oulput power is reduced to $24 \mathrm{MW}$ compared to 2.8 $\mathrm{MW}$ for the $450 \mathrm{GHz}$. Gain and $3 \mathrm{~dB}$ bandwidth are found to be quite similar for both operating conditions.

The FEM interaction code also predicts the electron beam energy distribution at the end of the interaction region. This is shom for the $450 \mathrm{GHz}$ case at peak gain in Figure 3 which also lists the initial and final average beam energy $\left\langle V_{i}\right\rangle$ and $\left\langle V_{p}\right\rangle$. This distribution can be used to estimate the ideal system efficiency of a multi-stage depressed voltage collector. Arranging 5 collectors between 0 and $200 \mathrm{kV}$, as shown in Figure $3_{1}$ one calculates the currenl collected and power dissipated for each collector. With a total power lost in the collector of $\mathrm{P}_{\text {lost }}=0.78$ $M W$ and an microwave output power of $P_{\text {out }}=2.8 \mathrm{MW}$ one finds the ideal total system efficiency 


$$
\eta_{T}=\frac{P_{\text {out }}}{P_{\text {out }}+P_{\text {lost }}}=7.82 .
$$

The efficieny of an actual system will, of course, be smaller.

Although all system requirements are met for the FEM parameters of Table I, it would be desirable to increase the gain bandridth. This could be done by increasing the interaction strength for example by increasing the beam current which also increase efficiency and output power. A previous conceptual design of a FEM for TIBER-I demonstrates this. Figure 4 shows efficiency and gain bandwidth using a $2.36 \mathrm{MV}, 40 \mathrm{~A}$ beam logether with $\lambda_{w}=5 \mathrm{~cm}, \mathrm{~B}_{w}=2.0 \mathrm{kG}$ wiggler resulting in $5.7 \mathrm{MW}$ output power at $240 \mathrm{GHz}$. Evidently the gain curve is now $10 \%$ wide at $75 \%$ of peak gain. 


\section{TABLE II}

\section{TIBER-II FEM parameters}

Electron Beam:

$$
\begin{aligned}
& V=2.7 \mathrm{MV} \text { (harmonic operation at } 450 \mathrm{GHz} \text { ) } \\
& V=1.9 \mathrm{MV} \text { (fundamental operation at } 225 \mathrm{GHz} \text { ) } \\
& \mathrm{I}=30 \mathrm{~A} \\
& \mathrm{I}=2.0 \mathrm{~mm} \\
& \mathrm{E}=40 \mathrm{~mm} \mathrm{mrad}
\end{aligned}
$$

Wiggler:

$$
\begin{aligned}
& \lambda_{W}=2 \mathrm{~cm} \\
& B_{W}=2 \mathrm{kG} \\
& \text { linear polarized, untapered. }
\end{aligned}
$$

Waveguide:

$$
\begin{aligned}
& 2 \times 6 \mathrm{~cm} \\
& \mathrm{TE}_{01} \text { mode }
\end{aligned}
$$

Input power: $2 \mathrm{~kW}$

$\begin{array}{ll}\text { Output Power: } & 2.8 \mathrm{MW}(450 \mathrm{GHz}) \\ & 2.4 \mathrm{MW}(225 \mathrm{GHz})\end{array}$

Expected total efficiency with beam energy recovery: $44 \%$ 


\section{Electron Beam Line}

As shown schematically in Figure 1, the eiectron beam is generated in an electron gun, accelerated to full high voltage in an acceleration column, deflected into and out of the interaction region with achromatic bends, decelerated to maximum collector voltage and collected in a multi-stage collector. The two most important aspects in the design of the electron beam line are:

\section{- Beam Emittance}

- Current loss at high voltage.

Electrons entering the wigglet with a finite angle or radius will perform betatron oscillations due to the alternating gradient focusing force of the wiggler field ${ }^{3}$. Consequently, the electron beam will have 1) an equilibrium radius given by the beam divergence (emittance) and the riggler field and 2) an increased effective longitudinal energy spread. Since both beam density and energy spread influence the FEM gain and efficiency, the beam emittance is a crucial parameter which should be as small as possible. It is, therefore, essential to design a high quality electron gun and to keep the emittance growth in the beam transmission system small.

The eurrent loss at high voltage should be kept small since it influences directly the current and therefore cost of the high voltage power supply. It will also generate the largest fraction of the power deposited in the high voltage components.

\subsection{Electron Gun}

The electron gun is modeled after the gun presently in operation at the TRW FEM, which was designed by a TRW consultant Dr. R. Hechtel, Redwood City. The electrode configuration, beam orbih phase space and normalizad current density at the gun exit are shown in Figure 5. The gun has two stages, the first, the actual gun, detemines the operational current from the voltage applied to its anode, the second accelerates the beam to $300 \mathrm{kV}$ in a relatively short gap in order to limit the space charge blow-up of the beam while still at low energy. A control electrode is placed between cathode and first anode which allows the beam to be pulsed on a microsecond time scale. This feature will faciliate electron beam line tune-up at the beginning of the system operation, since short beam pulses will limit 
the power deposition in the beam line by an untuned beam. The control electrode does not intercept the beam with a grid because both of power loading and emittance growth due to the potential distribution surrounding the wires. Pulsing the voltage of the electrode from - $10 \mathrm{kV}$ to $+10 \mathrm{kV}$ (w.r.t. cathode) will tum the gun from the "off" to the "on" stage. The sum of geometrical and thermal emittance at the gun exit is $10.7 \mathrm{~mm}$ mrad, considerably better than the minimum requirement of $40 \mathrm{~mm} \mathrm{mrad}$ for the FEM interaction.

\subsection{Ascelerator Column}

The transport of the high current, relativistic beam through the acceleration/deceleration columns was modeled with the EBQ code. EBQ is a particle simulation code for the sleady-state transport of high current, charged particle bearns in axisymmetric systems possessing external electric and/or magnetic fields. it includes the self-fields of the particles so as to obiain self-consistent charge and current distributions. In addition, because of the codes' unique method of handling the cancellation that occurs between radial electric and magnetic selfforces, the high current electron beam can be accurately tracked in its long distance fight through the accelerating/decelerating structures.

The extemal solenoidal focusing fields used in the simulations are those of an iron-shielded solenoid with a bore diameter of $25^{n}$ and a gap width-to-bore diameter ratio of 1 . A table of vector potentials for this coil geometry were generated using POISSON and input to the EBQ code.

Commercial accelerator sections like those built by the National Electrostaties Corporation can be used for the $120 \mathrm{~cm}$ long acceleration section. The beam modeling showed that additional magnetic focusing is necessany between the gun and accelerator column in order to focus the beam to a $5 \mathrm{~mm}$ sadius at the entrance of the first achromatic bend. Electrode and magnetic field configuration as well as beam orbit and phase space at the first and last accelerator sections are shown in Figure 6. To within the fluctuations of the code output, no emittance growth is observed. Also, the current intercepted by the accelerating structure is zero.

\subsection{Achromatic Bend}

While the input beam at the first bend is cold, it obtains a sizable energy spread (see Figure 3) during the FEM interaction. Deflection of the beam with a 
simple magnetic dipole, therefore, is not feasible for the output beam. A magnelic dipole - quadrupole - dipole conbination can serve as an achromatic bend. The design of such a system for the $2.69 \mathrm{MV}$ beam of TIBER-П is reproduced in Figure 7. The focusing action of both the quadrupole and the dipole pole faces is used in this design. The pole faces facing the quadrupole are rotated by $17.6^{\circ}$ from the normal with respect to the beam orbit. Since this achromatic bend, in addition to the energy independency also has excellent focusing and transport properties, it is used both at the wiggler input and output side.

\subsection{Wigpler Beam Transport}

See Section 5.

\subsection{Deceleraijion Column}

In the deceleration column, which is constructed from the same components as the acceleratron column, the beam energy is decreased to the lowest energy of the beam distribution. Since space charge forces become important as the beam is decelerated it was found to be necessary to include solenoidal magnetic focusing elements in the design.

\subsection{Multi-Stape depressed Voltage Collector}

Depressed voltage collectors are used extensively by the microwave tube manufacturing industry to boost the efficiency of space bome traveling wave tubes. One particular design, developed by Dr. R. Flechtel, Redwood City, for linear bearn tubes has demonstrated high efficienc, and has shown excellent agreement between predicted and actual performance ${ }^{4}$. The design features spherical collector surfaces in a configuration that spreads the collected beam elements over large areas to decrease local power loading and increase collectors efficiency. It also shows an excellent suppression of back streaming electrons. Recently, such a collector was built for the Free Electron Laser operated at the Quanturn Institute of the Universir; of California at Santa Barbara5.

The collector the the TIBER-jI FEM, whose design will be discussed in an addendum to this report, is similar to that of the present TRW FEM collector (Figure 8) which was designed specifically to simulate the conditions of a high power FEM like the TIBER-II design discussed in this report. Specifically. it can 
accomodate the total beam energy spread of $\Delta V N=15 \%$ of the IIPER-II FEM beam. From the design calculations a collector efficiency of $973 \%$ is predicted. From experience obtained with prediction and measurements it is expected nat the actual collector efficiency will be ${ }^{n} R=95-96 \%$. With a psedicted beam extsaction efficiency $n_{\bar{E}}=3.7 \%$ for the TIBER-II FEM one calculates from

$$
n_{T}=\frac{n_{E}}{1-\pi_{R}\left(1-\pi_{E}\right)}
$$

a total efficiency of $\eta_{I}=44-49 \%$.

Of concern is the powyr dissipation in the collector plates. In the example, of Figure 3. a maximum of $230 \mathrm{~kW}$ is dissipaled per stage. Assum $7 \mathrm{~g}$ an average power Joading of $250 \mathrm{~W} / \mathrm{cm}^{2}$, the collector plate radius should be $20 \mathrm{~cm}$. The required coolant flow is $17 \mathrm{gal} / \mathrm{min}$ for a water temperature increase of $100^{\circ} \mathrm{F}$.

\section{Magnetic Wiggler}

The design parameters for the magnetic wiggler are:

$$
\begin{aligned}
& \text { Wavelengthd } W=4.0 \mathrm{~cm} \\
& \text { Field } B_{W}=2.0 \mathrm{kG} \\
& \text { Gap Width } g=3 \mathrm{~cm} \\
& \text { Length } L=160 \mathrm{~cm} \\
& \text { Number of wavelength } \mathrm{N}=40 \\
& \text { Field Error } \triangle \mathrm{B} / \mathrm{B}<1 \% \\
& \text { Machining tolerance } 0.004 \text { inch. }
\end{aligned}
$$

Because the FEM is a C.W. device and because the wiggles is operated at high voltage it is advantageous to use a pernianent magnet rather than a power consuming electromagnetic device.

The technology of magnetic wigglers powered by permanent magnets has been advanced to a second generation. A hybrio wiggler concept using high permeability material as pole faces and either Samarium-Cohall or NeodyminumIron permanent magnets has been developed by $\mathrm{K}$. Haibach, Berkeley ${ }^{6}$. Such wigglers have been built at LBL and TRW. The magnetic design is schematically illustrated in Figure 9a). Soft iron poles which can be machined to high accuracy 
define the distribution of the fiejd in the interaction region. Slabs of transversely magnetized permanent magnets fill the space between adjacent poles. One pole with two magnets form individual pole modules that are attached via locating pins and screws to two parallel mounting plates as shown in Figure 10. Iron screws that are inserted into the back of each pole module can diver a fraction of the magnetic fux allowing individual pole tuning by $7 \%$. This feature is important because field errors can cause the beam to deviate from an exact sinusoidal orbil inside the wiggler and consequently be deflected to the waveguide wall. Random beam walkoff for the TIBER-II wiggler can be limited to $10 \%$ of the beam radius by keeping the field error $\triangle B / B<1 \%$. This requires for ${ }^{A} w=4 \mathrm{~cm}, g=3 \mathrm{~cm}$ and $B=2 \mathrm{kG}$ a mechanical machining tolerance of 0.004 inch.

Confined transport of the electron beam in the interaction region is accomplished by the wiggier field. The radial field gradient in the B-Z plane indicated in Figure 9a provides a radial restoring force on any electron propagating not on-axis. Consequently, the beam electrons perform betatron orbits and the equilibrium radius of the beam in the field direction is

$$
x^{2}=\frac{\sqrt{2} t y}{b}
$$

Where $c_{N}$ is the normalized emittance and $b_{W}$ the normalized wiggler field amplitude.

Focusing of the beam in the plane perpendicular $10 \mathrm{~B}$ can be achieved by obtaining a transverse field gradient with canted pole faces as indicated in Figure 9b. For the condition of the TIBER-II wiggler, a canting angle of $1^{0}$ is required.

\section{Microwave System}

With a single pass gain of 1400 and a $3 \mathrm{~dB}$ width of $7 \%$ as discoussed in section 3, the TIBER-II FEM could operate as a broadband amplifier if a suitable tunable input oscillator would be available. Also, a two stage FEM as proposed for TIBER-I that would use an input oscillator with a power level of several viatts seem to be unadvisable because no uni-directional transmission line components are available at the operating frequencies of 225 and $450 \mathrm{GHz}$. Such elements sould be necessary to attenuate reflected power between stages in the high gain system and therefore to prevent unwanted oscillations. 
$\mathrm{FC}^{-}$these reasons it is recommended to operate the FEM as a single stage tunable uscillator by reflecting a small fraction of the output power with a broadband reflector and re-reflecting that power back into the interaction region using a frequency selective rotatable grating. The addition of the grating, rather than the use of a ordinary laser cavity, is necessary since the longitudinal modes of a $4 \mathrm{~m}$ long cavity are separated by only $37.5 \mathrm{MHz}$ which is small compared to the system gain width of about $15 \mathrm{GHz}$ (Figure 2).

For a retro-reflecting grating at which the power is reflected back into the source, power maxima occur for

$$
\begin{aligned}
& \cos \theta=\frac{n \lambda}{2 d} \quad a=0, \pm 1, \pm 2, \\
& \operatorname{and} d \text { are defined in Figure 1la. From } \\
& \frac{d \theta}{d \lambda}=\frac{d \sin \theta}{d n}
\end{aligned}
$$

it can be seen that $\theta$ should be small for high resolution, but this would increase the necessary rotating angle for frequency tuning. For ${ }_{0}^{\circ}=25^{\circ}$, the wavelength selection can be changed by $\Delta \lambda / \lambda=5 \%$ by rotating the grating over $\Delta \theta=$

$15 \%$. Using the formalism for array antenna pattern one can maximize the grating configuration which is shown in Figure $1 \mathrm{lb}$ ) for $450 \mathrm{GHz}$ and reflection into first order. For these grating dimensions and assuming a distance of $50 \mathrm{~cm}$ between the waveguide end and the grating, a frequency resolution of $1 \%$ can be obtained if the grating contains 72 rulings. With the ruling dimensions shown in Figure $11 \mathrm{t}$ this translates in the minimum grating size of only $3 \mathrm{~cm}$.

The power balance of the system was estimated. Specifically, the following values were found:

$\begin{array}{ll}\text { Grating Efficiency } & 0.5 \\ \text { Overlap of returned beam } & 0.6 \\ \text { and waveguide } & \\ \text { Coupling from free space to } 0.7 & \\ \text { waveguide mode } & \\ \text { Mirror Reflectivity } & 0.98 \\ \text { Total Throughput } & 0.21\end{array}$

In order to find the fraction of the power that needs to be reflected at the broadband outpur reflector one can consider the oscillator condition 


\section{$\mathrm{T}_{0} \mathrm{~T}_{\mathrm{i}} \mathrm{T}_{\mathrm{g}} \mathrm{CG}>1$.}

With

$T_{0}=$ output reflector efficiency

$T_{\mathrm{j}}=$ Input reflector efficiency $=0.2$

$T_{g}=$ Waveguide transmission efficiency $=0.94$

$C=$ Coupling efficiency to $\mathrm{FEM}$ mode $=0.25$

$G=$ Power Gain

the oscillator condition is reduced to

$T_{0} G>21$.

It was shown in section 3 that the power gain is 1400 for the $450 \mathrm{GHz}$ FEM. Consequently, $T_{0}=0.015$, or $15 \%$ of the output power needs to be reflected for oscillator operation. No startup power is needed to initiate oscillations. It was showin in a previous TRW FEM experiment? that spontaneously radiated power is sufficient for that purpose.

The microwave power incident on the grating is $T_{0} P_{\text {out }}=40 \mathrm{~kW}$. For 450 $\mathrm{GHz}$ and copper the mirror losses are $1 \times 10^{-3}$ which means that the total mirror loading will be 40 Wath, or $1.6 \mathrm{~W} / \mathrm{cm}^{2}$ for a $5 \times 5 \mathrm{~cm}^{2}$ mirror.

Finally, in order to make the FEM consistent with TIBER-II tuning requirements, it will be necessary to rotate the grating by $30^{\circ}$ (.524 rad) within $t=6$ msec. This motion can be generated by a computer controlled motor drive built by Parker. The model KS/KSX22 "compumotor" has the following specifications:

$$
\begin{aligned}
& \text { Peak Torque }=1.29 \mathrm{~N}-\mathrm{M} \\
& \text { Speed }=3000 \mathrm{rpm} \\
& \text { Rotor Inertia }=13.2 \times 10^{-6} \mathrm{~kg} \cdot \mathrm{m}^{2} \\
& \text { Acceleration }=9.8 \times 10^{-4} \mathrm{rad} / \mathrm{sec}^{2}
\end{aligned}
$$

During the $6 \mathrm{msec}$ time interval of frequency tuning, the mirror has to be accelerated, rotated and decelerated, requiring an estimated acceleration of $6 \times 10^{4}$ $\mathrm{rad} / \mathrm{sec}^{2}$. This, logether with a mirror inertia of $8 \times 10^{-6} \mathrm{~kg}-\mathrm{m}^{2}$ and a rotor inertia of $13 \times 10^{-6} \mathrm{~kg}-\mathrm{m}^{2}$, results in a torque of $1.3 \mathrm{~N}-\mathrm{m}$. Both torque and acceleration 
requirements, therefore, are within the specification of the motor drive described above.

Since the interaction region is operated at high voltage, the microwaves have to be transmitted to ground potential. For windowless operation, this can be accomplished by free radiation from the waveguide as a radiator through a standard accelerator tubing like those used for accelerating the electron beam. A cross. section is shown in Figure 12. The maximal allowable electric field at the outside of the tubing determines the length of $120 \mathrm{~cm}$.

In Figure 12, the radiation pattern of a $450 \mathrm{GHz}$ signal from a $2 \times 6 \mathrm{~cm}$ waveguide at a distance of $120 \mathrm{~cm}$ is also plotted. Because the waveguide is operated in the $T E_{01}$ mode, the pattern width is similar in both 'ransverse directions. From the integrated power transmission it can be seen that $20 \mathrm{~cm}$ diameter tubing will allow $98 \%$ of the power to be transmitted.

\section{Power Supplies}

Figure 13a demonstrates schematically the arrangement of the FEM power supplies and the potential distribution in the beam line. The voltage of the anode power supply determines the beam current. For a well designed beam line, only a small fraction of the electrons is intercepted by the anode and the high voltage beam line. Consequently, both the anode and high voltage power supplies can be low currenh low cost supplies. Regulation requirements are also minimal, $2 \%$ for the amode supply to keep current variations within $3 \%$ and $1 \%$ for the high voltage supply. Voltage changes in the latter will shift the peak of the broad gain curve (Figure 2) but will not change the operating frequency which is given by the setting of the grating of the oscillator.

For the beam to be collected, the energy lost to radiation has to be made up by the collector power sypply. In this arrangement therefore, it is the collector supply, which also has to accomodate the full bearn carrent, who delivers the power converted into radiation. Operating in the multi-megaratt range, it is the most costly part of the FEM. Compared to power supplies of other microwave sources operating at similar power levels it is actually more cost effective because the regulation requirements are again low. Its voltage needs to be constant to within $1.0 \%$ of the high voltage of $2.69 \mathrm{MV}$ only, or to $27 \mathrm{KV}$, so that $10 \%$ regulation is sufficient. 
Figure $13 \mathrm{~b}$ demonstrates the arrangement of the collector power supply if a multi-stage collector for the example of Figure 3 is used.

High voltage power supplies in the muliti-megavolt range are commercially available. The Pelletron, manufactured by National Electrostatics Corporation, and used in the UCSB FEL ${ }^{5}$ has insufficient current ratings. The optimum choice for the TIBER-II FEM is the Dynamitron, built for electron beam systems used in materials processing and manufactured by Radiation Dysamics. It uses a cascading circuit operating at $10 \mathrm{kHz}$ as illustrated in Figuse 14. The high voltage rating depends simply on the number of stages and the current by the shield-to-electrode capacitance. $3 \mathrm{MV}, 50 \mathrm{~mA}$ supplies are catalog items. The current rating can, without any design changes, be increased to $100 \mathrm{~mA}$, which could make simultaneous operation of two electron beam lines with one high voltage power supply possible, reducing the cost of the system.

Figure 15 shows the layout of the main power supplies together with the $\mathrm{SF}_{6}$ pressure vessel containing the FEM. Because of internal structural constraints, the Dynamitron is operated preferentially in the upright position. The main power supplies and the FEM with the m:crowave transport and diagnostic facilities could then be positioned on separate floors. The magnetic wiggler of the FEM will be positioned in the center of the FEM pressure vessel. As indicated in Figure 15, one could add a second electron beam line, with the wigglers located parallel to each other and the acceleration and deceleration columns directed to opposite sides. With an increase of the shield-to-electrode capacitance of the dynamitron (Figure 14), the current can be boosted from the standard $50 \mathrm{~mA}$ to $100 \mathrm{~mA}$. Two electron beam lines located in one high voltage tank could then be operated from the same high voltage power supply, greatly reducing the system cost. 


\section{References}

1. Gary R. Smith, B. G. Logan, and A. H. Kritz: "Localized Electron Cyclotron Heating and Current Drive in the TIBER-Il Reactor Study." LLNL Internal Report 1987.

2. D. Arnush, H. Boehmer, M. Zales Caponi, and C.C. Shih: "Design of a High Power C.W. Free Electron Maser." Int. J. Electronies, 23,605 (1982).

3. E.T. Scharlemann: "Wiggler Plane Focusing in Linear Wigglers." LLNL Report \#UCRL-\$2429 (1985).

4. J. R. Hechtel: "A Novel Electrostatic Focusing Depressed Collector for Linear Beam Tubes." IEEE Trans. Electr. Devices, ED-24, 45, 1977.

5. L. R. Elias and G. Ramien: "Design of the UCSB FEL Electron Beam System." Physics of Quantum Electronics, 2577 (1981). L. R. Elias, G. Rausian, J. $\mathrm{Hu}$, and A. Amir: "Observation of Single Mode Observation in a Free Electron Laser." Phys. Rev. Letters, 57,424 (1986).

6. K Halbach, et al:: "CSEM-Steei Hybrid Wiggler/Undulator Magnetic Field Studies." IEEE Trans. Nuel. Se., NS-32, 364 (1985).

7. H. Boehmer, M. Zales Caponi, and J. Munch: "A Free Electron Laser Experiment", in Free Electron Lasers, S. Ma:tellucci and Arthur N. Chester, Ed., Plenum Press, Ner. York, 1983, p. 541. 
Suggested list of TRW contributors for the cover page:

H. Boehmer

B. Hauss

M. Lampel

H. Agravante

R. Campbell

T. Christensen

T. Samec

T. Smith

C. Wagner 


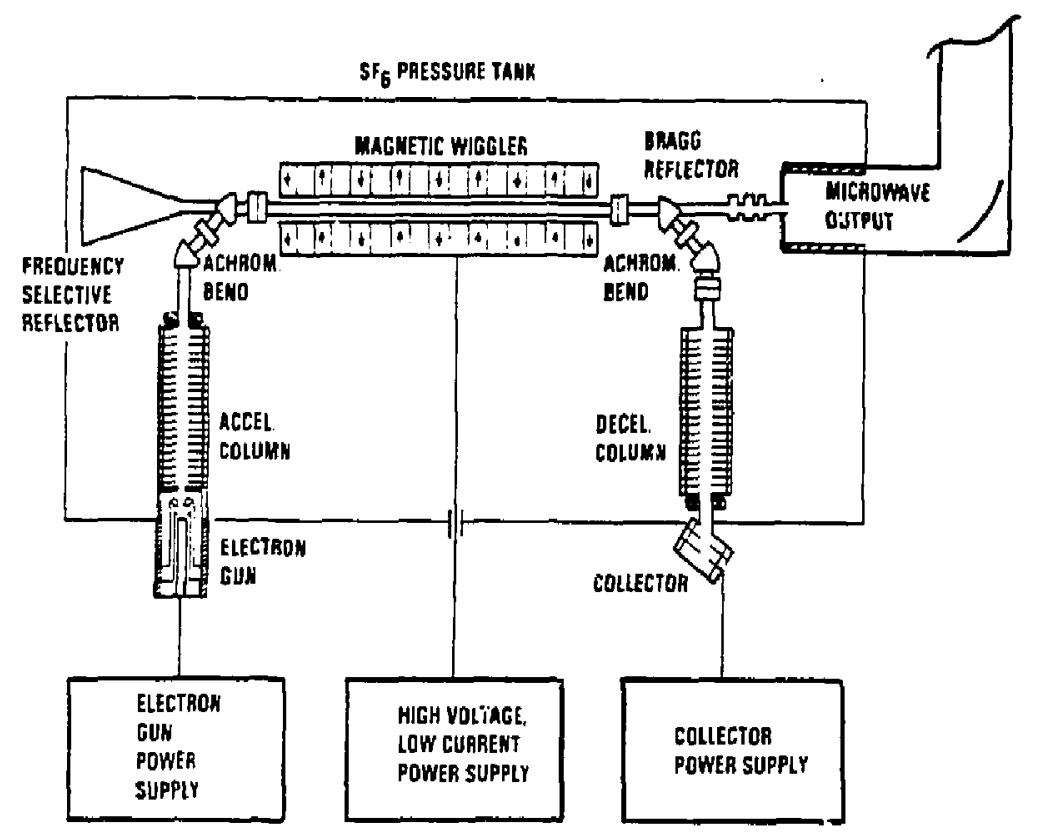

Figure 1. Schematic of a 2 MW Free Electron Maser Module for TIBER-II 

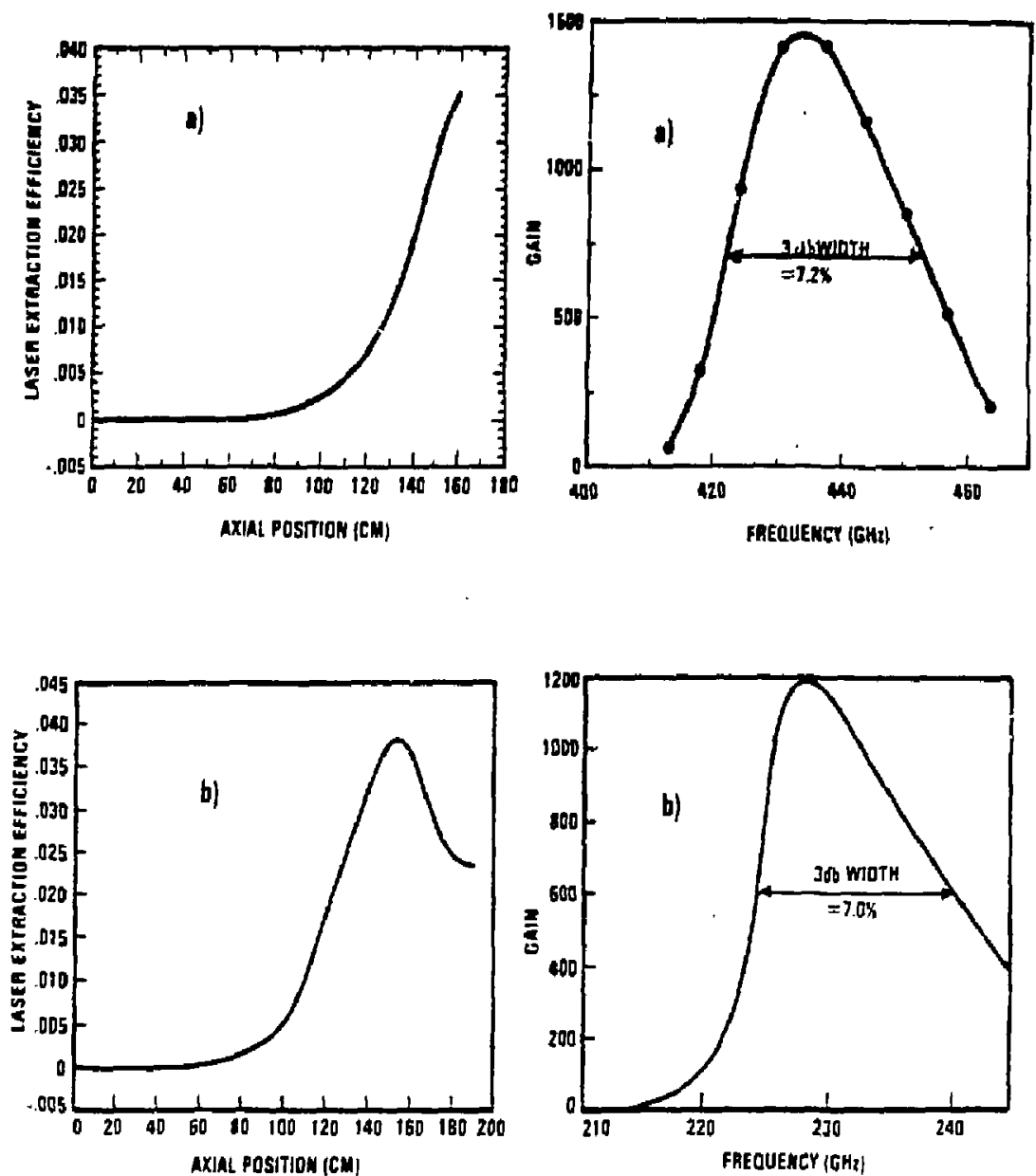

Figure 2. Modeling Results for TIBER-11 FEM

a) Operation at $450 \mathrm{GHz}$ with $2.69 \mathrm{MV}$ beam,

b) Opertition at $225 \mathrm{GHz}$ with $1.88 \mathrm{MV}$ beam, all other parameters as in Table II 


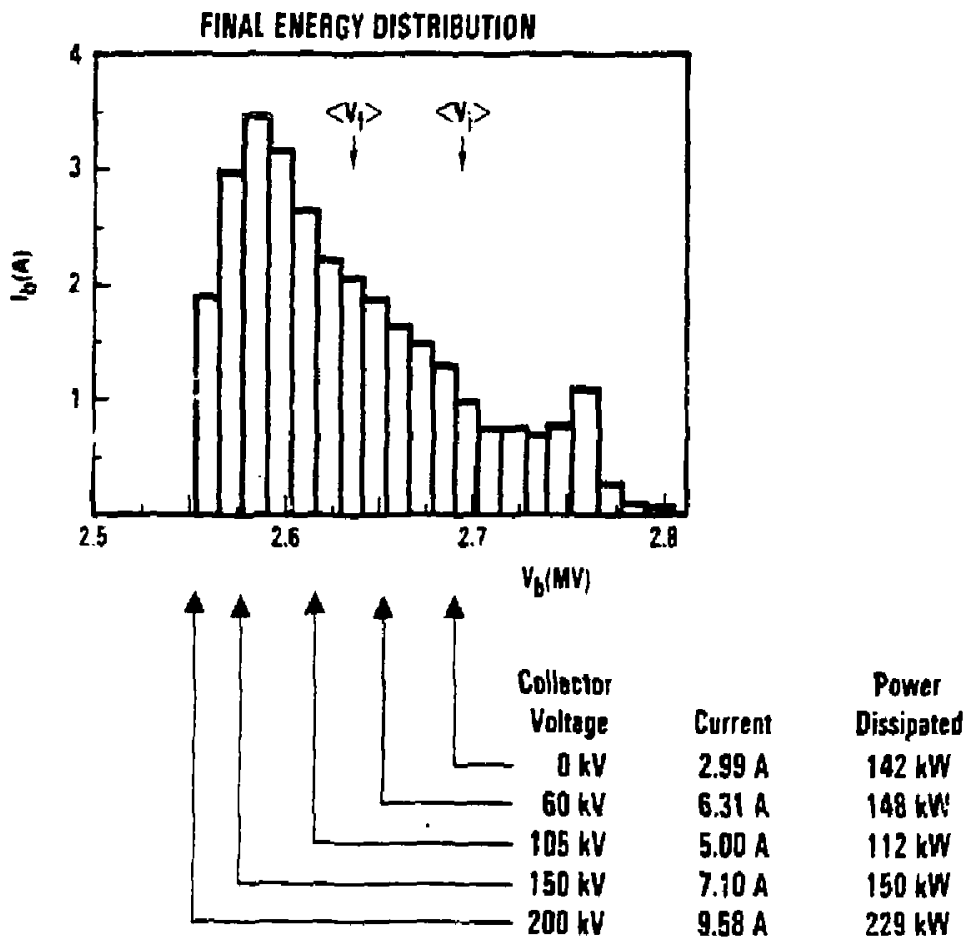

Figure 3. Energy Distribution of the Spent Electron Beam for the Case of Figure 2a). Also Indicated Are Voltuges, Currents and Power Dissiputed in the Plates ol an Assumed 5 Stuge Depressad Voltsge Collector 

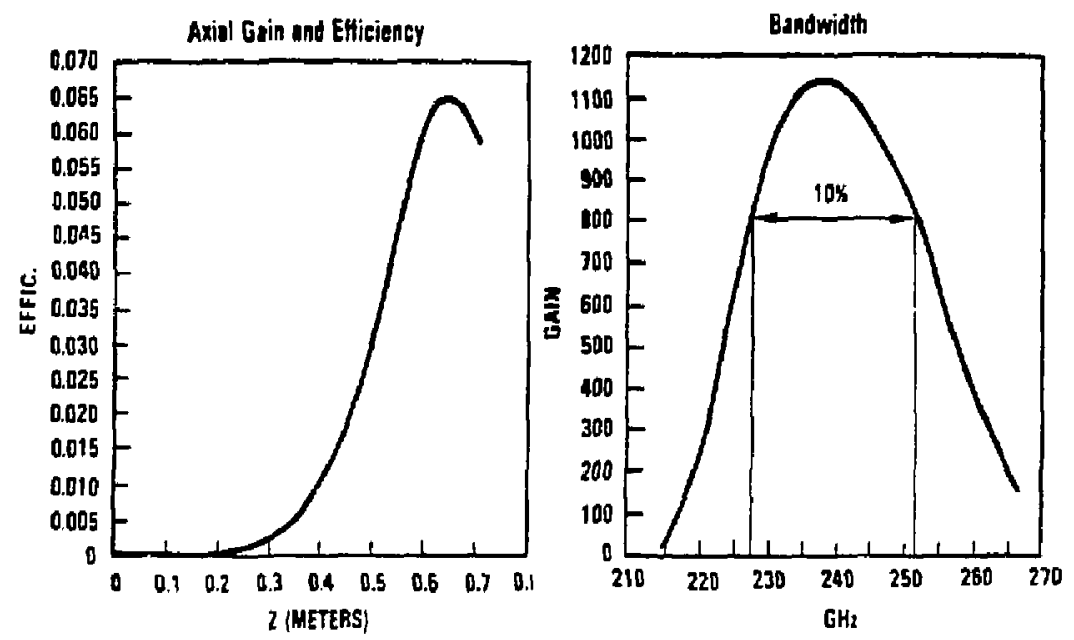

$$
\text { Beam: } \begin{aligned}
V & =2.36 \mathrm{MV} \\
I & =40 \mathrm{~A} \\
I & =1.5 \mathrm{~mm}
\end{aligned}
$$

$$
\begin{array}{r}
\text { Wiggler; } \lambda_{w}=5 \mathrm{~cm} \\
B_{w}=2 \mathrm{kG} \\
\text { Lin. Polur. } \\
\text { Untapered }
\end{array}
$$

Waveguide: 3 I $6 \mathrm{~cm}$ TE 01 made Input power: $5 \mathrm{~kW}$

Outpui power: $5.7 \mathrm{MW}$

Figure 4. Efficiency and Bandwidth al the High Power FEM for TIBER-I Operating at $240 \mathrm{CHz}$ 


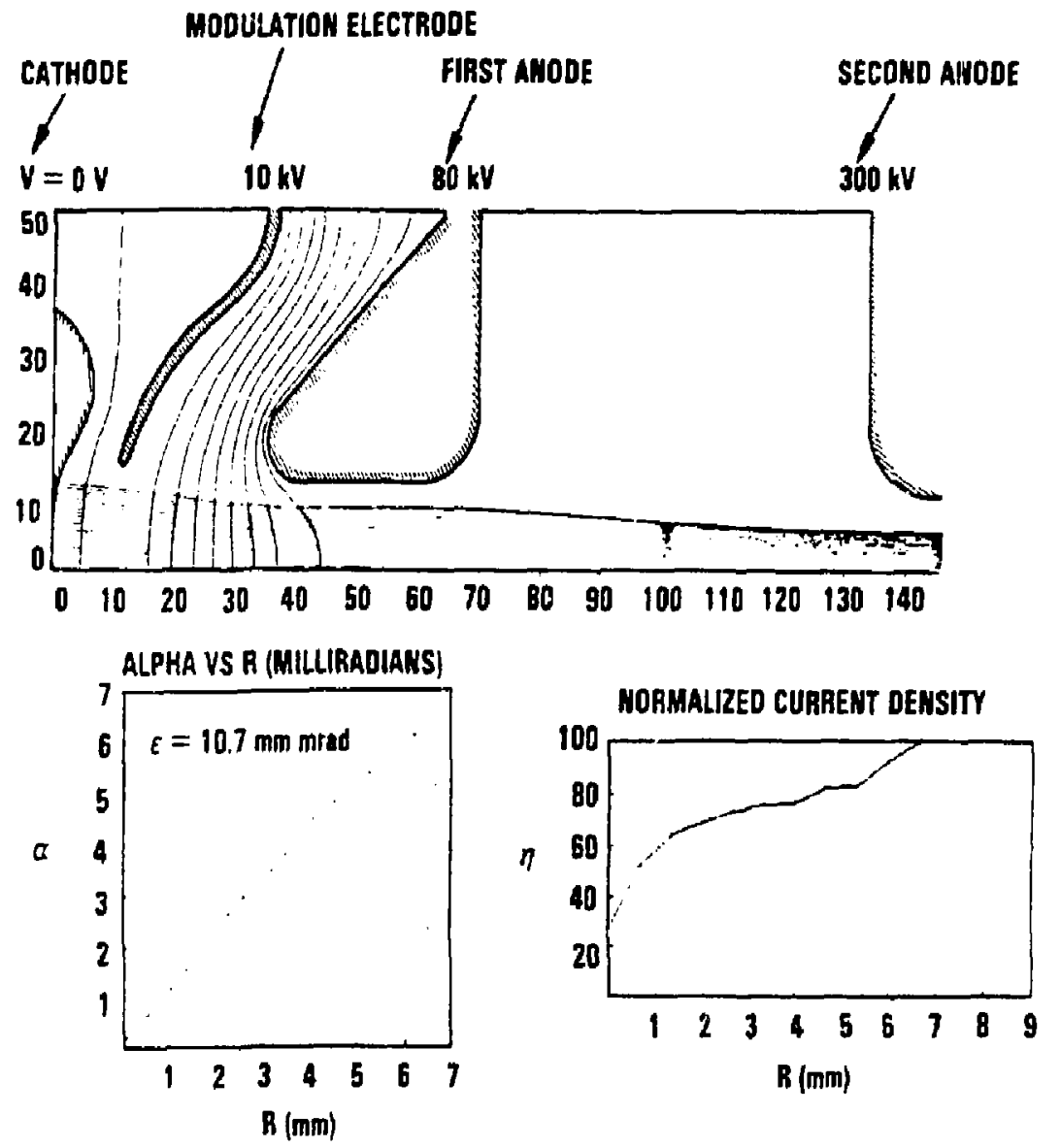

Figure 5. Electron Gun of the TRW FEM Showing Eloctrode Configuration. Beam Orbits, As Well As Phuse Space and Radial Current Density Distributions at the Gun Exit 


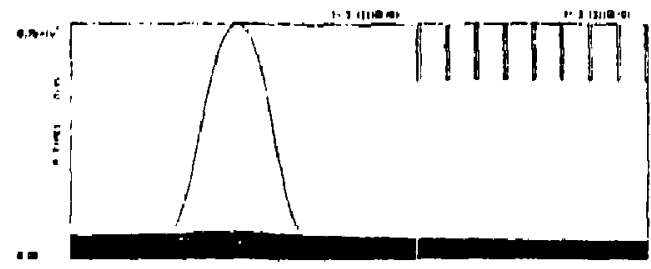

FIRST FOCUSING SECTION $(B=515$ G) AND AOJACEAT ACEELERATOR STAGE
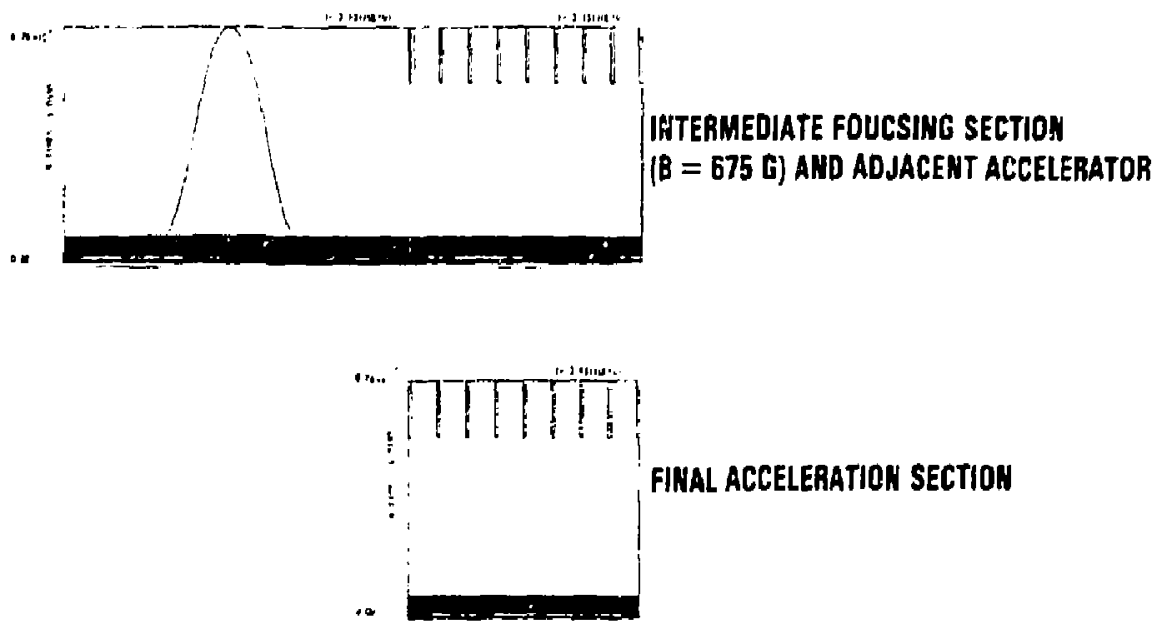

Figure 6a, Electron Beam Orbits In Accaleration Column. No Beam Current is Lost in Transit
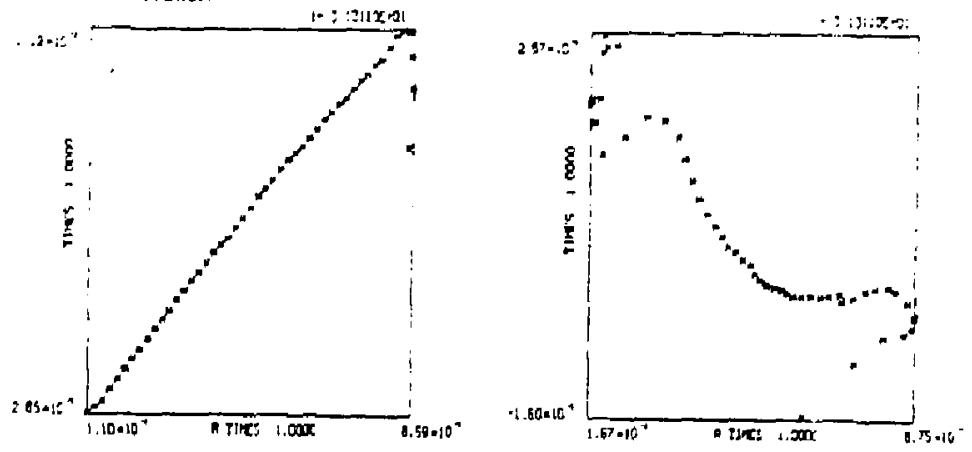

Figure Sb). Initial (Lefi) and Final (hight) Phase Space 

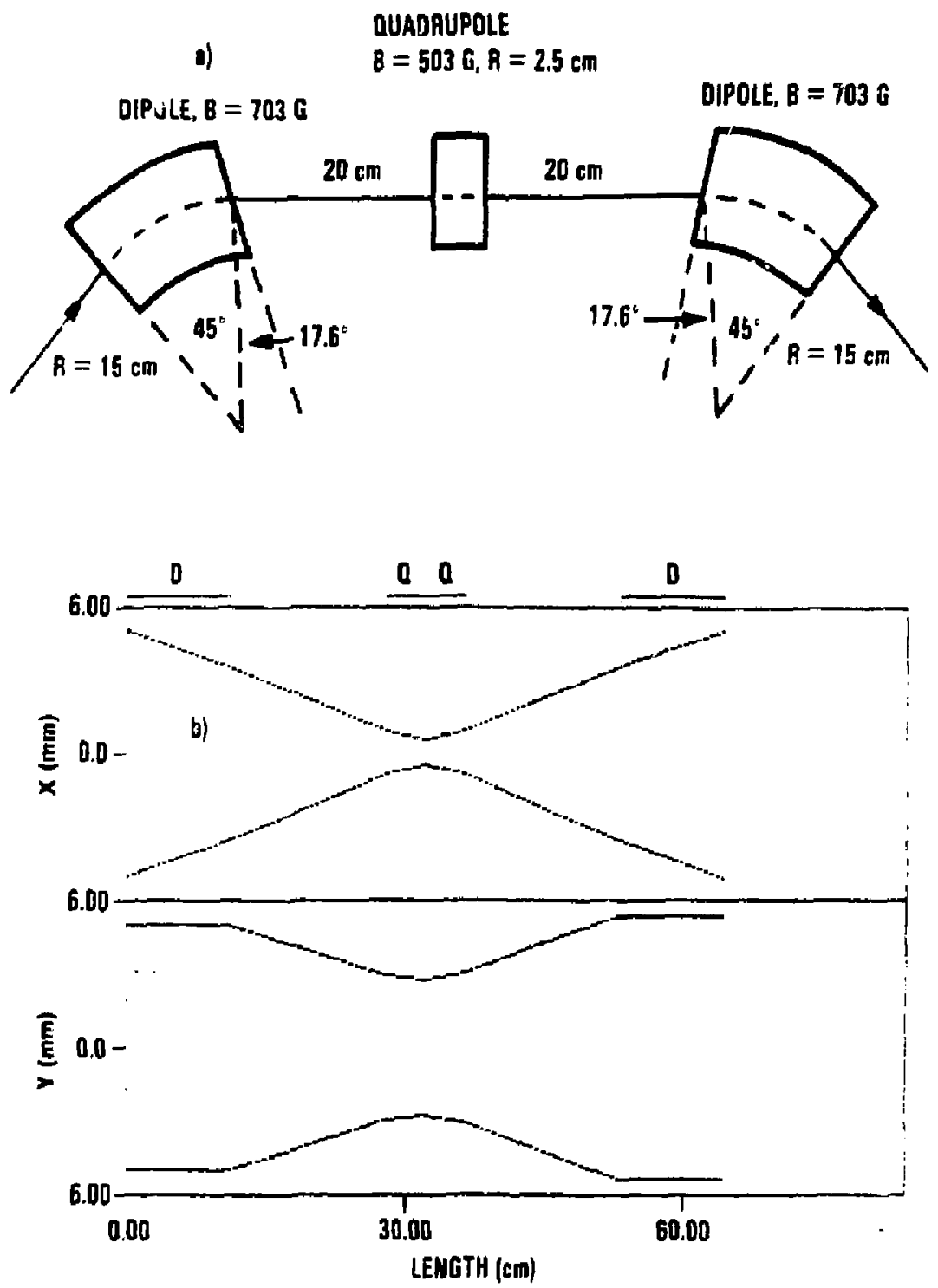

Figure 7. 180' Achromatic Bend. a) Configuration b] Beam Envelope in Bend and hon-Bend Planes of a 2.69 MV Beam With $5 \mathrm{~mm}$ Initial Radius 


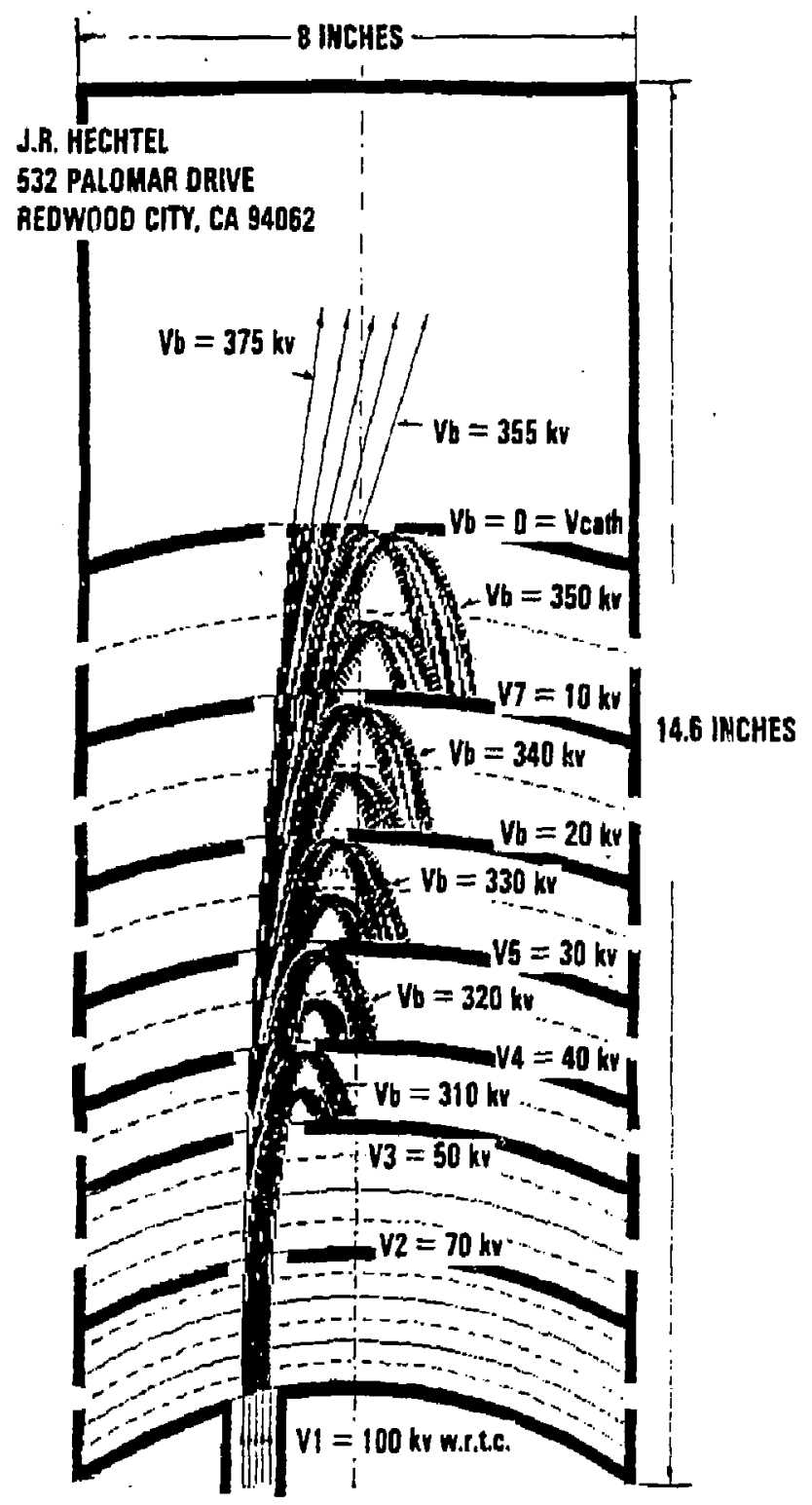

Figure 8. Cross-Sectional View of the Multi-Stage Depressed Voltage Collector for the TRW FEM. Design: R. Hechtel 


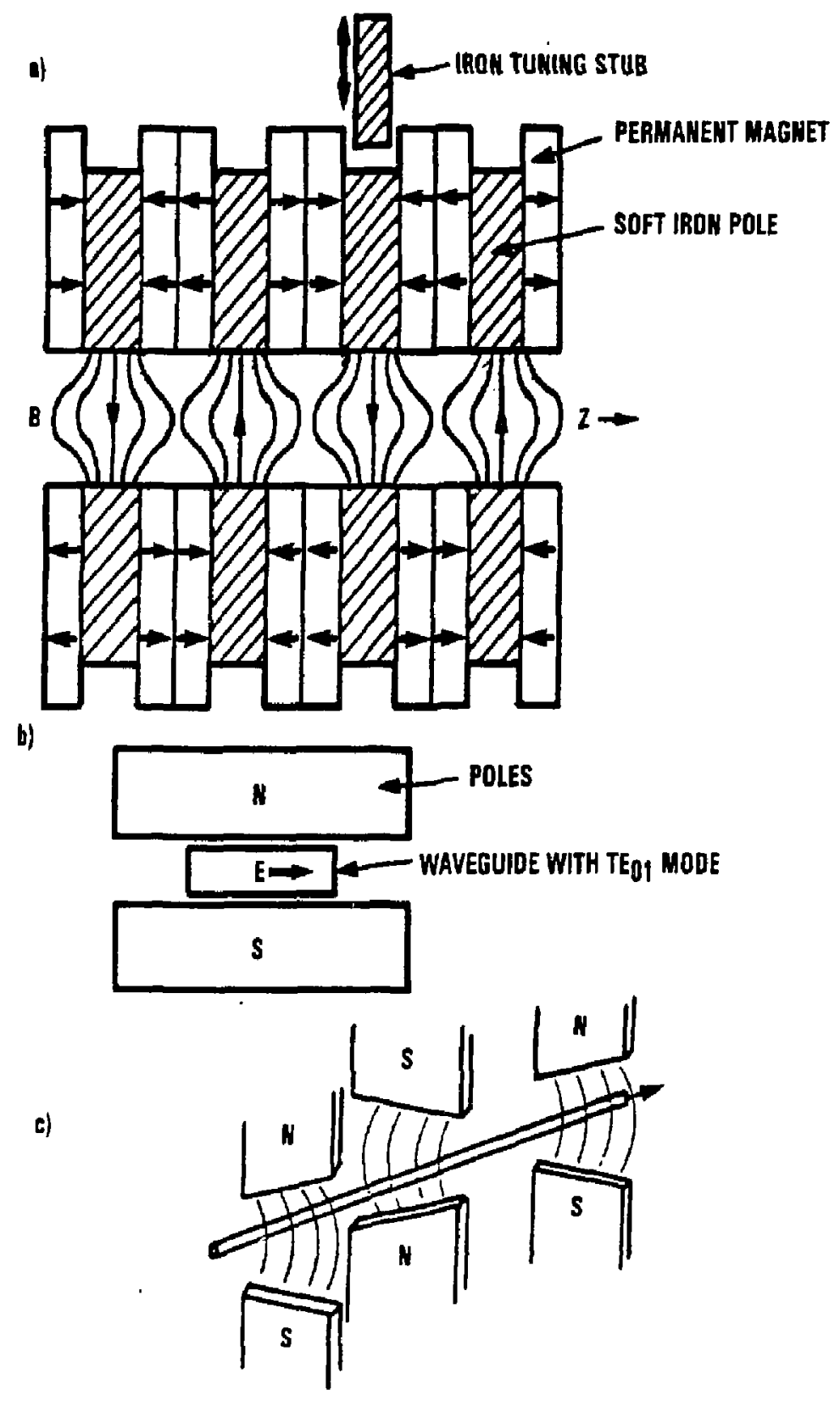

Figure 9. a) Schomutic of a Hporid Wiglot

b) Wiggler Cross-Section with Waveguide

c) Alernate Canting of Pole Faces for Transverse Focusing 


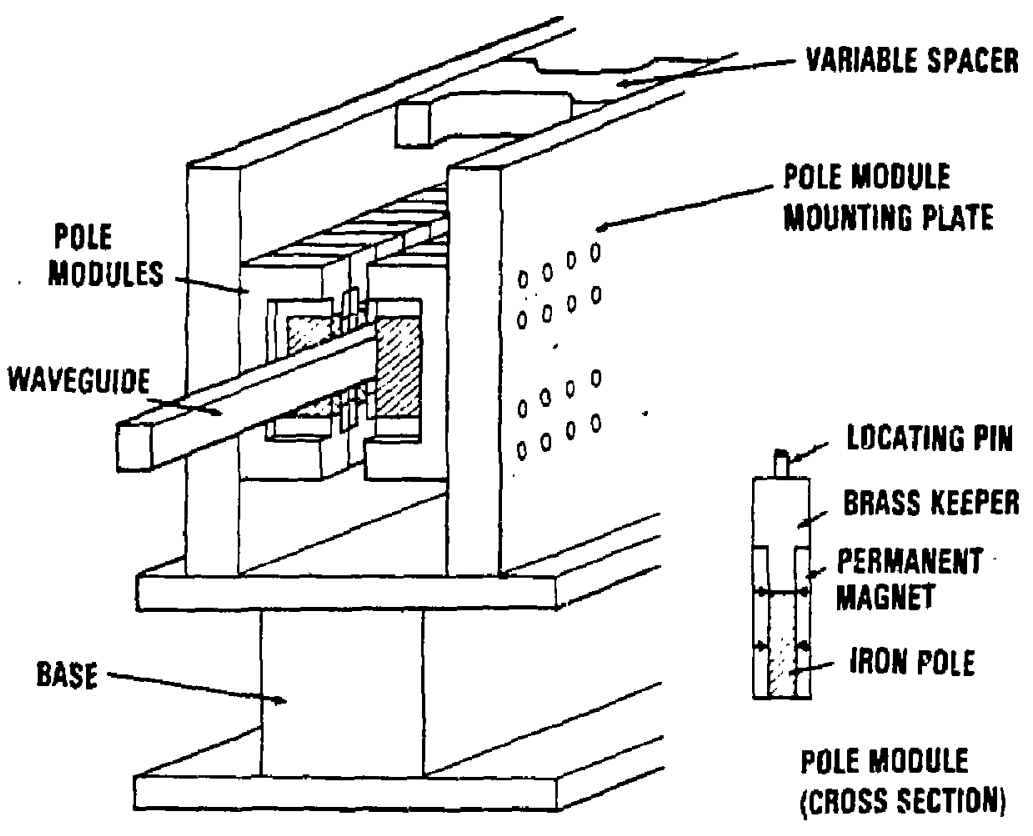

Figure 10. Schematic of Wingler Assembly 


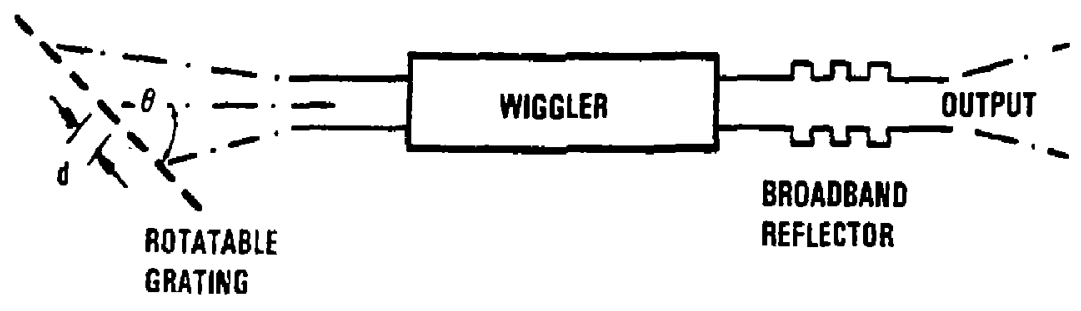

Figure 11a). Tunable Oscillator Operation With Broadband Output Reflector and Input Grating

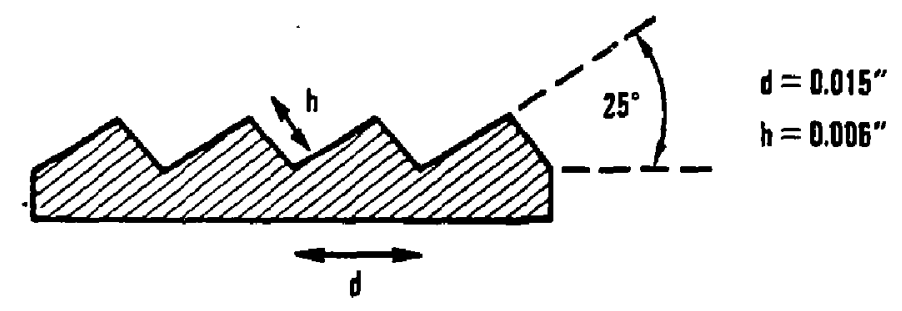

Figure 11b), Grating Dimensions lor 450 GHz. Power Optimized Into First Order 

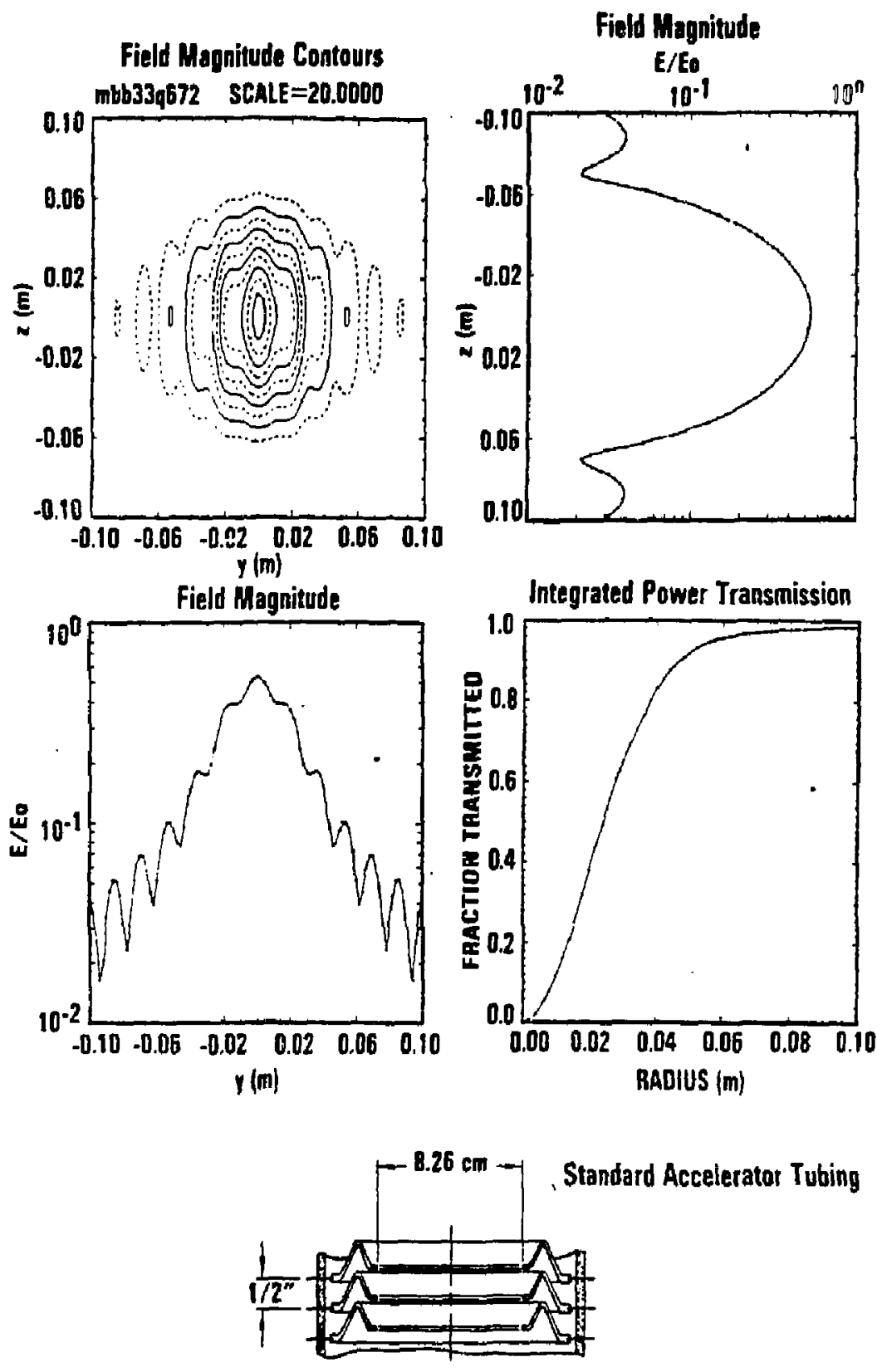

Figure 12. Radiation Pattern of the $450 \mathrm{GHz}$ Microwave Sighal From a $2 \times 6 \mathrm{~cm}$ Wayeguide Operated at the TE01 Mode, Observed at a Distnnce of $120 \mathrm{~cm}$. Standard Accelerator Tubing Can Be Used for Power Transmission from High Voleage to Ground 


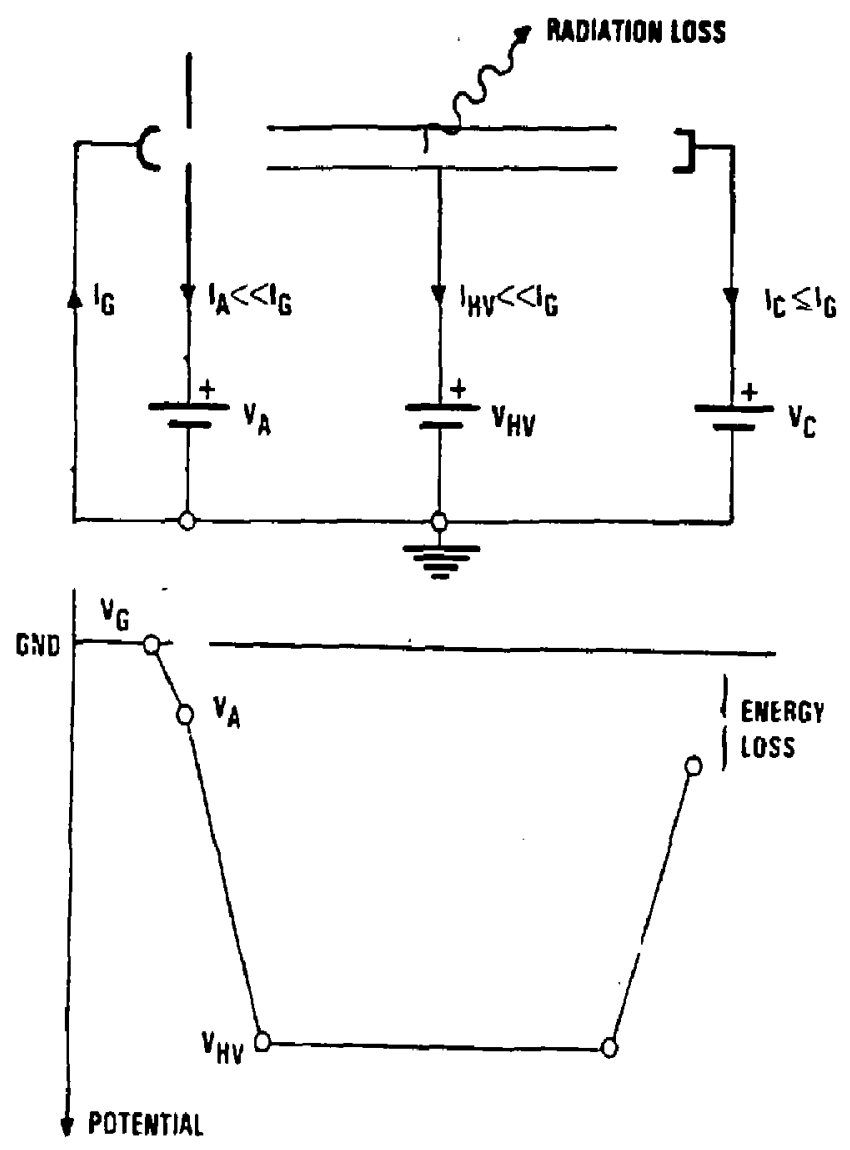

Figure 139). Principle of Operation and Potential Distribution of Electron Beam Line With Energy Recovery

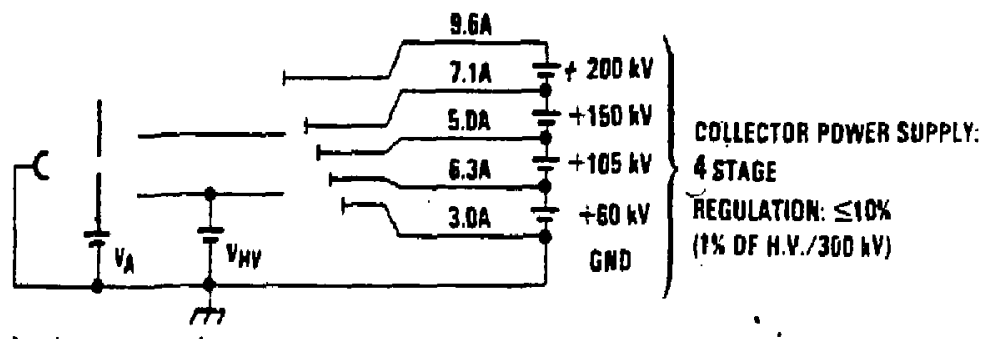

Anode power supply:

$V_{A}=100 \mathrm{kV}, 1 \leq 10 \mathrm{ma}$

regulation: $\leq 2 \%$ (10 $\Delta \mathrm{l} / / 1 \leq 3 \%)$

Figure 13b). Operation with Multi-Stage Collector 


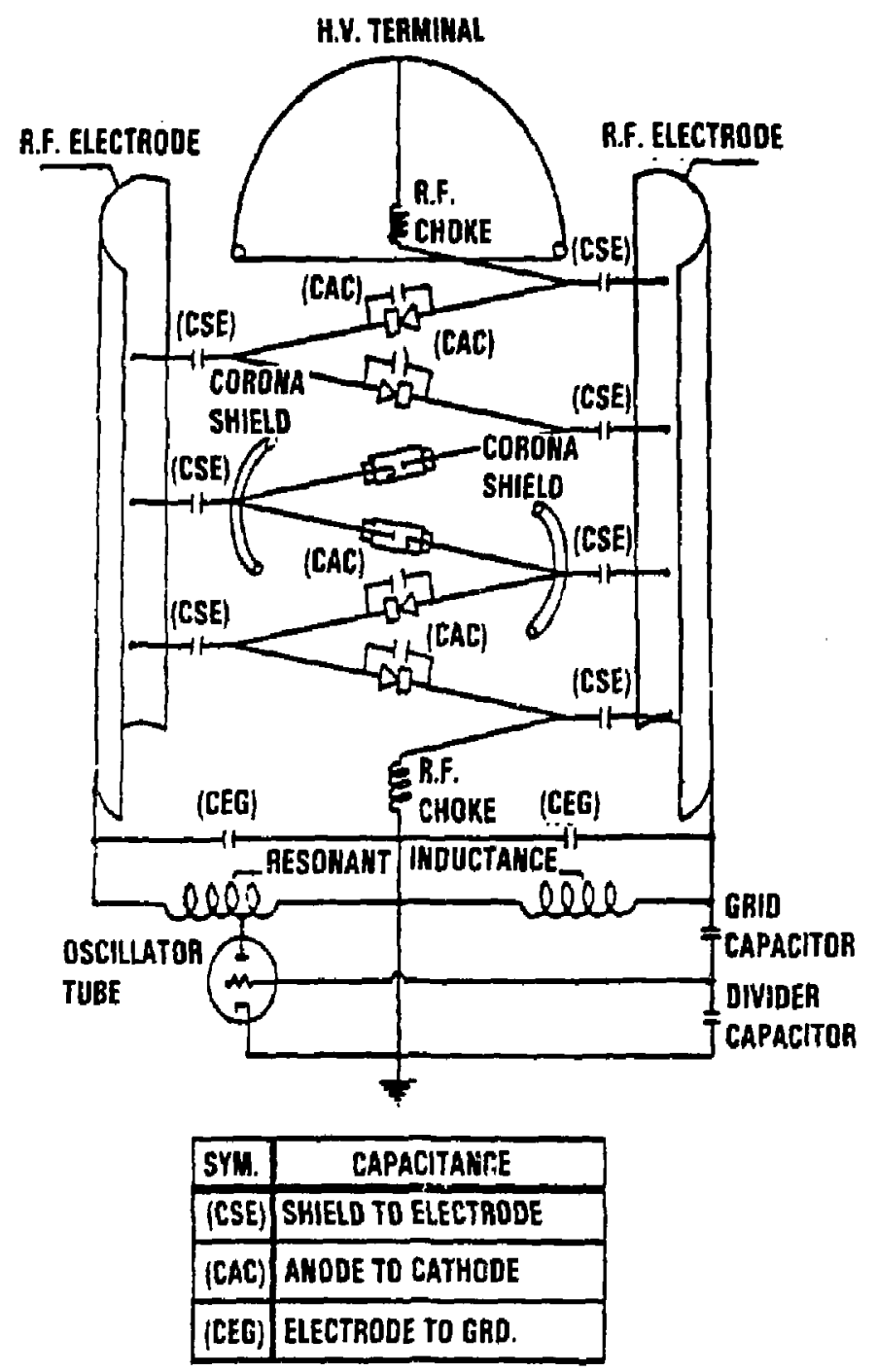

Figure 14. Schematic Dizgram of a Dynamitron Cascade Circuit 


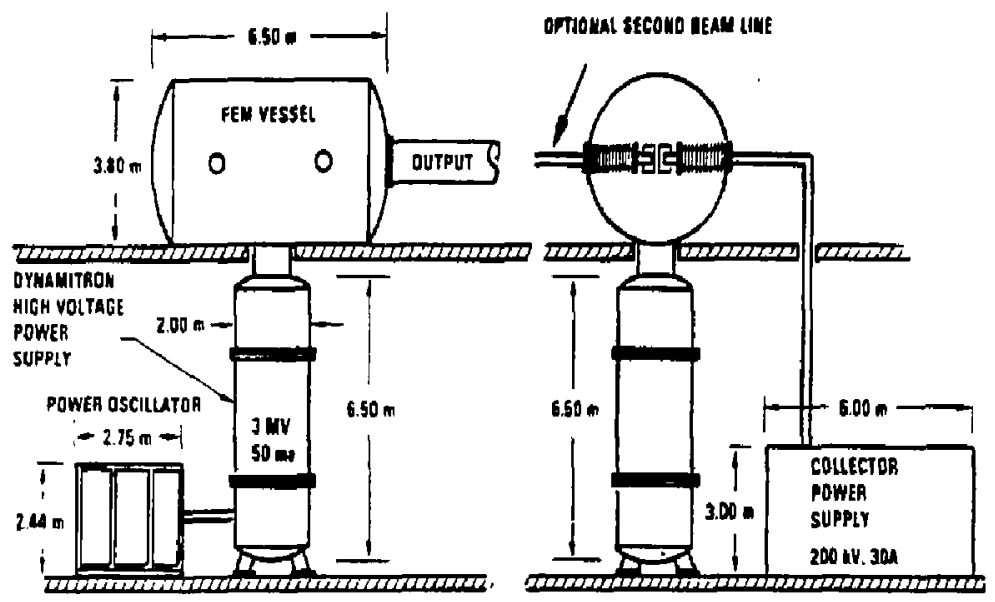

Figure 15. Layoul of the 2 BW TIBER-II FEA Showing the High Voltupe Tank, High Voltage and Collector Powor Supplies. Two FEM Beam Lines Could be Operated in One High Voltage Tank 


\title{
PART 4A
}

\section{ADDENDUM TO FREE ELECTRON LASER REPORT}

\author{
CONTRIBUTORS: H. BOEHMER \\ B. HAUSS \\ M. LAMPEL \\ H. AGRAVANTE \\ R. CAMPBELL \\ T. CHRISTENSEN \\ T. SAMEC \\ T. SMITH \\ C. WAGNER
}


FREE ELECTRON MASER FOR TIBER-II

ADDENDUM TO FINAL REPORT 


\section{TABLE OF CONTENTS}

PAGE

1. Introduction 1

2. hoceleration Column 1

3. Achromatic Bend 2

4. Deceleration Column 2

5. Mult1-Stage Depressed voltage Collector 2

6. Conclusion 5

7. References 5 


\section{Introduction}

As part of the TIBER.II developpent program, a conceptual design of a C.W. Free Electron Maser (FEM) was performed. The FEM is Intended as a source of microwaves for suppression of disruption in the Tokamak reactor via ECRH. 2 WW units at 450 and $225 \mathrm{GHz}$ were considered. Apart from the modeling of the Fay Interactions which w11 determine the baseline parameters of the syster, the most critical and time consuming part is the proper design of the electron beam line. Because of a late start of the FEM part of the ILBER-II program not all beam line calculation, particularly the design of the high power depressed voltage electron beal collector, could be done in time for the preparation of the flnal report, necessitating this addendur to the wain report.

\section{Acceleration Column}

The acceleration and deceleration columns were designed and the electron beat trajectories and the phase space distribution of the electrons were calculated using the EBQ-code. As discussed in srction 4.2 and Flgure 6 of the final report, two solenoldal focusing lenses, one at the beginning and one in the center of the acceleration colum were necessary to overcome the defocusing space charge forces. During further investigations it was found, that the number of mesh-points used for the EBQ-code in the acceleration modules was not quite sufficlent for a correct calculation of the space charge forces. To remedy this, the accelerator module gize was reduced from 8 to 4 acceleration apertures. For the same reason, the radial scale of the printout of the beam orbit in the solenold (Figure $1, \& c$ ) and acceleration section (Figure ib \& d) are now different. The beam shows an excellent lawiner flow, the beam density distribution at the end of the accelezation colum is flat (Figure $\mathrm{lg}_{\mathrm{g}}$ ) and the phase space (Figure Ih) is improved over the previous calculation. 


\section{Achromat1c Bend}

The geonetry of and the bean onvelcpe in the achrometic bends was shown In Figure 7 of the final raport. In Flgure 2 of this addendum the microscopic beam behevior is illurtrated by the output of PAREELA-code calculations. The perticlo donsity in phase and real space can be seen to remain uniform throughout the syatem. the outfut beam diameter reasins about $1 \mathrm{~cm}$ which means that the assumed gap apacing of $2.5 \mathrm{~cm}$ of the dipole magnats is stefficlent. The transverse emittance growth is $c_{x}-16.5 \pi$ arad and $c_{y}-5.3 \pi$ and arad.

\section{Deceleration Columan}

In the decelerstion column, the electron energy is changed from the initial $2.69 \mathrm{kV}$ to $400 \mathrm{kV}$ at the input of the multi-stage beam collector. As ' en from Figure 3 of this addendum, this colum is the mirror lagae of the acceleration column, with solenoidal focusing fields halfway through and at the 1 d of the coulumn. The positioning of the magnetic lenses at lox and intermediate energies in both columns reflect the fact that at these points space charge is more important compared to high energles. Again, the bear flow is laminar, the output density distribution flat and the angular divergence snall remaining between -21 and +1 mrad.

\section{Multi-Stage Depressed Voltage Collector}

The dp-rressed voltage beam collector is an asserctal element in the design of a C.W. FEY as detailed in the IIBER.II FaH report. Its design will 1mpect the sapital cost via the high power power supplies necessary to operate the collector and operating expenses via the toal system efficiency.

Depressed voltage bear collectors have been used extensively to boost the toal efflolency of olcrowave tubes. Inear beam tubes, like the traveling wave tube (TWT) and the FEM are particularly adaptable to bean eaergy recovery. The 1mportance of efficiency in satellite borne TW's has matured the technology to routine applications of the 
concept. In the wid 70th, R. Hechtel(1) developed atw mult1-stage collector configuration that used hyperbalic focusing surfaces for beam trajectory shaping and electron collecting. This collector type has been proven to 1) have a far superiar collectlon efficlency over unfform facusing and parabolls defocusing types of retarding flelds and 2) successfully suppresses seconiary electrons from propagatirg back in the retarding fleld. The collector design has become reliable to a degree that manufactured collectors deviate in thelr coliection efficlency by most 1.2 from the design value.

It sinould be noted that the task of designing a mlti-stage collector is considerably simpler and the resulting efficlency higher for a FEM beam in comperison to a TWT beam since the bean energy spread of 158 and angulas bean divergence of $1.6^{\circ}$ (21 mrad) is wuch smaller than the energy spread of a TWT beam which can be as large as 50 ind $20^{\circ}$ (300 mrad) respectively.

The multi-stage collector design was performed by $R$. Hechtel while a TRW consultant. The following system parameters vere used, corresponding to the FEM code calculations detalled in Table II and Figure 2 of the IIBER.II final report:

$\begin{array}{ll}\text { Beam Current } & 30.0 \mathrm{~A} \\ \text { Initial Beam Voltage } & 2.69 \mathrm{wN} \\ \text { Extraction Efficlency } & 3.68 \\ \text { RF Power Output } & 2.92 \mathrm{HW}\end{array}$

Longltudinal beam energy distribution sa Figure 3 of the ortginal report.

The geometrical configuration of the collector, equipotential lines and electron orblts belonging to selected energy bins are shown in Figure 4. The ideally byperbolfc collector plates are approxioated by spherical surfaces to faciliate fabrication of the device. The beam enters the collector off the axis of symetry to force the beam Into favorable orbit. Evidently, wost of the electrons are collected at the back side of the collector plates elfminating backstreaming of secondery electrons.

Like in any tube generating microwave power with electron benms, a 
Fraction of the lectrons te accolerated beyond the fritial energy of, in this cass, $2.69 \mathrm{nv}$. In the low power case of the TRU FEM colloctor decalled in Figure 10 of the original report these electrons vere simply allowad to dissipato thatr onargy at ground potential. In the high power case of the TIBER-II FEM, a fraction of this energy is retrleved by two collector plates blased $-30 \mathrm{kV}$ and $-65 \mathrm{kV}$ below the cathode potentials.

The current collected, power recovered and dissipated on each plate is tabulated in Flgure 5. From these numbers one calculates the collector efflclency to be 99.62 . Frow past experfence with manufactured collectors, the actual recovery efficlency ( $\eta_{R}$ ) is estimated to be $97 \%$. With a predicted extraction efficiency of $\eta_{E}$ 3.6 one calculates from

$$
\eta_{T}=\frac{\eta_{E}}{I-\eta_{R}\left(1-\eta_{E}\right)}
$$

a total FEM efficiency of $\eta_{\mathrm{T}}=55 \mathrm{t}$.

The total electron beam power dissipated in the collector plates is $298 \mathrm{kh}$. While this a small fraction of the microwave output power of $2.9 \mathrm{MW}$, it represents still an engineering problem to supply sufficient cooling. The design code calculations shoved that the peak power deposition density $1 \mathrm{~s}$ about $1 \mathrm{~kW} / \mathrm{cm}^{2}$. While this, compared to power loading in neutral beam dumps, is stlll a manageable value, it can be reduced by the following modifications:

1. Substitute the cylindrical, 2-didensional plates for the at present shperical plates. As a result, the beat will be focused in the $x-z$ plane only and expand in the $y$-direction.

2. Convert the present circular cross-section of the beam Into a ellipical one. This can be done by substituting a quadrapole focusing magnet for the solenoldal magnetic lens at the end of the deceleration coluan.

While the wulti-stage collector for the IRW FEM described in 
Figure 20 of the original report is the final design that can be used for aechanical design and conttruction, the design of the collector shown on Figure 4 of this addendum is preliminary. As discussed sabove, change in the cross-sectional shape of the beam can decrease the density of power deposition. Furthermore, engineering requirements related to vacuum housing and cooling wight require design changes.

\section{Conclusion}

The FEY design detalled in the TIBER. II and in this addendum to the final report shows that a.w. microwave source based on the FEM principle with electrostatic accelerator and depressed voltage beam collector is a feasible choice for ECH in TIBER-II. Both second harmonic and fundamental heating are considered. Only standard technology is used in the design. With a total efficiency of 558 at $450 \mathrm{GHz}$ and $2.9 \mathrm{MH}$ output power, the FEM should be a cost effective component of the IIBER.II reactor.

\section{References}

1. Hechte1, 3.R., IEEE Trans. Electr. Dev., ED24, 45 (1977) 

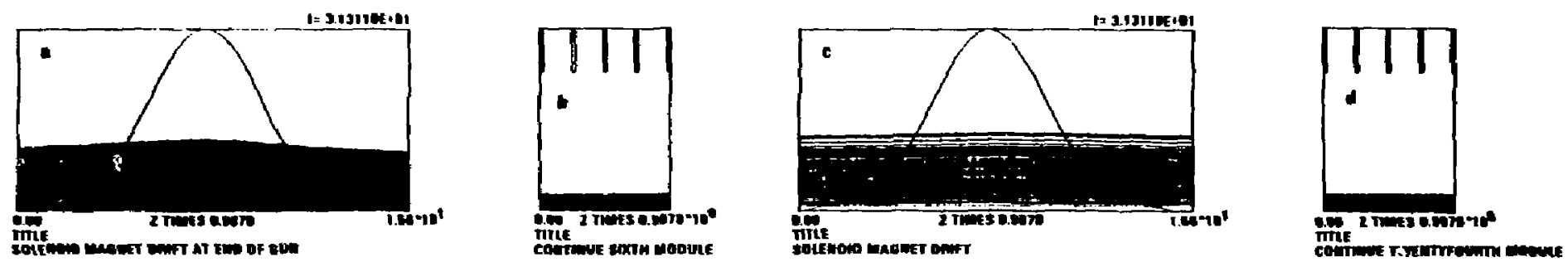

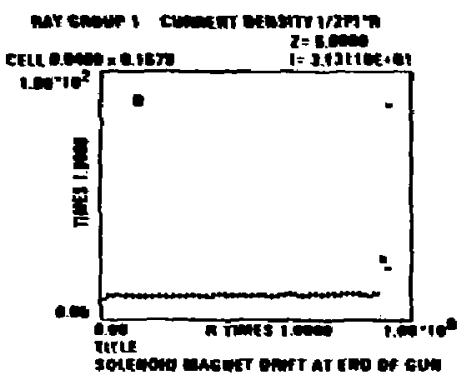

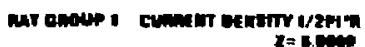

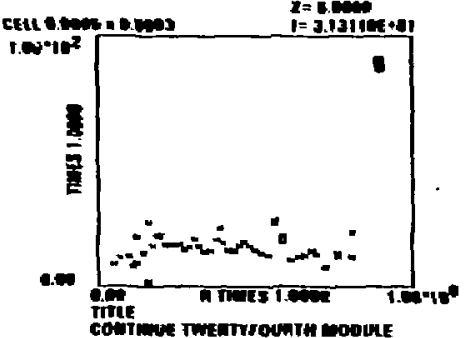

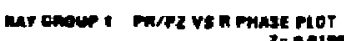

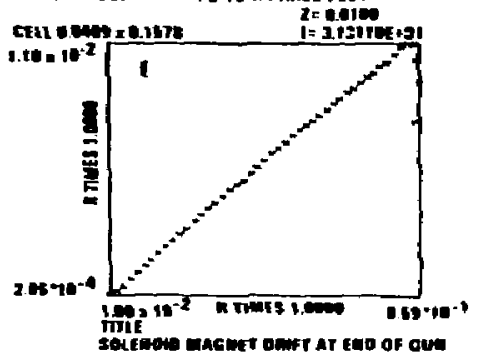

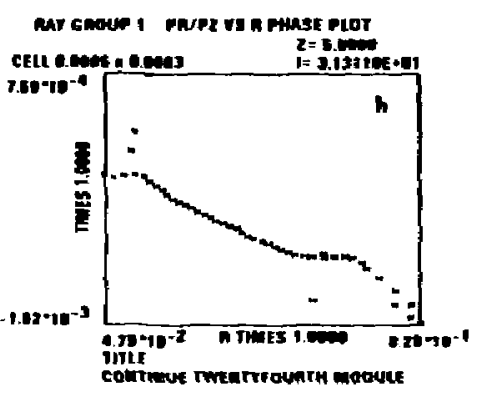

Figure 1. Electron Beam in Acceleration Column.

Beam Orbits are Shown in a) Initial Focusing

Solenoid, b) Intermediate Acceleration Module,

c) Infermetriate Focusing Solenoid, d) Final

Acceleration Moduls. A Total of 24 Acceleration

Modules are Used. The Aadial Scales are Difficult for the Solenoid and Acceleration Sections. e) and b) Initial and g) and h) Final Current Density Distribution and Phase Space. 

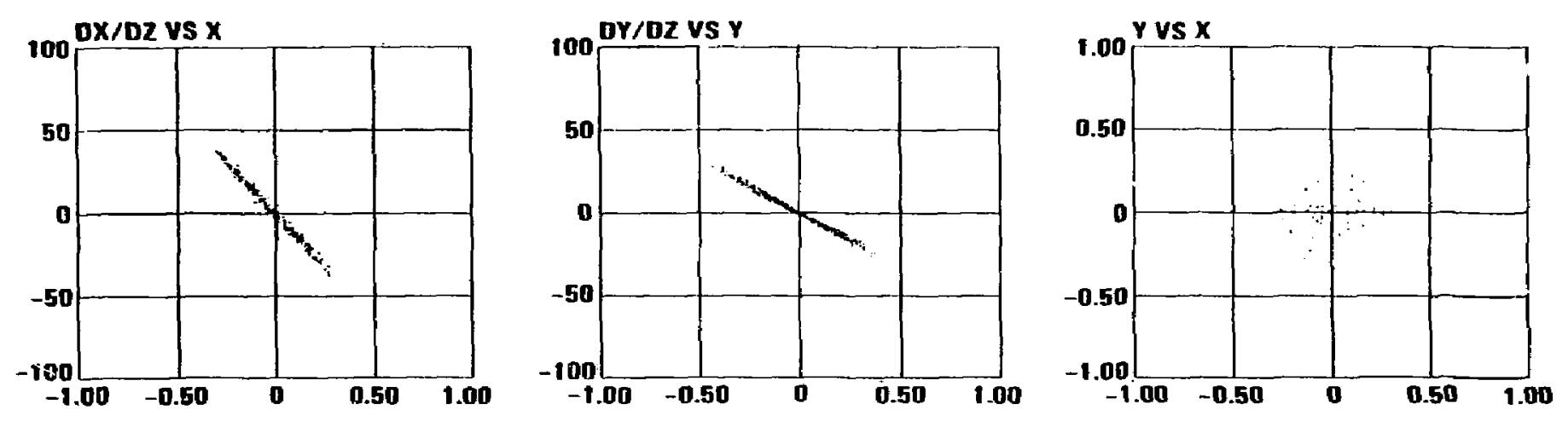

$-\sqrt{ }$
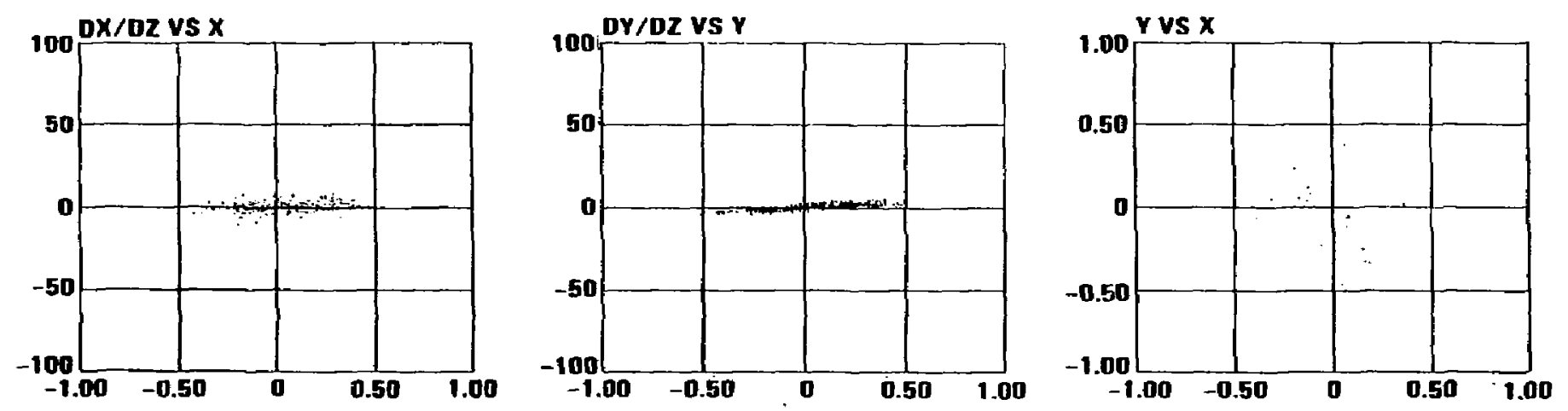

Figure 2. Beam Transport Through Achromatic Bend. Transverse Phase Space and Spatial Particle Distribution at End of First Dipole (Upper Three Panels) a id at End of System (Lower Three Panels) 

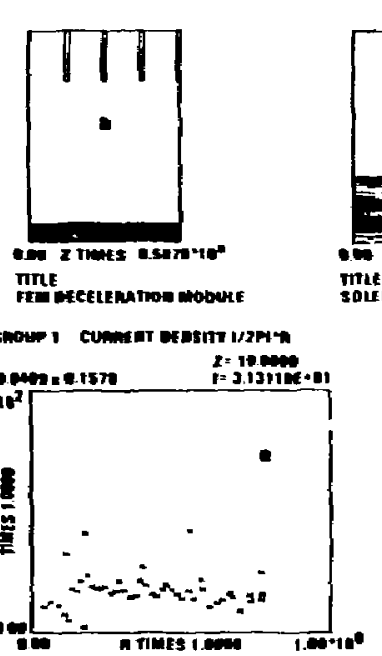

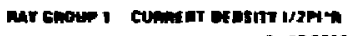

$\infty$

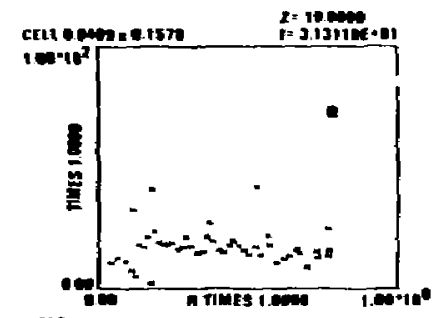

Trit:
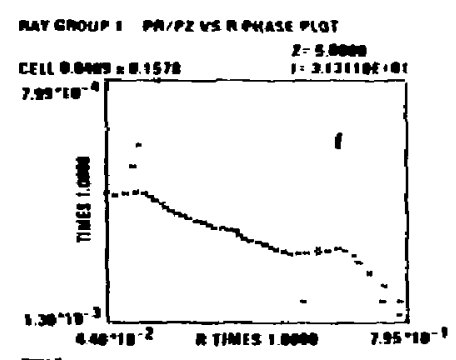

SOLEF

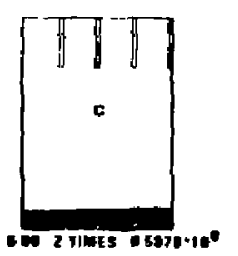

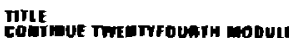

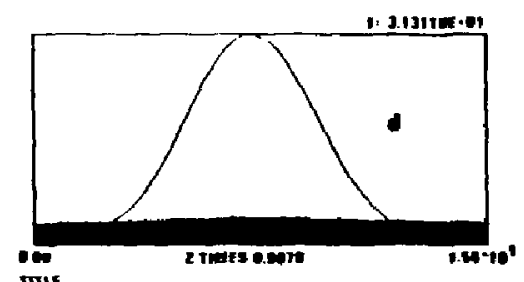

Tilf
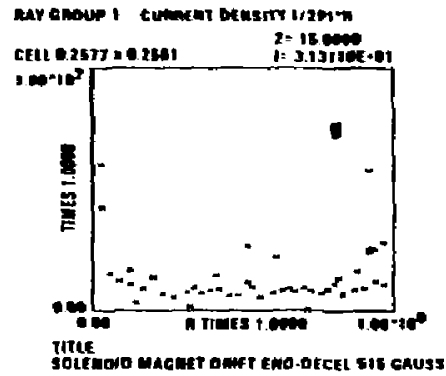

mar chaup 1 more vs a phese mor
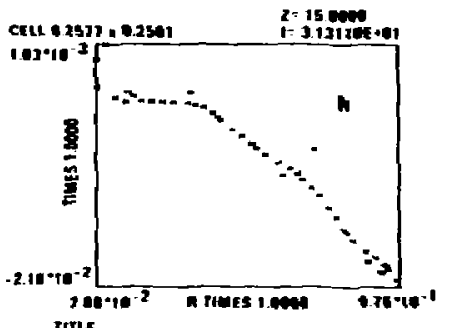

SOLLF
Figure 3. Electron Beam in Deceleration Column. Beam Orbits are Shown in a) Initial Deceleration Modula, b) Intermediate Facusing Solenoid, c) Intermediato Deceleration Module, d) Final Focusing Solenoid. A Total of 24 Deceleration Modules are Used. The Radial Scales are Different for the Deceleration and Solenoid Sections. e) and $f)$ Initial and g) and h) Final Current Density Distribution and Phase Space. 


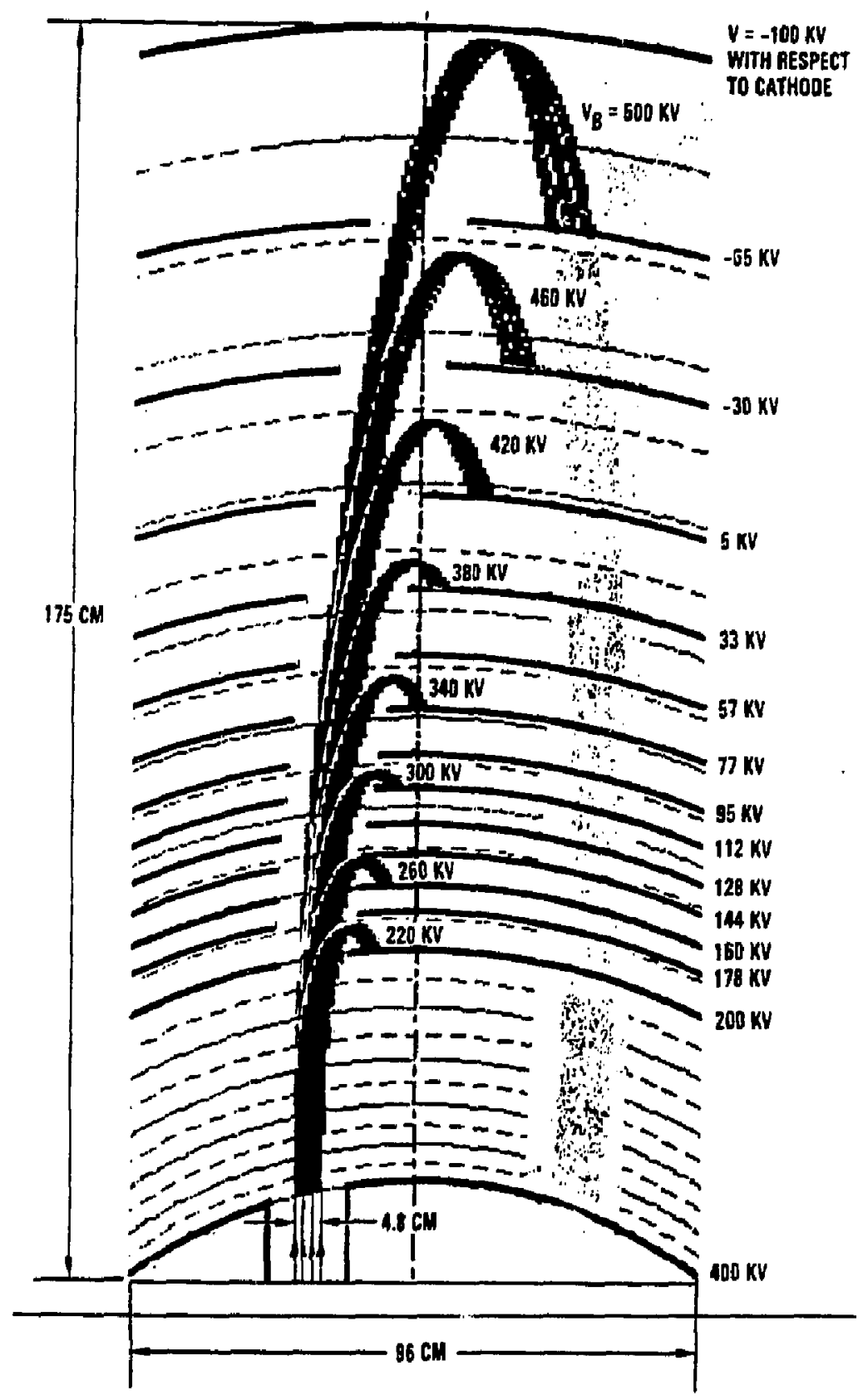

Figure 4. Schematic Cross-Sectional Viaw of High Power Multistage Depressed Voltage Collector for the TIBER-II FEM. Maximum Power Dissipation is $1 \mathrm{kw} / \mathrm{cm}^{2}$. Design by R.Hechtel, Redwood City, CA 


\begin{tabular}{ccccc}
\hline Stuge & Vd/kodts & ip/amps & Pruc/kVA & Pdiss/kVA \\
\hline 1 & 2485 & 1.6 & 3976 & 25 \\
2 & 2507 & 2.9 & 7270 & 25 \\
3 & 2525 & 3.1 & 3828 & 25 \\
4 & 2541 & 3.1 & 7877 & 25 \\
5 & 2557 & 3.1 & 7929 & 25 \\
6 & 2573 & 3.0 & 7719 & 25 \\
7 & 2590 & 2.8 & 7252 & 25 \\
8 & 2608 & 2.4 & 6259 & 24 \\
9 & 2628 & 2.1 & 5519 & 25 \\
10 & 2652 & 1.7 & 4508 & 24 \\
11 & 2680 & 1.5 & 4020 & 26 \\
12 & 2715 & 1.5 & 4073 & 26 \\
13 & 2750 & 1.2 & 3300 & 18 \\
14 & 2785 & - & - & - \\
\hline All & & 30.0 & 77540 & 298
\end{tabular}

Vd = Voltage depression below circuit (wiggler)

Ip = Phate current for an individual stape

Prec = Beam power recovered in an individual stage

Pdiss = Buam power disssipated in en inćividual stape

The initiol beam power is given by

$$
P_{0}=10+V_{0}=30^{2} 2.692=80.36 \mathrm{MVA}
$$

The genersted RF-power is

$$
P_{H} f=0.036 \cdot P_{0}=2.92 \mathrm{MVA}
$$

The basm power enlering the collector is

$$
P \text { ent }=P_{0}-P_{f f}=77.84 \text { MVA }
$$

The collector efficiency is defined as

$$
\text { (eto) } \text { coll }=\text { Prec } / \text { Pent }=77.54 / 77.84=0.996
$$

Figure 5. Pradicted Performanee of High Power multistage Collector.

Design by R. Hechtel, Redwood City, CA 